\title{
MATERIAL POLITICS OF MICRO URBAN HOUSING
}

\author{
by \\ Shea MacDougall \\ BAS, Carleton University \\ 2010 \\ A thesis \\ presented to Ryerson University \\ in partial fulfillment of the \\ requirements for the degree of \\ Master of Architecture \\ in the Program of \\ Architecture \\ Toronto, Ontario, Canada, 2019 \\ (C) Shea MacDougall 2019
}





\section{AUTHOR'S DECLARATION FOR ELECTRONIC SUBMISSION OF A THESIS}

I hereby declare that I am the sole author of this thesis. This is a true copy of the thesis, including any required final revisions, as accepted by my examiners.

I authorize Ryerson University to lend this thesis to other institutions or individuals for the purpose of scholarly research.

I further authorize Ryerson University to reproduce this thesis by photocopying or by other means, in total or in part, at the request of other institutions or individuals for the purpose of scholarly research.

I understand that my thesis may be made electronically available to the public. 



\title{
MATERIAL POLITICS OF MICRO URBAN HOUSING
}

\author{
Master of Architecture, 2019 \\ Shea MacDougall \\ Architecture Program. Ryerson University.
}

\begin{abstract}
This thesis investigates various socio-material trends that influence housing culture within increasingly intensified urban conditions. These trends indicate emerging societal values relating to affordability, the sharing economy and the reterritorialization of both domestic and urban environments. Design research contemplates how these values align with emerging theories related to material politics and how the design of our built environment can inform society's perception of a greater affective density. These theories describe the interrelationships between architecture, our shared consumption of energy and resources, material agency, and designed flexibility of urban and domestic space. These interrelationships define a set of objective comparators that are used in the evaluation of various housing types that are familiar to western cultures. An analysis of this evaluation describes a morphology of domestic architecture that guides the design process of creating a micro housing model located in Toronto's urban core.
\end{abstract}





\section{ACKNOWLEDGMENTS}

Firstly, I would like to thank the Ryerson University Graduate Program for their support and funding of my graduate education.

To my family, thank you for your endless support and encouragement throughout my educational and professional experiences.

A special thank you to Miljana Horvat, for your dedication and support throughout this past year. 



\section{Table of Contents}

Abstract $\quad v$

List of Figures xiii

List of Appendices xviii

$\begin{array}{lr}\text { Part 1: Introduction } & 1\end{array}$

1.1. Methodology 2

1.2. Research Question 2

1.3. Outline of Thesis 3

1.4. Literature Review 4

1.4.1. Toronto's Missing Middle 4

1.4.2. Material Politics 7

1.4.3. Affective Density 10

$\begin{array}{ll}\text { Part 2: Research } & 17\end{array}$

2.1. Convergence of the Domestic and Urban Realms 18

2.1.1. Domestic Space and the Domestic Exterior 18

2.1.2. Urban Space and the Urban Interior 19

2.2. Politics of Shared Space $\quad 20$

2.3. Socio-material Trends Affecting Housing Culture 22

2.3.1. Variability in Toronto's Densification Strategy 22

2.3.2. Micro-Housing 24

2.3.3. The Sharing Economy 29

2.4. Identity and Morphology of Housing Types 32

2.5. Common Need / Social Objectives

2.6. Common Values / Cultural Idealizations 36

2.7. Comparators for Case Study Analysis $\quad 37$

2.8. Case Study: The Sub-urban and Rural Bungalow 38

2.8.1. Inscription of Metabolic Infrastructures 38

2.8.2. Disruption of the Sensible $\quad 39$

2.8.3. The assembly of Socio-Material Entanglements 40 
2.9.1. Inscription of Metabolic Infrastructures 41

2.9.2. Disruption of the Sensible 42

2.9.3. The Assembly of Socio-Material Entanglements 42

2.10. Case Study: Co-Housing 43

2.10.1. Inscription of Metabolic Infrastructures 43

2.10.2. Disruption of the Sensible 45

2.10.3. The Assembly of Socio-Material Entanglements 46

2.11. Case Study: Co-operative Housing / Group Build / Integrated Living 48

2.11.1. Inscription of Metabolic Infrastructures 48

2.11.2. Disruption of the Sensible 52

2.11.3. The Assembly of Socio-Material Entanglements 56

2.12. Case Study: Typical and Micro Condominiums 58

2.12.1. Inscription of Metabolic Infrastructures 58

2.12.2. Disruption of the Sensible 60

2.12.3. The Assembly of Socio-Material Entanglements 62

2.13. Case Study Summary and Design Development 63

2.13.1. Inscription of Metabolic Infrastructures 63

2.13.1.1. Material and Energy Processes 63

$\begin{array}{ll}\text { 2.13.1.2. Boundaries and Areas } & 71\end{array}$

2.13.1.3. Local Effect 74

2.13.2. The Disruption of the Sensible 78

$\begin{array}{lll}\text { 2.13.2.1. Proximities } & 78\end{array}$

$\begin{array}{ll}\text { 2.13.2.2. Exposure } & 79\end{array}$

2.13.2.3. Spatial Variability 80 
2.13.3.1. Architectural Framework \& Material Modification

$\begin{array}{ll}\text { 3. Design } & 84\end{array}$

3.1. Project Description $\quad 84$

3.2. Design for The Inscription of Metabolic Infrastructures 85

3.2.1. Material and Energy Processes $\quad 85$

3.2.2. Boundaries and Areas 87

3.2.3. Local Effect 89

3.3. Design for The Disruption of the Sensible 90

3.3.1. Proximities 91

3.3.2. Exposure 93

3.3.3. Spatial Variability 95

3.4. Design for The Assembly of Socio-Material Entanglements 98

3.4.1. Architectural Framework and Material Modification 98

$\begin{array}{ll}\text { 3.4.2. Setting System } & 100\end{array}$

$\begin{array}{ll}\text { 3.5. Conclusion } & 101\end{array}$

$\begin{array}{ll}\text { Appendix A } & 103\end{array}$

$\begin{array}{ll}\text { Figure Credits } & 107\end{array}$

$\begin{array}{ll}\text { Bibliography } & 112\end{array}$ 



\section{List of Figures}

*Figure credits can be found on page 107

1-01 Author's modified dwelling: Live, work and sleep in $39 \mathrm{~m}^{2} \quad 1$

2-02 Unit Mix by Construction Period - GTA 5

3-03 Share of units 2 bedrooms or larger by construction period and location 6

4-04 Definition of Affective Density 11

5-05 Identification of Differences between cultures 13

6-06 Research Methodology 14

$\begin{array}{ll}\text { 7-07 Comparison of Setting Systems } & 15\end{array}$

8-08 Comparison of unlike setting systems 15

$\begin{array}{ll}\text { 9-09 Differentiation of setting systems } & 16\end{array}$

2-01 Base model by BARarchitekten $\quad 19$

2-02 Toronto's Downtown Growth 23

2-03 Typical floor plan of Carmel Place, New York City, 2016

2-04 Shared Space Axonometric of Carmel Place, New York City, 2016

2-05 Toronto Midrise Floor Plan 29

2-06 Toronto Midrise Floor Plan with Micro Housing Concept Applied 29

2-07 WeWork Space Toronto 31

2-08 Co-operative Housing Community Space, Chicago 31

2-09 Smart House amenity space, Toronto, 2017

2-10 Typical Cohousing Common House 33

2-11 Suburban and Rural Type with maximum horizontal dimension 39

2-12 Gregory House Exterior Room 40

2-13 Semi-detached housing type with near proximity to spatial variation 42 
2-14 Vancouver Co-Housing Gardens

2-15 Vancouver Co-housing Shared Exterior $\quad 43$

2-16 Vancouver Co-housing Site Plan $\quad 45$

2-17 Vancouver Co-housing Site Section 46

1-18 Vancouver Co-housing Building Section 46

2-19 Sebastopol Co-housing Site Arial $\quad 47$

2-20 Toronto Co-operative Building Section 49

2-21 Vienna Integrated Living Site Plan $\quad 50$

2-22 Berlin Baugruppe Building Section $\quad 50$

2-23 Vienna Integrated Living Unit Plan

2-24 Berlin Baugruppe Unit Plan $\quad 53$

2-25 Vienna Integrated Living Sectional Building Axonometric 54

2-26 Toronto Co-operative Private Residence Amenity 55

2-27 Berlin Baugruppe Building Section $\quad 55$

2-28 Vienna Integrated Living Public Amenity 55

2-29 Berlin Baugruppe Raw Finish 56

2-30 Berlin Baugruppe Completed Finish $\quad 57$

2-31 Toronto Co-operative Private Resident Gardens 57

2-32 Berlin Baugruppe Live-work Space $\quad 58$

2-33 Vienna Integrated Living Community Gardens` 58

2-34 Toronto Micro Condo 3rd Level Amenity Space 60

2-35 Toronto Mid-Rise Condominium Floor Plan 61

2-36 Toronto Micro Condominium Unit Plan $\quad 61$

2-37 Toronto Mid-Rise Condominium Setting System 62

2-38 Toronto Micro Condominium Setting System 63

2-39 Arial photographs of Test Site One 57 Brock Avenue, Toronto 65 
2-40 Arial Photographs of Test Site Two, 35 Bellevue Avenue, Toronto 66

2-41 Elevation of original house at 45 Bellevue Avenue 68

2-42 Vacant lot at 45 Bellevue Avenue $\quad 69$

2-43 Reterritorialization of the residential base $\quad 69$

2-44 Sustainable Energy and Communal Consumption Strategies 70

2-45 Developer proposed site plan with micro unit configuration overlay 71

2-46 Relationship to City and Local Infrastructure 72

2-47 Reduced Private Space $\quad 72$

2-48 Massing on Site One to test boundaries and areas 73

2-49 Massing on Site Two to test boundaries and areas 73

2-50 Three three-bedroom micro dwellings at 45 Bellevue Ave. 74

2-51 Controlled Interaction $\quad 75$

2-52 Site Plan Investigation of Site One $\quad 75$

2-53 Site Plan Investigation of Site Two 76

2-54 Investigation of semi-private and public interior interface 77

2-55 Common space supporting a local effect at 45 Bellevue Avenue 77

2-56 Identification of a Local Network $\quad 77$

2-57 Clustering of Units Around Various Shared Spaces 78

2-58 Equitable access to additional open space in near proximity to private dwellings 79

2-59 Circulation with exposure variability $\quad 79$

2-60 Spatial Variability in the Vertical and Horizontal Dimension 80

2-61 Investigation of variable unit composition $\quad 81$

2-62 Flexible Architectural Framework investigation 82

2-63 Limit the differing to off-site activities 83

2-64 Open access within a setting system 83

3-01 South West axonometric of micro housing model 84 
3-02 Micro Housing Site Plan $\quad 85$

3-03 Micro Housing South East site access from Market 86

3-04 Micro Housing access from Bellevue Avenue 86

3-05 Micro Housing Level One $\quad 88$

3-06 Micro Housing Sublevel One $\quad 89$

2-07 Public Interior Space $\quad 90$

3-08 Micro Housing Level Two 91

3-09 Micro Housing Level Three $\quad 91$

3-10 Interior corridor with natural day lighting 92

3-11 Micro Housing Section A with Emphasis on Semi-Private Space 93

3-12 Exterior perspective of laundry lounges from elevated terrace 94

3-13 Resident supervision of exterior spaes 94

3-14 West Elevation at Bellevue Avenue $\quad 95$

3-15 West Elevation at interior courtyard 96

3-16 Section C $\quad 97$

$\begin{array}{ll}\text { 3-17 Section B } & 97\end{array}$

3-18 Resident Shared Space $\quad 98$

3-19 Modular Micro Unit Floor Plans 99

3-20 Section D 99

3-21 On-site setting system to defer the translation of activities to external sites 100 



\section{List of Appendices}

\section{Appendix A}

Tabulated assessment of the comparators used in the case study analysis of this thesis 



\section{Part 1: Introduction}

It is our role as architects to engage the representations of dwellings and identify those models that have faded or morphed into new forms. As an architect, I take this opportunity to draw on the challenges relating to increased housing density hat are demonstrated in this body of research, challenges that affect so many in today's urban environments. For much of my early adult life, I have dwelled in many places with small square footages and shared living areas, both often modified to improve livability (Figure 1-01). I've often viewed the constraints of small apartments with limited exposure to share spatial and material resources as political acts of the less conscientious designer, actions that use materiality against the inhabitant by confining activities or translating them to secondary locations. These choices defer the responsibility of conceptualizing improved livability of our domestic environments which ultimately contributes to transient and precarious housing conditions. It is this notion that lead me to Leandro Minuchin's acknowledgment of the moment of construction and its influence over people. It is through this moment of construction that materiality is political and where alternative perspectives of the microhousing movement can be tested.

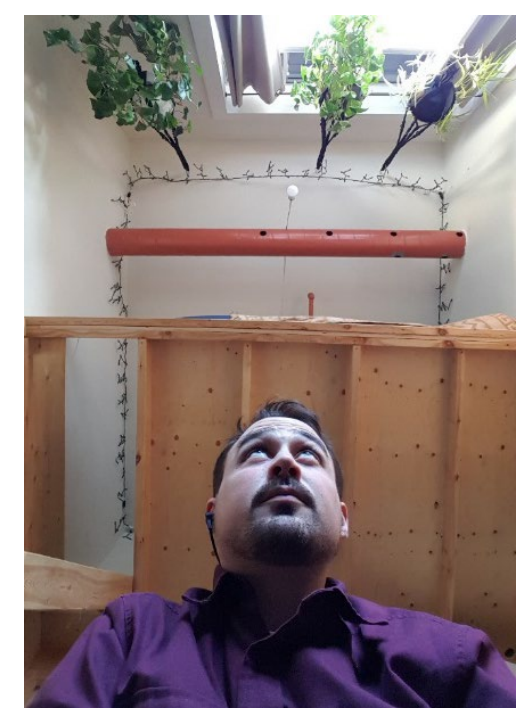

Figure 1-01 Author's modified dwelling: Live, work and sleep in 39m2 


\subsection{Methodology}

This thesis Investigates how Leandro Minuchin's theories on material politics and Amos Rapoport's definition of affective density can inform the design of a micro housing model within Toronto's urban context.

In addition to investigations that consider evolving socio-material trends associated with housing and how they inform the design of architecture for the convergence of the domestic and urban spheres. These investigations seek to identify interrelationships between Toronto's intensification strategy, the emergence of the sharing economy and the micro housing movement.

This thesis seeks to determine if Minuchin's theories regarding material politics are substantiated in the design of various housing types to develop a design methodology that establishes sets of objective comparators for each of the three theory stands proposed by Minuchin. It is to be determined how these objective comparators can be used to evaluate architectural forms that represent various housing cultures.

This process will inform the development of a conceptual 'missing-middle' housing model that synthesizes the analytical findings to demonstrate the implication of material politics and a perception of affective density within Toronto's urban core.

\subsection{Research Question}

What are the current issues and trends affecting Toronto's housing culture?

How are Leandro Minuchin's theories on material politics substantiated by Western housing cultures and their associated housing forms? 
How is a perception of affective density informed by an architectural framework that represents the sharing of space in both the domestic and urban context, and how is the design of ground related housing informed by this condition?

\subsection{Outline of Thesis}

This thesis is comprised of 3 parts. Part 1 is an introduction to subjects of the research, the methodology used in the development of research, the proposed research questions and the literature review.

Part 2 is the body of research, it includes; definitions of both urban and domestic space, interpretation of the politics regarding shared space, identification of the issues and trends affecting Toronto's housing culture, and evidence of a morphological convergence of housing types based on common needs and values. Part 2 includes a comparative analysis of housing case studies and how these designs demonstrate Leandro Minuchin's theories relating to material politics which are then demonstrated in the development of preliminary design strategies for a micro-housing model.

Part 3 is entirely comprised of the final design as described through the objectives of design that demonstrate the proposed theories relating to material politics and how these objectives inform a perception of affective density in Toronto's urban core. A conclusive analysis culminates part 3. 


\subsection{Literature Review}

\subsubsection{Toronto's Missing Middle}

Within architectural practice, there is an ongoing discussion regarding the deterioration and revitalization of the housing fabric that brings form to our urban centres. This discussion provides evidence of Toronto's current housing crisis while informing a direction forward regarding how architecture is designed and constructed in the city. This thesis contemplates the design of domestic architecture for a future, where a sustained increase in one-person households will further implicate rising housing costs, or where there is either a sudden increase in multi-person households; where both scenarios require an intensification strategy that combines less domestic space and more shared urban space so as to improve the perception of an affective density - will guide the design of housing development in Toronto, and how people interact with each other and the city. Both conditions require a questioning of current development practices and criticism of the housing models that are built today and in the future. Toronto's housing market is unique and needs to be analyzed as a distinct region apart from the rest of the GTA.

Trends in the creation of mixed unit housing in the GTA have varied over the past three decades and current projections show an emerging misalignment with the current demographics of the city (Figure 1-02). A contributing factor to the increased construction of one- bedroom or bachelor unit condominiums in multi-unit buildings, is the speculation that the $24 \%$ of single person households would sustain a market whereby one-bedroom or bachelor units comprised $70 \%$ of new stock constructed between 2011 and 2014 (City of Toronto, 2015). In the same time, the affordability of these units is becoming increasingly out of reach for the $22 \%$ that opt to rent their condominium out of necessity to maintain ownership. 


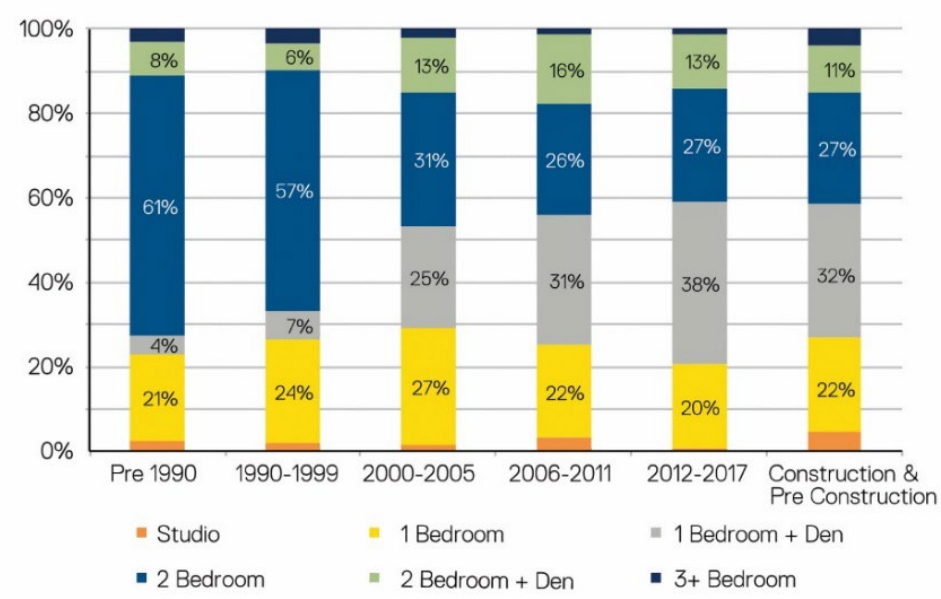

Figure 1-02 Unit Mix by Construction Period - GTA

The cost of renting in Toronto has also risen in the past decade, when in 2011, 44\% of renters were spending $30 \%$ or more of their income on housing, up from $21 \%$ in 2001 (City of Toronto, 2015). In response, the Province of Ontario passed the Affordable Housing Act in December of 2016 that introduced the recommendation of inclusionary zoning policies that require private developers to allot $10-30 \%$ of new units to be rented at below market rates. Additionally, the average square footage of these dwellings has decreased from over 1000 sf in 1996 to just over 800 sf in 2014 and where microunits at $300 \mathrm{sf}$ are being added to the market (City of Toronto, 2015). The creation of more units with reduced square footage creates additional challenges for the housing market whereby the smaller dwellings cannot be easily modified to suite peoples housing needs over time as did the older, larger units; which can result in an eventual relocation of one's home.

Most commonly, the decision to marry or raise a family will likely affect people's housing needs through time. In this regard, Toronto's housing market has not adjusted for the influx of people with families choosing a closer proximity to the core over longer commute times to the suburbs. Considering the projected increase in population and housing affordability context, it is expected that the GTA will require more family 
oriented housing options in low and mid-rise buildings (Bedrooms In the Sky, Ryerson City Building Institute, 2017); and yet only 3\% of the expected condo apartment builds will be ground related and classified as the 'missing middle' (Urbanation Database, 2017).

Currently, the remaining $30 \%$ of new housing stock in multi unit buildings is comprised of two-bedroom units (24\%) and three-bedroom units (6\%) to house families that comprise $67 \%$ of all households in the city (City of Toronto, 2015). These figures are rather low when compared to the building trends of the past decades (Figure 1-03), and it is expected that the architectural profession and building industry must now respond to the cultural expectations of changing demographics. At the same time, there is now an emerging trend in Toronto where $47 \%$ of young adults aged 20 to 34 are living with their parents (StatsCan, 2016); all of which indicates the need for alternative housing options that support families and their dependents, which has been commonly identified as the 'missing middle'.

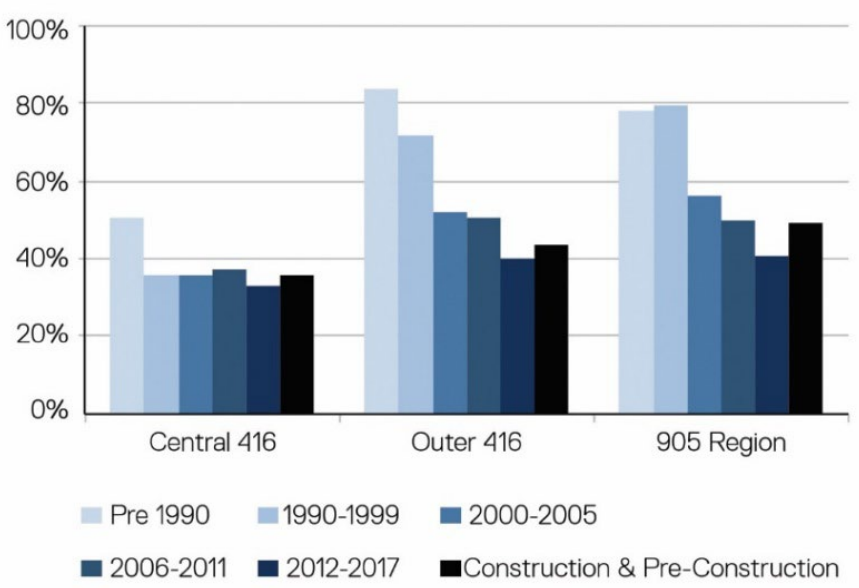

Figure 1-03 Share of units 2 Bedrooms or larger by Construction Period and location 
Toronto's cultural diversity is sustained by the inclusion of diverse populations; many people prefer living in the in the core of the city where they are in closer proximity to the social, cultural and economic benefits that support a more equitable and diverse society. This thesis seeks to determine the level of engagement of architects have in developing housing forms to fill the missing gap in Toronto's development, and to propose a design approach for a 'missing middle' typology that contemplates the values that may be associated to Leandro Minuchin's Theories on material politics.

\subsubsection{Material Politics}

According to Leandro Minuchin, the notion of Material Politics frames architecture and the moment of construction as a language for local politics and activism (Minuchin, 2017), viewed here as the vehicle for agency regarding Toronto's mounting housing crisis. What is built, and how it is built is the basis for argument in the politics of addressing the lack of housing form that responds to an awareness of increased density and shared material resources that re-territorialize public and private space. Identifying that there is a need for variability in the dwelling typology to align with emerging lifestyles and a convergence of cultures within the city of Toronto; this research will investigate the missing gap within a morphology of housing types that have been created in both north America and Western Europe. Analysis of these housing types will consider how the architecture influences our perception of affective density and how this experience can be evaluated through Leandro Minuchin's theories regarding material politics.

Leandro Minuchin is affiliated with the Master of Architecture program at the University of Manchester as a lecturer in Architecture and Global Urbanism. His work identifies how the politics of construction and the design of infrastructures can inform the consolidation of extended networks of solidarity and association within society. This is 
demonstrated through investigations into how social movements, local organizations, developers, and construction firms use the moment of construction to prefigure territorial articulations. Of interest is how these territorial articulations are manifested in Minuchin's notion of peripheries, which he defines as the socio-material entanglements that propagate through the urban fabric of a developed setting. New imaginaries for society can occur at the peripheries of an architectural morphology, where the periphery of the 'missing middle' implies a gap in a morphology of dwelling types that will be investigated. This research will seek to determine if Minuchin's theories on material politics are substantiated by the design of domestic architecture and, if so, do these theories present values that influence a perception of affective density within an intensified urban condition. This will be investigated by proposing sets of comparators that attempt to demonstrate Minuchin's theories regarding material politics, which may be used in an analysis and evaluation of a morphology of dwelling types. The following is a brief introduction to the theory strands of material politics and the proposed comparators that seek to demonstrate how these theories are to be contemplated in architectural design.

Minuchin's Three Strands of Material Politics:

1. The inscription of metabolic infrastructures that influence the sum total of the technical and socio-economic processes that occur within buildings and cities, resulting in growth, production of energy and the elimination of waste. This concept addresses the need to design places within the urban environment that are sustainable on all counts: places that create economic, environmental, and social value (Haas, 2012). Looking beyond the context of North America, evidence from Europe demonstrates that if people live in settlements that equitably distribute amenities while integrating into a strong public realm that affords social interaction, pedestrian movement and proximity to shared amenity, then they will consume fewer resources in the immediate activities of getting around and passing time (Hass 
\& Mehaffy, 2012). It is proposed by this thesis that this inscription is demonstrated in how material composition and energy consumption within the boundaries and areas of an architectural design can support a local effect amongst residents and neighboring communities.

2. The disruption of the sensible considers the agentic properties of materials and their capacity to disrupt established social and technical assumptions and regulations. Agency is primarily identified as conceptualizing an entry-level housing model that improves the perception of increased density in established neighborhoods; while contemplating the need for spatial and material conservation. This concept is supported by industry professionals who identify the need for housing alternatives that provide less private space and more shared community places that are more efficient and less expensive overall (Haas \& Calthorp, 2012). It is proposed that the properties of materials and how they are assembled in place provides agency to the user through the mediation of proximities and exposures within spatial variability which ultimately informs our experience of an affective density.

3. The assembling of socio-material entanglements considers the design flexibility of space in relation to socio-material processes that reposition materials into new function; which in turn, alter and redefine local experiences and practices (Minuchin, 2013). It is proposed that the assembling of socio-material entanglements is demonstrated in how an architectural framework can support the material modification and flexible configuration of setting systems to align with emerging trends in housing.

The design for future flexibility in housing design is a familiar concept that originates in the modern context during the 1930's following the second CIAM congress of international architects entitled Die Wohnung fur das Existenzminimum which is translated as 'The Subsistence Dwelling'. At this time, architects would begin to 
conceptualize the best solutions for reduced space standards. Jeremy Till identifies that two notions of flexibility emerged at this time; the first notion relates to the provision of rooms of indeterminate use, and the second notion relating to the folding and unfolding of architectural elements. (Schneider \& Till, 2007)

These three theories are the basis for Minuchin's concept of Material Politics and will be further investigated through their inter-relationships with housing design and our perception of urban density.

\subsubsection{Affective Density}

The housing crisis that is evident in Toronto and many other metropolitan centers in North America motivates this research to examine how density is perceived, accepted and ultimately designed within intensification strategies. In 1975, Amos Rapoport wrote a short paper titled Toward a Redefinition of Density, in which he proposes a term 'Affective Density' that considers our experience of density beyond objective quantification. Amos Rapoport is an architect and a founding member of Environment-Behaviour Studies with expertise on the influence of cultural variables and cross-cultural studies. Of interest, is his work that explores how the environment, human behaviour and culture can affect architectural form specifically within an intensified urban condition, and how we perceive density.

Amos Rapoport claims that the concept of affective density is of central importance in planning, urban design and architecture. He identifies that density is commonly understood as the number of people per unit area but that the issues related to density require a new conceptual approach and redefinition of the term. This redefinition considers the perceived experience of density as either isolating, 
satisfactory, or crowded (Rapoport, 1975); and ultimately affected by the following terms

(1) People interaction, coding, rules, homogeneity

(2) Space organization and various physical cues in sensory modalities

(3) Various associational and symbolic meanings of the environment

These terms are related through the design of the built environment and its effect on the processing of social and sensory information as shown in (Figure 1-04), where a reduced amount of information can be perceived as isolating and an excess of information would result in a sense of crowding. Rapoport claims that, somewhere in between, for any given group and context, there is a limited range of acceptable and preferred densities as perceived (Rapoport, 1975).

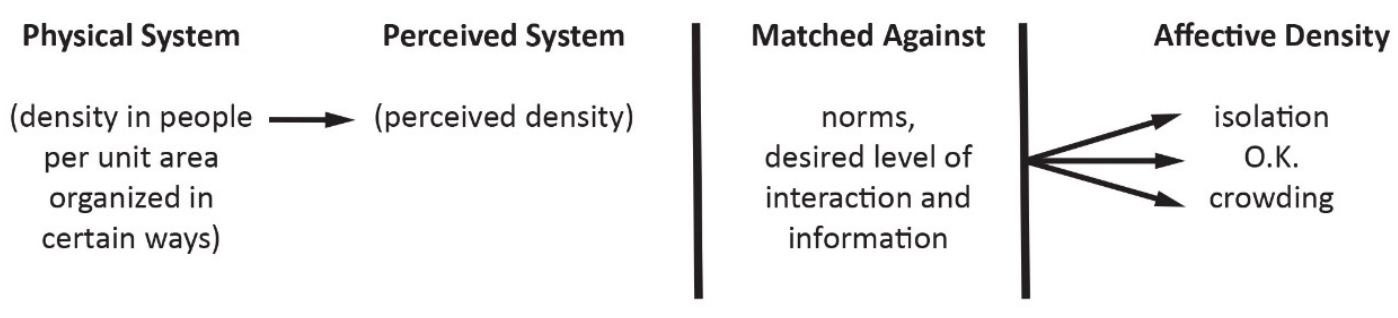

Figure 1-04 Definition of Affective Density

The redefinition of density is needed for a reimagining of urban life, where design professionals and those they design for must navigate an increased awareness of other people through sensory perception and physical cues. I believe that Rapoport's notion of a collective consciousness related to the sharing of space, along with the cultural and physical defenses, not only that control the awareness of others but inform societal values that are to be reflected within our built environments (Rapoport, 1975). It is to 
be investigated how these societal values align with emerging cultural trends related to the sharing economy and local identity, and whether Minuchin's Theory of Material politics can be demonstrated in the design of domestic peripheries to reflect these societal values.

This thesis seeks to determine how the inscription of metabolic infrastructures, the disruption of the sensible, and the assembling of socio-material entanglements informs the design of an improved perception of affective density through architectural design. It has been previously identified that although Toronto celebrates a rich cultural diversity, the built environment of the city struggles to support equitable access to housing for many, while the dwellings that are created often misalign with the lifestyles of those that increasingly prefer urban living. Urban densification will inevitably implicate both the urban and domestic realms, resulting in a morphology of social domestic space and a potential increase in the sharing of supportive living environments within urban dwellings. This condition must consider the affective density as perceived through the morphology of domestic space and its influence on the processing of social and sensory information.

The morphology of social domestic space, specifically the design of shared supportive living environments, is challenged by the differences amongst various cultural groups and their preferences for how a shared environment is to be used as an extension of private domestic space. These differences can vary greatly within a culturally diverse society, as identified in Rapoport's comparison of traditional and contemporary groups (Figure 1-05). Therefore, it is essential to design for the social variables that are common between convergent cultures, namely the homogeneous values that influence the choice of a preferred environment. At the outset, these homogeneous values relate to the acceptance of less private space and the consumption of shared resources that include construction material, open and enclosed space and technology - all of which 
are pertinent to the design of contemporary housing models and the greater architectural discourse of our time.

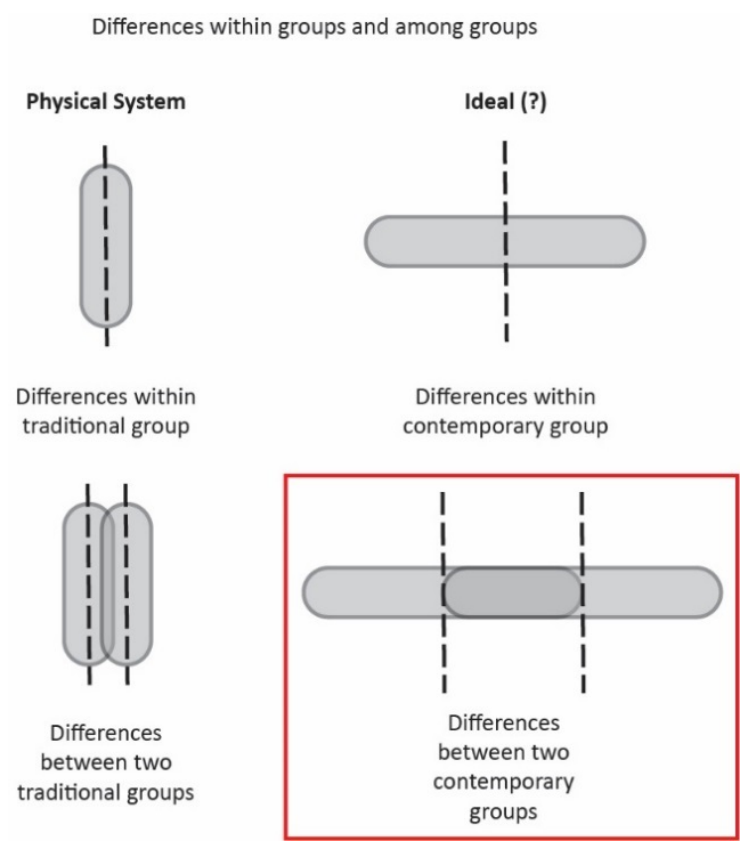

Figure 1-05 Identification of Differences between Cultures

The morphology of domestic space within an increasingly densified urban condition must consider the interrelationships between the values that are reflected in the design of the physical environment and how this design can improve the perception of the affective density. Inclusion of Minuchin's three theory strands of material politics provides a means of identifying the objective interrelationships between the physical environment and virtual urban networks while providing the foundation for a set of comparators that may be used to evaluate the morphology of domestic space within the North American context. It is the purpose of the research to determine if there are values associated with Minuchin's theories of material politics that are cross culturally accepted in the design of domestic and urban space which ultimately informs our perception of an affective density (Figure 1-06). 


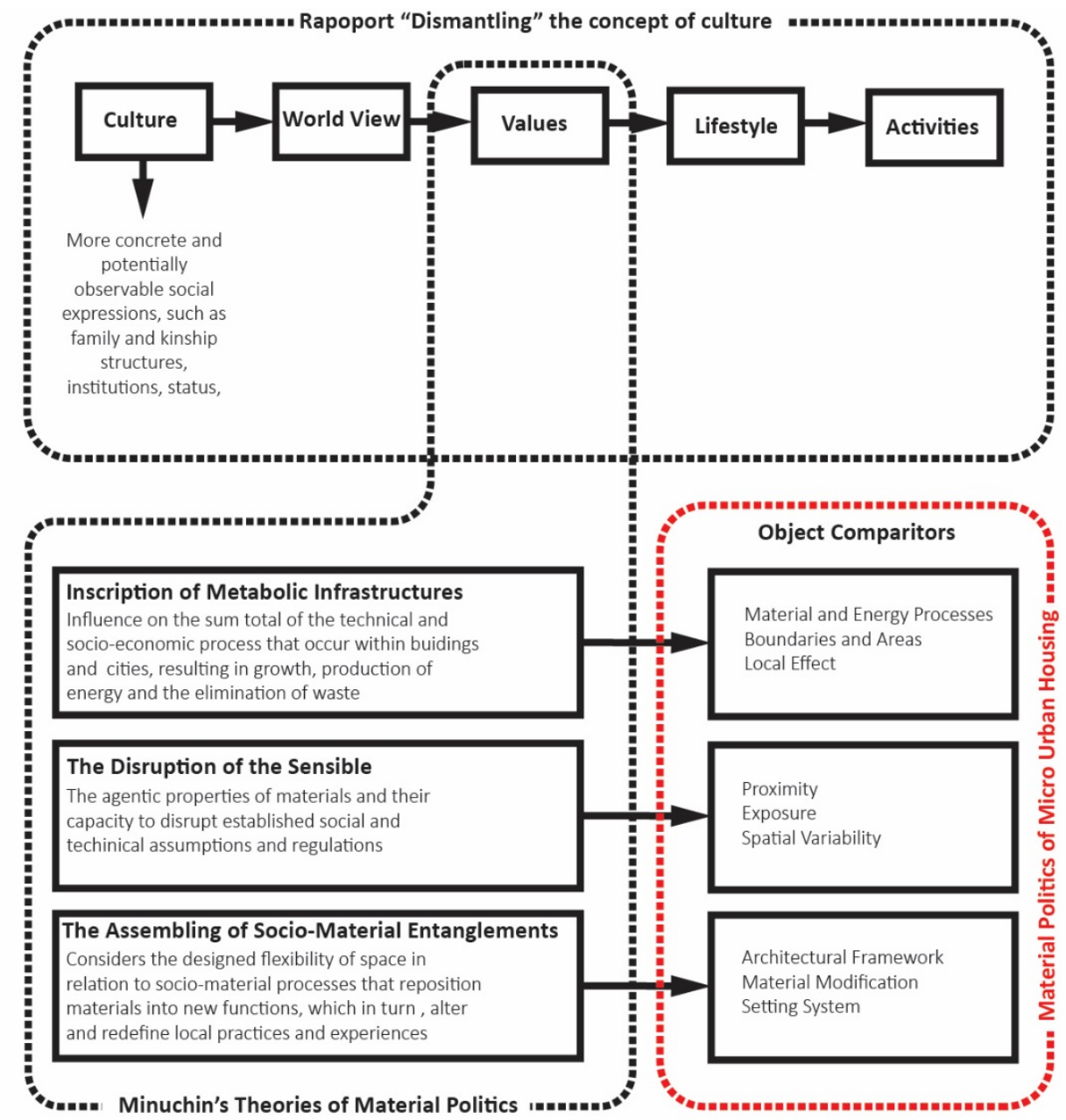

Figure 1-06 Research Methodology

Architecture encloses behaviour and it is of interest to investigate how social expressions of culture, namely groups of people, family structures and social networks, utilize urban and domestic space in the context of increased densification. In this way, it is possible to link built form to both the activities and settings that are associated with various domestic lifestyles (Kent \& Rapoport, 1990). This investigation will consider a variety of housing typologies, lifestyles and the potential of shared supportive living environments, as evaluated through the synthesis of Minuchin's theories on material politics. 
Activites within a single setting versus activity systems in systems of settings

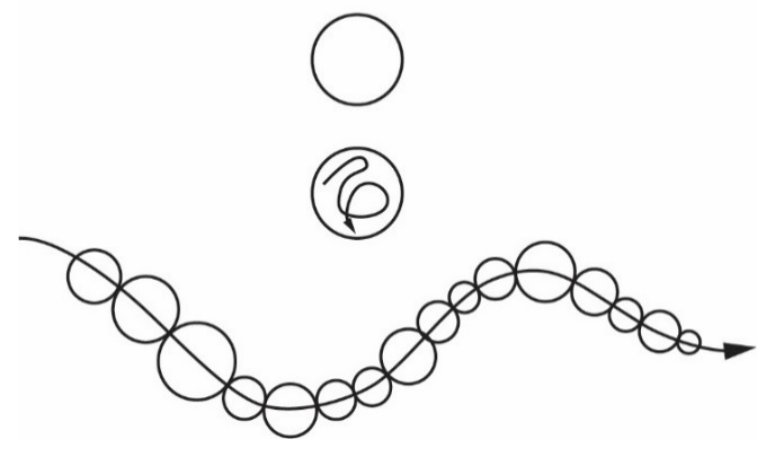

Figure 1-07 Comparison of Setting Systems

Rapoport identifies that single activities do occur in a single setting, but that people link these activities into a system of activities as they go about their lives, and in doing so they modify their settings to suite their activity needs (Figure 1-07). Therefore, systems of activities occur in systems of settings. With this notion, Rapoport then attempts a definition of "dwellings" that would be suitable for cross-cultural analysis (Rapoport, 1980) whereby similar activities can occur in two different dwellings but vary in the dispersion of their system of settings (Figure 1-08).

Definition of "Dwelling" in terms of activity and setting systems suitable for cross cultural comparison

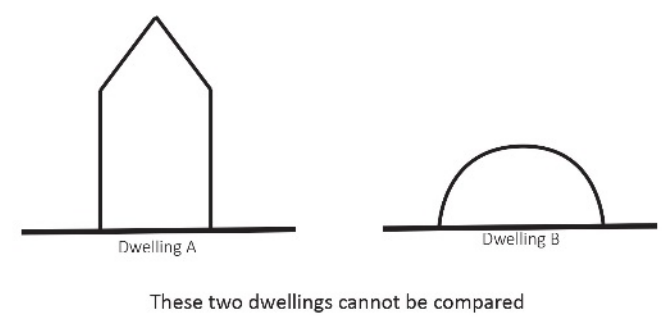

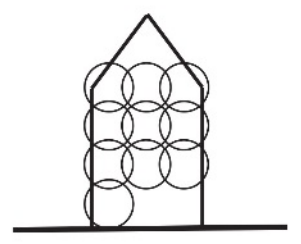

Dwelling A- ten settings for activity

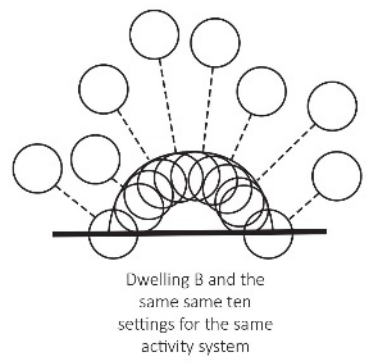

activity system

These two systems of ten settings each constitute the units of comparison

Figure 1-08 Comparison of unlike Setting Systems 
For Rapoport, it is not the dwellings that are to be compared but rather the system of settings within which a system of activities occurs. I would agree that systems of activities do occur within systems of settings but would argue that the form of a dwelling is not limited to a singular culture and that people are increasingly modifying their systems of activities and settings to suit the form of their dwelling. Therefore, the form of a dwelling cannot be simply assumed; it ought to support the desired activities of the inhabitants which according to Rapoport's proposed relationship between the differentiation of settings and the heterogeneity of contemporary societies (Figure 109), supposes many highly differentiated settings, non-overlapping activities, with highly redundant cues. It is contestable whether or not Rapoport's expectations regarding activity systems are met by contemporary trends in north American urban dwelling; specifically, in growing metropolitan centers like Toronto where more people are increasingly constrained and underhoused with limited housing options that support a variety of lifestyles that are inherent to our supposed rich cultural diversity.
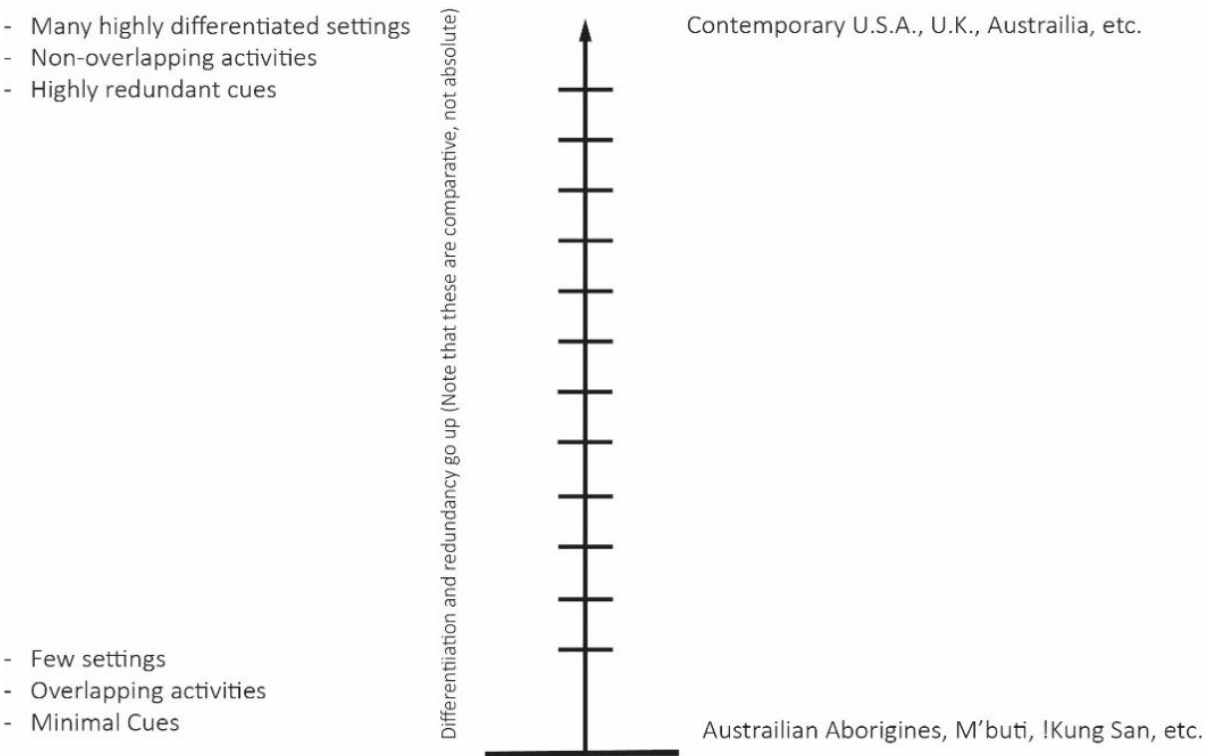

Figure 2-09 Differentiation of System Settings 
It is the purpose of this research to determine how domestic and urban space is defined by the architecture of various housing types and how these relationships can improve the metabolic infrastructure of cities and buildings, act with agency for the user and how this alters or redefines local practices and experiences of architecture as per Minuchin's Theories on Material Politics and Rapoport's redefinition of urban density.

\section{Part 2: Research}

The literature review identifies the challenges associated with the design of domestic and urban space in Toronto's increasingly densified built environment. Furthermore, the identification of the clear misalignment between lifestyles and the housing to suit that requires an improved perception of affective density as described by Amos Rapoport. Where the perception of an affective density is informed by architecture and the moment of construction as described by Leandro Minuchin's Material Politics. Considered in parallel, Rapoport's notion of an affective density and Minuchin's Material Politics call for established values in the design of housing form amidst local politicisation and activism for increased housing variability.

The following research looks at contemporary definitions of both domestic and urban space in the context of a convergence in an increasingly densified environment. Furthermore, it investigates how this convergence is substantiated in the material politicisation of shared space through the emergence of socio-material trends affecting housing culture, namely the claimed variability in Toronto's densification strategy, the sharing economy and the micro-housing phenomena. These trends indicate common needs and values within a housing culture that seemingly align with Minuchin's three theory strands regarding Material politics. Therefor, an analysis of various housing types was completed to identify how built form represents cultural idealizations that 
relate to common social objectives within north American society and the works of both Minuchin and Rapoport.

\subsection{Convergence of the Domestic and Urban Realms}

\subsubsection{Domestic Space and the Domestic Exterior}

Politically, the domestic exterior refers to Modernism and its influence on the domestic sphere; when reformers of the Progressive Era backed an infrastructural domain that was dedicated to the home's support and preservation. Susan Edmunds proposes that this evolution was substantiated during the modern progressive era, when literary reformers subverted the domestic sphere through the creation of the domestic exterior, where the space of domesticity was turned inside out to become an extension of the political will toward a welfare state (Edmunds, 2008). Consequently, through the erosion of domesticity and vital social services, more individuals within society must now rely on the extraneous support that is gained through their daily encounters with one another in the built environment. Architecturally, the domestic exterior refers to the shared places of comfort and leisure that have been dispelled from the domestic interior through economic and material efficiencies that limit private social spaces in urban residential design. These spaces are often described as community amenity and public open space, of which this thesis seeks to investigate and describe through design explorations in the context of a micro urban housing model. 


\subsubsection{Urban Space and the Urban Interior}

The urban interior is a redefinition of interior urbanism, which is a concept that refers to the 'semi-autonomous' public spaces that were devised throughout the modern period to enclose seemingly out door spaces for the comfort of customers, commuters, and consumers (Rice, 2016). These spaces are formally represented in the atria of shopping malls, airports, train stations, hotels, hospitals, etc., and can be identified as the nonplaces for the momentary interaction and movement of people. The urban interior refers to an organized extension of the urban exterior, whereby the public can temporarily occupy interior space. Mae Architects indicate that this can be achieved through the design of the interface between building and city, where the façade, thresholds and stoa conditions become mediating devices for environmental and social exchange (Bose \& Shumi, 2015). This concept is demonstrated in the work of BARarchitekten and their proposition of internal urbanism that actively contributes to the continuing evolution of the city as a meeting place, where the base of midrise development is comprised of the ground and first floor from which there is an interface between street and building, public and private (Figure 2-01). Viewed as a prototypical component of the city, the base provides a neutral urban interior for both living and working and encourages interaction between street and building (BARarchitekten, 2015).

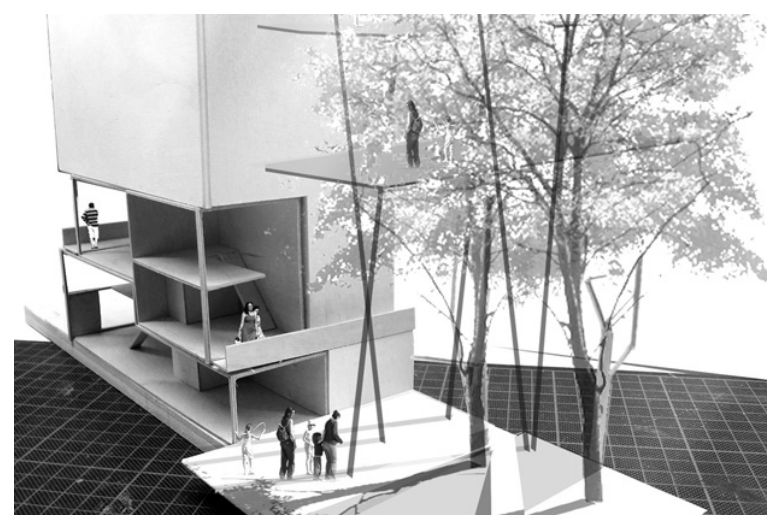

Figure 2-01 Base model by BARarchitekten 


\subsection{Politics of Shared Space}

The politics of shared space within the urban fabric of Toronto is formulated through the material composition of our built architecture and its relationship to the expanding urban condition. These relationships are both physical and virtual, and through their consideration can reformulate the territories of public/private, domestic/urban space while moving toward an open configuration that supports emerging social relations that rely on the fluid circulation of people within local networks. Shared space is political, and the inhabitation of increasingly densified urban environments must consider the politics of shared space and how the material composition of architecture can empower and support a local group of inhabitants.

Affective density must consider the political engagement of people that is no longer confined to streets, squares, and public spaces but is increasingly taking place within the domestic areas of life. Where the reduced private living areas associated with micro housing ought to support a spatial composition that encourages the social engagement of a local community and expansion of a collective communication network. Within this context, material politics and the collaboration between heterogeneous technologies and domesticity can inform a way forward in architectural practice and the reformulation of the urban fabric (Upmeyer, 2016). This is important to the conceptualization of micro housing alternatives to support emerging cultural trends in society which relate to communal consumption and consideration of the limitations and benefits of shared space within the urban and domestic realms.

Increased density will inevitably draw the urban and domestic realms closer in the extent that people will rely more on urban space to supplement reduced private space. Therefor, it is the responsibility of architects to consider new 
compositions of these spaces, in addition to novel forms of materialization through architecture that articulate equitable modes of distributing people and things within the city (Minuchin, 2013). As a result, the urban ecology becomes increasingly political and the relevancy of Bruno Latour's vision of an expanded public space must be considered, specifically his instruction to analyse the influence of power relations in the composition and consolidation of urban networks. Minuchin identifies three different lines of material politics that are applicable to urban and architectural theory as they inform the interrelationships between the physical environment and virtual urban networks. As follows, the three strands of material politics are then placed in the context of shared spatial and material consumption in multi-unit housing.

The inscription of metabolic infrastructures: Defined as "the sum total of the technical and socio-economic process that occur in cities, resulting in growth, production of energy and elimination of waste." (Kennedy, 2007). This concept will be investigated within this thesis in relation to the how people inhabit the city and how the architecture of multi unit residential buildings mediate these processes. As a portion of the sum total, the interior/exterior and physical/virtual interrelationships of a multi-unit housing type within the city will be considered. Scale is essential to this concept, where buildings are likened to a city and inversely, cities to the buildings that comprise them; where the complexities of urban life are not resolved entirely from the top down but incorporate the local and domestic.

The disruption of the sensible: Is described by Jane Bennett's revision of Jacques Ranciere's theory of disagreement whereby the physical composition of matter can inscribe new interpretations of the sensible. In Ranciere's work titled Disagreement: politics and philosophy, the field of politics is defined by unveiling an alternative logic of delineation; that when taken in relation to the built 
environment will renew a call for equality that interrupts the established planning of names and places while engaging a sense of inclusivity within society (as cited in Minuchin, 2013). Architecture, as a composition of matter, must consider how this composition is sensed; especially in multi-unit housing where the design will influence an isolating or overcrowded experience of affective density.

The assembling of socio-material entanglements: Considers the designed flexibility of space in relation to socio-material processes that reposition materials into new functions, which in turn, alter and redefine local practices and experiences. The micro housing concept puts an emphasis on the shared consumption and multifunctionality of space as necessity to prevent a sense of overcrowding while supplementing an individuals limited private space.

With a consideration of material politics, architects can provide a dimension to the urban environment that responds to an increased use of shared resources and space. This thesis will investigate the condition of domestic exterior and urban interior spaces of residential models and the capacity to shape urban actions, identities and experiences. Determining how people cohabit the city relies on the inclusion of architectural form and materiality, and their role in defining urban experiences that support urban networks and inclusion of differing collectives that are constitutive of the urban condition.

\subsection{Socio-material Trends affecting Culture}

\subsubsection{Variability in Toronto's Densification Strategy}

Architects must conceive viable housing alternatives in collaboration with government and both private and non-profit sectors to accomplish projects that 
provide more purpose-built rental and entry level housing to support Toronto's culturally diverse society. The continual increase in Toronto's downtown population (Figure 2-02) will require an urban intensification strategy that addresses the need for a variety of housing types. Variability of housing types provides options that support a variety of lifestyles to sustain the diverse culture that is represented both socially and physically in the built urban form.

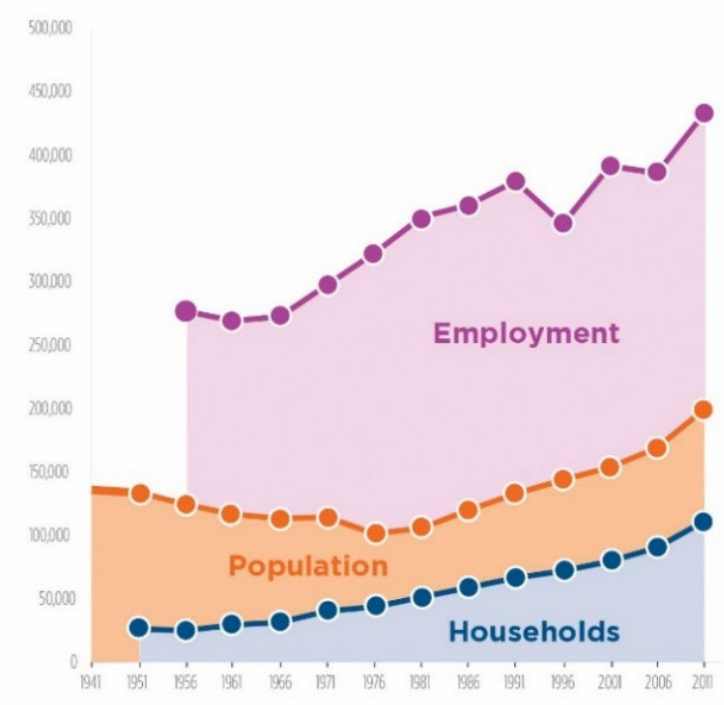

Figure 2-02 Toronto's Downton Growth

It is of my opinion that Toronto's adoption of the Avenues and Mid-rise building strategy provides direction for the creation of more variety in housing options. Where the strategy indicates that a 50 percent of the expected growth in Toronto can be addressed by mid-rise built form along the avenue corridors, representing 200 kilometers of the 324 kilometers of property frontage to accommodate approximately 250,000 new inhabitants (City of Toronto, 2010). The strategy follows Toronto's Official Plan by directing growth to designated mixed-use areas, where main streets and areas with existing infrastructure, including social services, transit, retail, and regeneration areas will be re- 
urbanized. More specifically, the report identifies the need for high-quality design and material specification to define new built form at the periphery of the city's established neighborhoods. Where built form supports the functional relationship between the avenue and surrounding neighborhood while becoming the social center for the community.

It is along these avenues and corridors that urban densification will occur to support the improved livability of the city. Where experimentation of missingmiddle development can fill the space between the city's neighborhoods, which are comprised of older detached and semi-detached housing stock and the inevitability of more condominium towers on the horizon. Here, architectural design will operate at scales that respond to small-scale communities that are internal and external to the architecture and mediate the boundaries between public/private and the urban interior/exterior.

\subsubsection{Micro-Housing}

In addition to mid-rise development, the Canada Mortgage and Housing Corporation's (CMHC) publication, the Housing Observer 2017, reports on micro dwellings as an emerging socio-economic phenomenon that reformulates our approach to city living. The ongoing discussion of micro dwellings draws on past experiences of tenement housing, the material politics associated with urban dwelling and how the evolution of housing typologies are attempting to align with emerging lifestyles through equitable access to city living.

Although we can identify the rational causes related to affordability and density, micro housing is considered a phenomenon because it also represents an acceptance of a crowdedness that is reminiscent of the controversial mass 
housing concepts of earlier social housing programs. Micro housing is not a new concept; global cities like Tokyo, Hong Kong and Berlin have long acknowledged the need for this typology, let alone the design parameters for successful projects. Interestingly, North American cities like New York and Toronto are now experimenting with this housing typology that further defines the accepted conventions related to a culture of urban dwelling. The micro-housing phenomenon in the Canadian context, destabilizes our notions of urban living and sustains an evolution in thematic, if not more equitable, housing models.

This destabilization is associated with the material and spatial politics that are being defined by those who inhabit micro housing and the design of projects which are gaining cultural support. $\mathrm{CMHC}$ identifies the micro dwelling as the downsizing of traditional studio accommodation or as an upscaling of the single room occupancy (SRO) concept, and is promoted as alternative housing to accommodate those willing to forgo private living space for access to a central urban location, where the city becomes an extended living room and backyard for social interaction (CMHC, 2017). The micro-housing phenomenon, unveils a reformulation of the domestic territory, creating affordable housing within the private sector but also applicable to social housing programs. In 2016, New York City began experimentation of affordable subsidized housing that incorporates the micro unit concept while redefining the affordable housing parameters of the city.

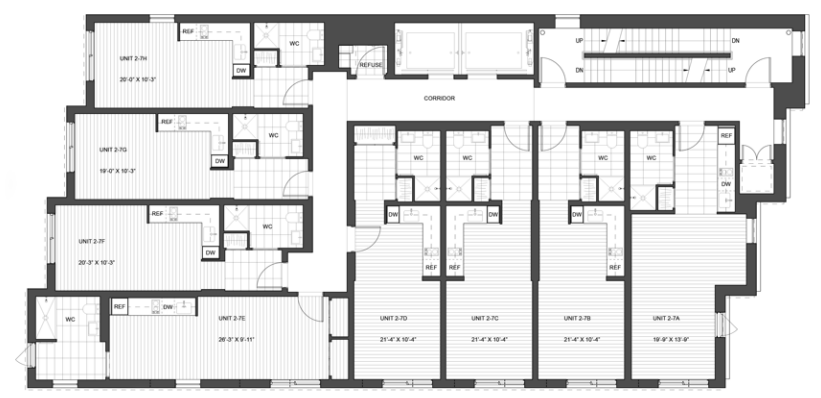

Figure 2-03 Typical floor plan of Carmel Place, New York City, 2016 
The typical floor plan of Carmel Place (nARCHITECTS, New York City, 2016) represents the compactness that is commonly associated with micro unit design (Figure 2-03). All units are prefabricated to accelerate on-site assembly. There is minimal variation in the unit design and its relationship to other units, where all units are assembled around a typical high-rise corridor. There is little evidence for the consideration of social engagement in the design, outside of the typical amenity spaces that seem disproportionate to the quantity of units in the building. Shared space is located on the upper and lower levels of the midrise tower, where proximity, and adaptability of program and seasonal use appear limited. Openness is maintained on the ground level, where a residential street is both lounge and recreation area (Figure 2-04).

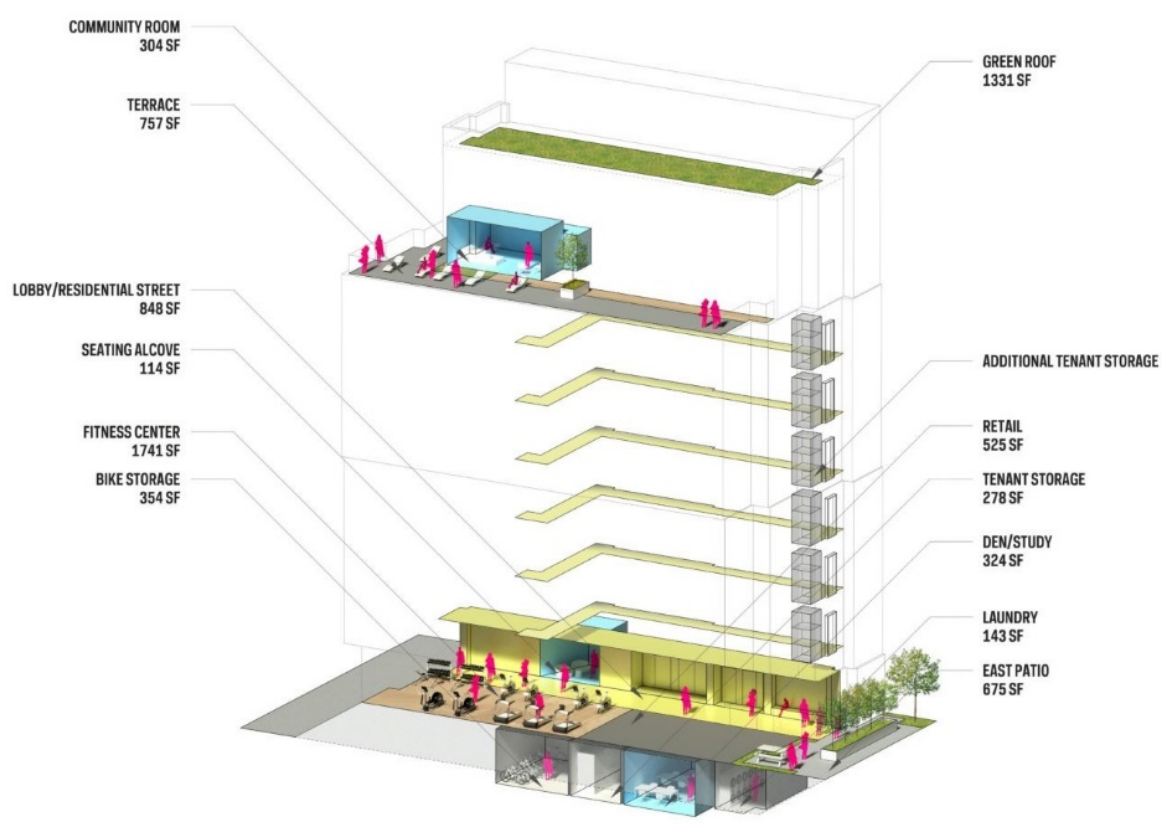

Figure 2-04 Shared Space Axonometric of Carmel Place, New York City, 2016

In the context of Ontario, Toronto's design parameters for affordable units far exceed the spatial conditions that are characteristic of the micro unit concept 
and further demonstrate the destabilization of how urban living is to be defined by architecture and city policy. It is important to note that these relationships are specific to the unique region of Toronto, which increasingly resembles a global city and is unlike most other cities in Canada. Toronto's design parameters for affordable housing, relating to private area, are as follows (City of Toronto Affordable Housing Office, 2015, pg3);

\section{Toronto Affordable Housing Design Guidelines:}

- $40 \%$ of all housing units should contain one bedroom and should be no less than $525 \mathrm{ft}^{2}\left(48.7 \mathrm{~m}^{2}\right)$ in area. The average of all one-bedroom affordable units will be no less than $590 \mathrm{ft}^{2}\left(55 \mathrm{~m}^{2}\right)$ (+/- 5\%). Bachelor units are not acceptable.

- $40 \%$ of all units should contain two bedrooms and should be no less than $650 \mathrm{ft}^{2}\left(60 \mathrm{~m}^{2}\right)$ in area. The average size of all two-bedroom units should be $725 m^{2}(+/-5 \%)$.

- $15 \%$ of all units should contain three bedrooms and should be no less than $900 \mathrm{ft}^{2}\left(84 \mathrm{~m}^{2}\right)$ in area. The average size of three-bedroom units should be $1000 \mathrm{ft}^{2}(+/-5 \%)$.

- $5 \%$ of all units should contain four bedrooms and should be no less than $1100 \mathrm{ft}^{2}\left(102 \mathrm{~m}^{2}\right)$ in area. The average size of all four-bedroom units shall be $1175 \mathrm{ft}^{2}(+/-5 \%)$ 
It is still too early to evaluate the impacts of New York's experimentation, but it provides evidence that regardless of social status, more people are having to adapt their cultural values to the challenges of contemporary urban life, where increased density results in equitable housing and an increased provision of shared space in proximity to the domestic sphere.

The following diagrams demonstrate how the micro-unit concept provides more flexibility in comparison to a typical mid-rise residential floor plan. A onebedroom dwelling is typically arranged with consecutive private spaces following the long dimension of an elongated $625 \mathrm{ft}^{2}$ area (Figure 2-05). This arrangement imposes a hierarchy in domestic space that relies on the confinement of private spaces to fill the depth of the total building area and partitioned semi-private spaces at the outer perimeter. This hierarchy is increasingly accepted resulting in more windowless bedrooms and redundant storage spaces that further isolate social areas within inflexible $625 \mathrm{ft}^{2}$ areas. Framing domestic space this way challenges the idea of combining or dividing units for expanding or contracting households and becomes an architectural issue to be investigated in this thesis. A preliminary investigation by the author shows that an alternative approach can be taken to create four quadrants that can be subdivided to provide four 300$350 \mathrm{ft}^{2}$ micro-units, two $650 \mathrm{ft}^{2}$, or one $1300 \mathrm{ft}^{2}$ apartments without decreasing the quantitative density. This creates the possibility of increased shared space that can be used as common amenity to be appropriated for a variety of uses (Figure 2-06). This configuration attempts to provide equitable access to natural light within livable spaces and increase the proximity and exposure between inhabitants and the exterior environment. 


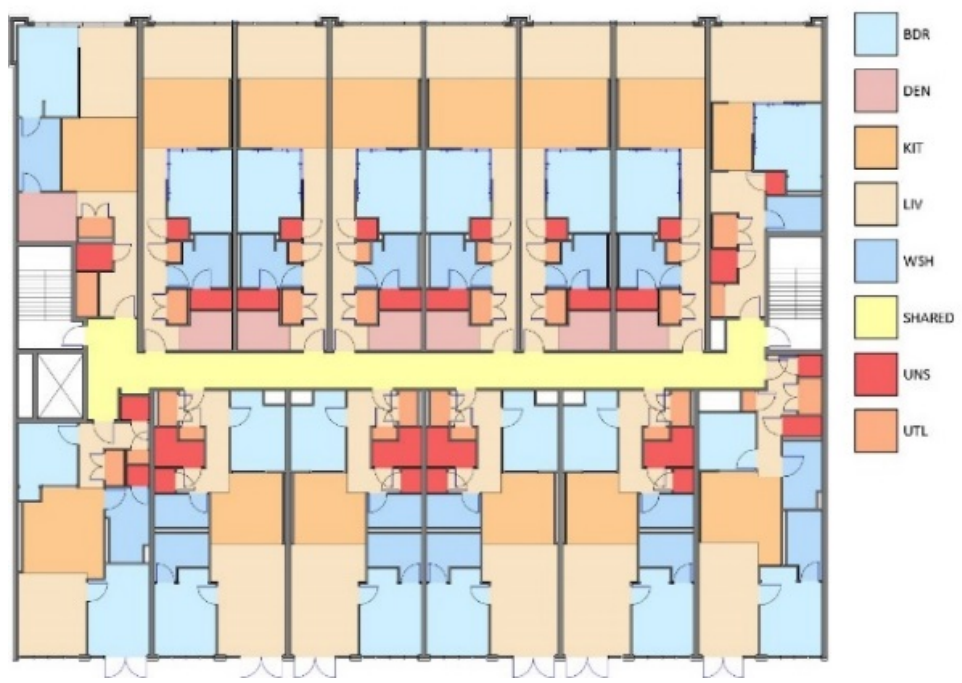

Figure 2-05 Toronto Midrise Floor Plan

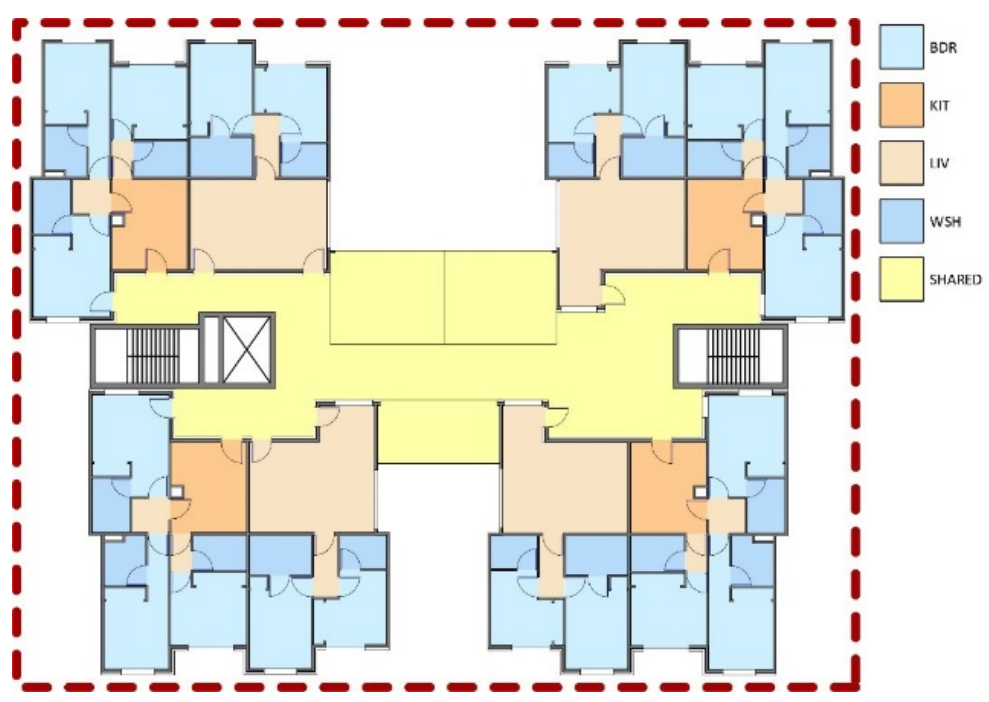

Figure 2-06 Toronto Midrise Floor Plan with Micro Housing Concept Applied

\subsubsection{The Sharing Economy}

The Charter of Athens was formulated in 1933 by CIAM in attempt to define modern cities and to represent what was important about them. Many planning 
ideals that were developed at that time are evident in our cities of today such as suburban development of cluster housing, emphasis on the automobile, standalone buildings in large open spaces, and the separation of functions. This has become a benchmark of how we evaluate our cities; however, as cities continue to develop it has been identified that these ideals have created a formula that is misaligned with the complexities of contemporary city life as demonstrated by our current housing crisis and the growing preference to forgo the commute to a suburban dwelling.

Today there is a growing effort to reverse the effects of separatist schemes which have influenced Toronto's livability. Improvements to public transportation will improve commute times while connecting isolated communities in outer suburbs. More people are choosing to forgo the commute altogether by locating themselves nearer to the city centre in support of bicycle and pedestrian movement. More young people are choosing to live in the city centre but make continued sacrifices in the amount of material possessions and private living space they acquire. Rainer Langhans identifies this as a transitional phenomenon towards another way of living following the 2008 economic crisis, which he defines as a post materialism that leads to a stronger virtuality (Upmeyer, 2013). This virtuality supports networks of people and the communal consumption of resources, which have lead to the success of bike shares, car shares, and office shares; all of which improve the livability of the city through the shared and effective use of resources. 


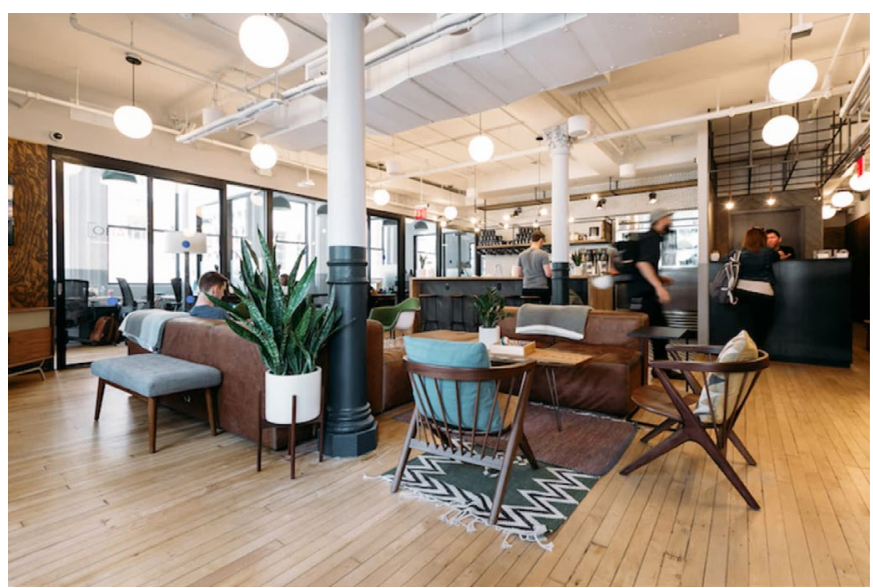

Figure 2-07 WeWork Space, Toronto

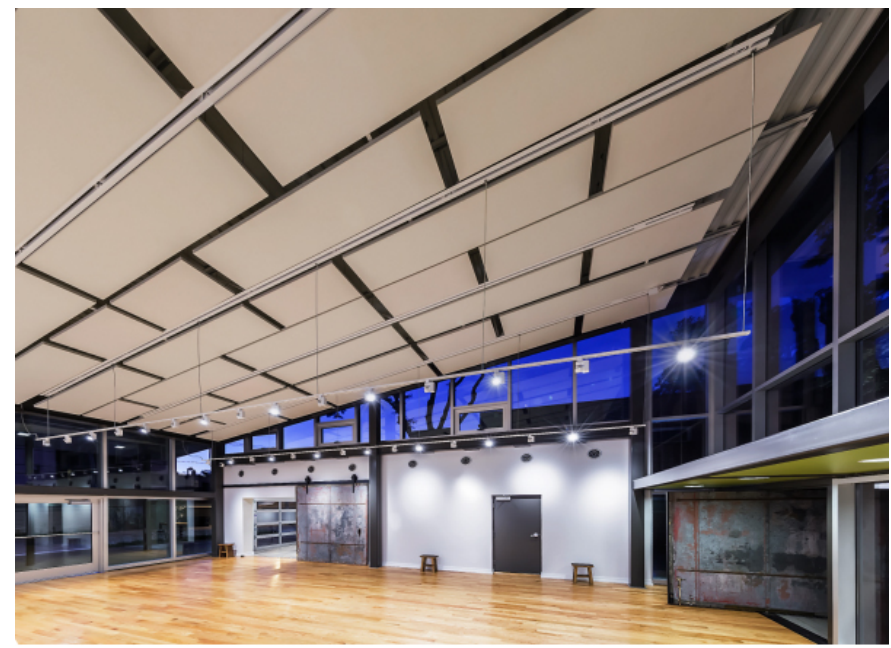

Figure 2-08 Co-operative Housing Community Space, Chicago

Physical space is now being shared by more people and it is invaluable for those that chose to live with less private space (Figures 2-07 \& 2-08). The challenge is how this space is to be shared and mediated through architectural design. As the city continues to develop vertically, there is a sustained effort to support communal and domestic life for people moving into and around existing neighborhoods. Regarding these socio-material relationships, Herman Hertzberger believes that towers, as they are commonly constructed, will 
negatively impact the domestic lives of their inhabitants because people become disconnected from the street and their neighbours. He further states that houses in the future will most likely be smaller but that residential design should advocate a 'nearbyness' so as to make better connections with shared space (Upmeyer, 2016). This 'nearbyness' is defined by architecture and has an affective proximity and beneficial convenience to a local group. This thesis seeks to determine how architecture can improve dense living conditions, where the affects of minimal private space are mediated by proximity to both shared interior and exterior environments.

\subsection{Identity and Morphology of Housing Types}

There is much to be considered in the design of micro unit housing as the phenomenon gains acceptance within contemporary Canadian society. Preliminary observations of current designs that incorporate the micro unit concept indicate a shift in the perception of shared space and how it is to be used. This then informs other design parameters relating to scale, materiality and the character of architectural elements that may enhance the living experience of inhabitants. A misalignment in perception or expectations of shared space could reverse the urban renaissance of today, resulting in more people leaving the city or choosing further commutes into the city. The anticipated minimum livable area of micro units represents the dissolution of social domestic space within an individual's dwelling that requires a reformulation of shared space exterior to one's home; investigations into the domesticity of these spaces are pursued in this thesis.

An initial critique of Smart House (architectsAlliance, Toronto, 2018) which is Toronto's first tower micro-unit project, reveals the incorporation of design 
sensibilities that are characteristic of cohousing models, specifically regarding the shared amenity space of Smart House (Figure 2-09), and its similarity to the design and function of the 'common house' which is characteristic of cohousing schemes (Figure 2-10).

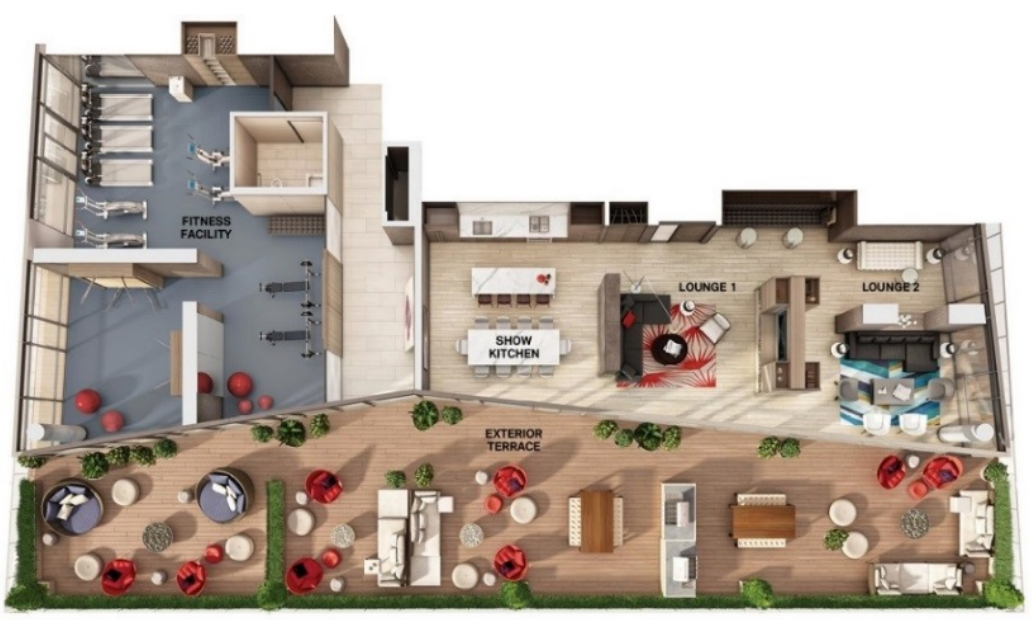

Figure 2-09 Smart House amenity space, Toronto, 2017

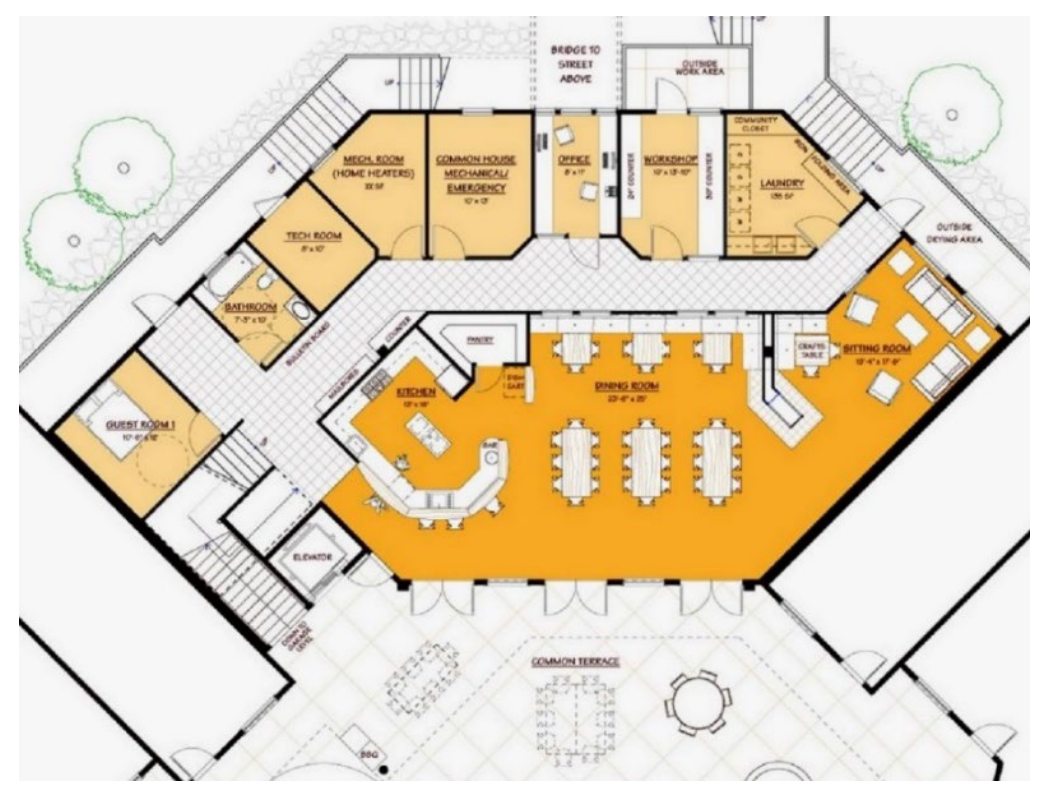

Figure 2-10 Typical Cohousing Common House 
Both Smart House and typical cohousing plans incorporate open access to a variety of shared domestic places that include, a community kitchen, dining room, living room arrangements, washrooms, work space, recreation and access to an exterior terrace. It is worth noting that open access to these amenities is not common in typical condominium developments but became accessible within the context of the micro-unit phenomenon. Smart Home developments insist that the amenity space is meant to highlight the recognition that people who choose to live small should have plenty of opportunity to exercise, lounge, party and be social on-site (SmartHouse, 2017)

The intent seems appropriate, but it is doubtful whether the designed space can support the community of 241 units in a 25-storey tower. Issues relating to proximity and ratio of private to shared space is questionable. Furthermore, depending on the flexibility of floor plans, the concentration of micro units with few options for multiple bedroom units presents a challenge for those seeking modifications to shared spaces to better suit changes in lifestyles. It is worthwhile to consider the values, sensibilities, and designed elements that are inherent to residential typologies that advocate an emphasis on shared space that is external to one's private dwelling, and how these sensibilities encourage community and the longevity of local support structures.

The Smart House design represents a movement to create multi-unit residential buildings and common space that align with a lifestyle or common identity of the inhabitants; this approach is supported by the City of Toronto, Ryerson City Building Institute, and demonstrated in European baugruppe and integrated housing schemes that will be discussed in the case studies of this thesis. As mentioned, Toronto's Avenues \& Mid-Rise Buildings Study advocates mid-rise development, where the architecture and shared space is more conducive to the creation of community within a local group. Additionally, the Growing Up: 
Planning for Children in New Vertical Communities report identifies the guidelines for the improved function of larger households at the scale of the unit, the building and the neighbourhood (City of Toronto, 2017), where shared space is to support the livability of smaller unit design for young families with children. It is expected that the young families and senior demographics will grow to a combined population of nearly 700,000 people in the coming decade, and that multi-unit residences will need to be designed to their needs, specifically an increase in 2+ bedroom units (Ryerson City Building Institute, 2017), although these numbers speculate that aging millennials will actually seek more space to accommodate growing families and that seniors will prefer living in the city. What is important is that these reports support an approach for the design of housing that operates at a local scale and considers how the architecture and design of common space can improve the livability of urban centres.

\subsection{Common need / Social Objectives}

More people need sensible housing options that support their individual lifestyles. These people are increasingly aware of the complexities of urban life relating to the affordability of individual space and the need to accommodate more people through the creation of shared space. This is demonstrated in the willingness to fit their lifestyle into smaller living environments and participation in the communal use of amenity space. The challenge is to determine the appropriate relationships with common space and how it can best represent the

collective needs of a local group. Private accommodation of individual needs has resulted in redundancies in private green space, recreation facilities, and the infrastructure to support private transportation to and from the built-in individualism of the urban and sub-urban landscape. These redundancies 
directly correspond to the waste of resources and time, and people are now adopting alternative strategies of collective consumption that breakdown individualist services while supporting the need of a more sustainable living environment (Bost \& Howeler, 2013). This thesis seeks to determine how shared space can reflect these common needs while designing for the emergence of community and local support structures.

\subsection{Common Values / Cultural Idealizations}

Within the collective conscious, people recognize that cooperation is important to society, in that it supports the organization of life, but that it is not an alternative to one's life (Siupsinskas, 2013). This statement encompasses a general understanding of how people choose to associate themselves with society, where choice and preference hold a higher value than co-operation, but that cooperation does exist in the world. My position is that residential architecture should provide the option for local cooperation and a sense of belonging. If people value cooperation, their environments ought to support that potential as opposed to isolating it.

This thesis seeks to determine how shared space is mediated by architectural design, where more variety in shared space represents varying degrees of membership associated to proximity and scale. Common use of space exposes individuals to sociable environments that create the potential for local support structures and improve the livability of our city. Architects must work with clients to determine the suitability and accommodation of shared space to facilitate the potential of an inclusive community, where the design of shared space can create a sense of belonging, comfort and ownership. 


\subsection{Comparators for Case Study Analysis}

The following definitions of Leandro Minuchin's theory strands on Material Politics and my proposed comparators are reiterated in support of the following analysis of case studies which include the sub-urban and rural bungalow, the semi-detached house, co-housing, three forms of co-operative housing, and both typical and micro condominium housing models.

\section{The inscription of metabolic infrastructures:}

Influence the sum total of the technical and socio-economic processes that occur within buildings and cities, resulting in growth, production of energy and the elimination of waste. It is proposed that this inscription is demonstrated in how material composition and energy consumption within the boundaries and areas of an architectural design can support a local effect amongst residents and neighboring communities.

Proposed Comparators:

- Material and energy processes

- Boundaries and areas

- Local effect

\section{The disruption of the sensible:}

Considers the agentic properties of materials and their capacity to disrupt established social and technical assumptions and regulations. It is proposed that the properties of materials and how they are assembled in place provides agency 
to the user through the mediation of proximities and exposures within spatial variability which ultimately informs our experience of affective density.

Proposed Comparators:

- Proximities

- Exposures

- Spatial Variability

\section{The assembling of socio-material entanglements}

Considers the design flexibility of space in relation to socio-material processes that reposition materials into new function; which in turn, alter and redefine local practices and experiences. It is proposed that the assembling of sociomaterial entanglements is demonstrated in how an architectural framework, can support material modification and the flexible configuration of a setting system to align with emerging trends in housing.

Proposed Comparators:

- Architectural framework and material modification

- Flexibility of setting system

\subsection{Case Study: The Sub-urban and Rural Bungalow}

\subsubsection{Inscription of Metabolic Infrastructures}

Gaining popularity throughout the $20^{\text {th }}$ Century, the bungalow is associated with the idea of a cottage retreat with strong connections to the natural environment. Over time, this association has been adapted to suit the desired privacy of low density 
neighborhoods resulting in the expansion of human populations away from central urban areas and therefor contributing to the condition of urban sprawl. Although sustainable energy and material strategies can be implemented relatively easily by the resident, the benefits are outweighed by the boundaries and areas which are higher than average dwelling areas; resulting in the proliferation of both the spatial and physical divisions of space that support various lifestyles without compromising individual privacy. This results in a small resident group inhabiting maximum transition space with minimum interaction with the public realm and a notable decrease in a local effect.

\subsubsection{Disruption of the Sensible}

Interior and exterior paths of circulation provide access to an increase in shared recreation space with private spaces in both far and near proximity (Figure 2-11). Optional access points provide increased control over the exposure of an individual inhabitant, providing the option of high and low visibility within shared spaces. There is maximum spatial variation in the horizontal dimension with continuity between interior and exterior places with split-level conditions providing some variety in the vertical dimension.

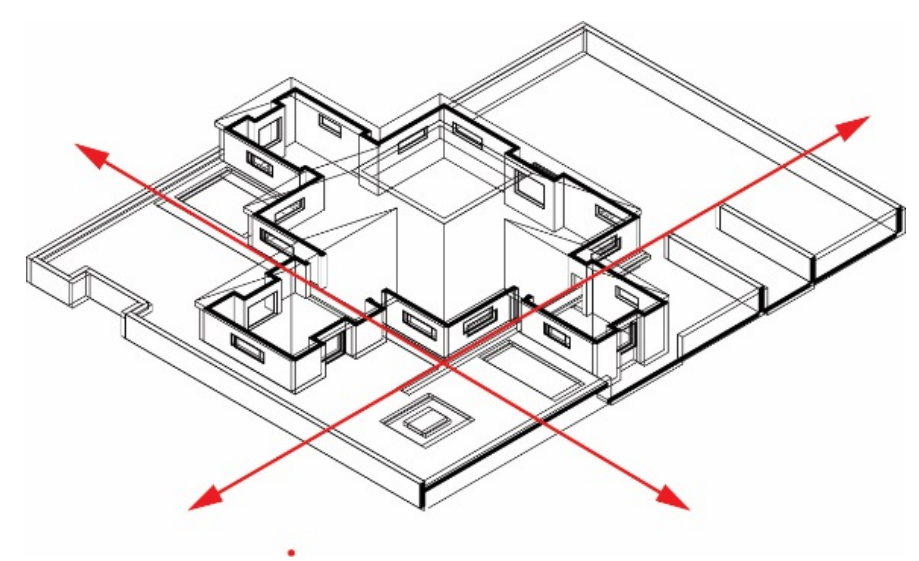

Figure 2-11 Suburban and Rural Type with maximum horizontal dimension 


\subsubsection{The Assembly of Socio-material Entanglements}

Light frame construction supports modifiable partitions within a lose spatial enclosure, resulting in the option to create a variety of designed spaces for specific residential uses. Enclosed courtyards and covered verandahs make physical the tenants of landscape architecture as proposed in Margaret Goldsmith's 1942 Designs for outdoor living:

To extend 'house living areas into outdoor rooms'; to encourage the value of living close to out-of-door'; to promote the concept of the whole terrain as a single unit of three dimensional space made up of smaller units of design, some under roofs and some not, but all related, as our legs, arms and organs are related-actual connected parts of the whole living organism, capable of many necessary human activities simultaneously' (Kiley, 2000, pg 12)

Additionally, a brick retaining wall surrounds the Gregory house and defines the outer edge of the outdoor living space (Figure 2-12). This wall is topped by a granite lintel that is multifunctional in that it is a balustrade, a bench and prominent datum for the staging of social interaction and seasonal changes. (Kiley, 2000)

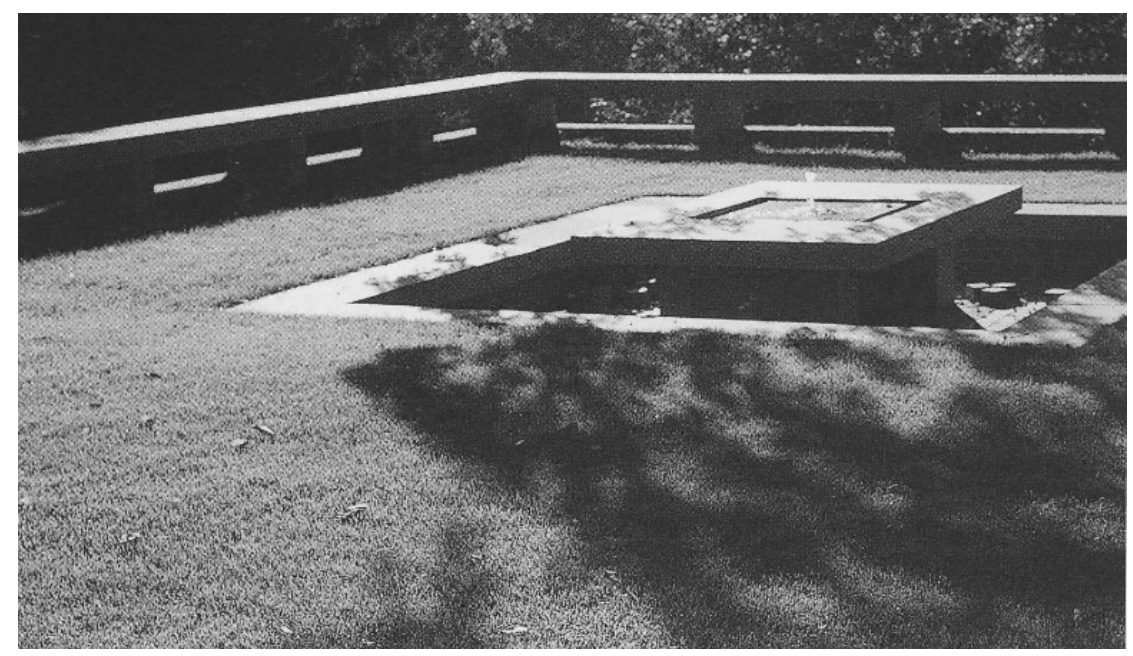

Figure 2-12 Gregory House Exterior Room 
Interestingly, these tenants retain their value but inadvertently contribute to the motivation of urban sprawl through their misappropriation within the suburban context. These tenants ought to be followed more closely within the urban context where the idea of living close to out of door is increasingly compromised by architecture that promotes separation from the natural environment and the use of shared space.

\subsection{Case Study: The Semi-detached House}

\subsubsection{Inscription of Metabolic Infrastructures}

Sustainable energy and material use strategies are easily implemented by the inhabitant. Where physical divisions within the boundaries and areas of semi-private living spaces support sustainable living without compromising individual privacy. These dwellings provide higher than average unit areas depending on the extent of renovation and year of construction. This dwelling type can support a small resident group in a lowrise condition; where minimal setbacks define the extents of transition spaces that provide opportunity to engage with the public and a local effect. Nearly half of the occupied private dwellings in Toronto have these characteristics (Statscan ,2017); with many people preferring the sense of community that is created through patterns of informal interaction with nearby residents. Every year fewer and fewer dwellings of this type are constructed, and existing neighborhoods that are comprised of semi and fully detached houses are increasingly at odds with the encroachment of increased densification. 


\subsubsection{Disruption of the Sensible}

Interior and exterior paths of circulation provide access to limited exterior and interior shared space with private space in near proximity. Limited access points provide lower control over the exposure of an individual inhabitant. There is typically high visibility in shared semi-private spaces located at grade, where the option for a duplex configuration provides spatial variation in the vertical dimension (Figure 2-13).

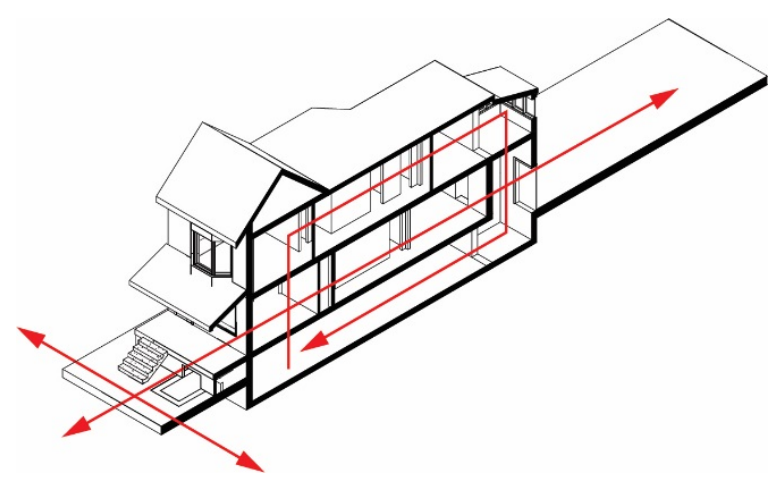

Figure 2-13 Semi-detached housing type with near proximity to spatial variation

\subsubsection{The Assembly of Socio-Material Entanglements}

Architectural framework and Material usage

Light frame construction supports modifiable partitions within a tight spatial enclosure which can be reconfigured to create new spaces for changing lifestyles.

\section{Setting System}

Spaces are designed for specific domestic uses although spaces of similar dimensions are easily converted to support alternative uses. 


\subsection{Case Study: Co-Housing}

\subsubsection{Inscription of Metabolic Infrastructures}

\section{Material and Energy Processes:}

Most cohousing communities attempt to integrate sustainable ecological and energy efficient strategies into the design of their communities to improve affordability and further define a group identity (Figures 2-14, 2-15). The physical qualities inherent to the domestic exterior of cohousing include maximizing natural light to building interiors and the facilitation of use throughout the year and during climatic change (Scotthansen \& Scotthanson, 2005).

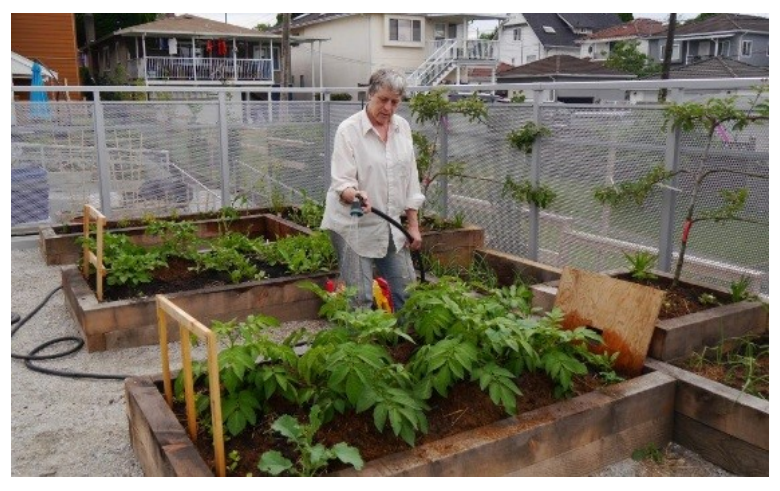

Figure 2-14 Vancouver Co-Housing Gardens

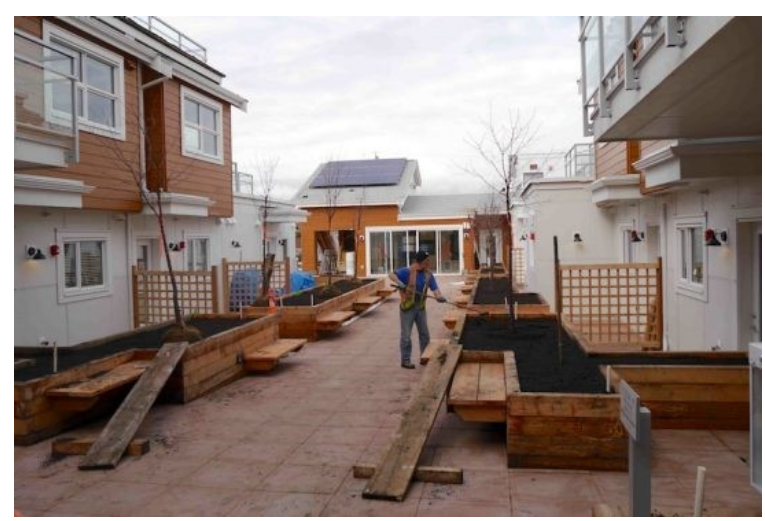

Figure 2-15 Vancouver Co-housing Shared Exterior 


\section{Boundaries and Areas:}

It is essential that the needs of the individual remain in balance with the needs of the community. Regarding the individual dwelling units, the participatory design process of cohousing can produce a variety of unit types ranging from studios to four or fivebedroom dwellings. Unlike development housing, this range of choices supports the diversity of household types that are typical within a cohousing community. Communities are commonly designed to incorporate a separation between an individual dwelling and the shared use of common facilities. Individual dwellings are to include separate washrooms and kitchen facilities while common areas are designed for daily use as a supplement to the privacy of the individual dwelling.

Local Effect:

The scale and optimum size of cohousing models is between 12 to 36 units or 10 to 40 households to support the diversity of a local group and the sharing of space and resources. Beyond this density people lose the ability to recognize all the people who co-inhabit the space and provoke a sense of insecurity within their co-living environment. (Scotthansen \& Scotthanson, 2005). The ownership structure typically supports private ownership and control of what is privately owned; although there are variations to this financial model that support collaborations between government housing agencies, non-profits and resident groups to build rental units (McCamant \& Durrett 2011). Although traditional co-housing represents less than one percent of new builds within North America, many within the cohousing movement prefer the cooperative model because of the cooperative nature of the community that intends to sustain a life in a local place, without speculation or potential of relocation (Scotthansen \& Scotthanson, 2005) 


\subsubsection{Disruption of the Sensible}

\section{Proximities:}

A greater portion of shared exterior area can be dedicated to recreational green space resulting from the compact clustering of individual dwellings; this strategy creates a sense of being surrounded by nature while facilitating access to exterior recreation space and the possibility of locally grown organic food (Figure 2-16).

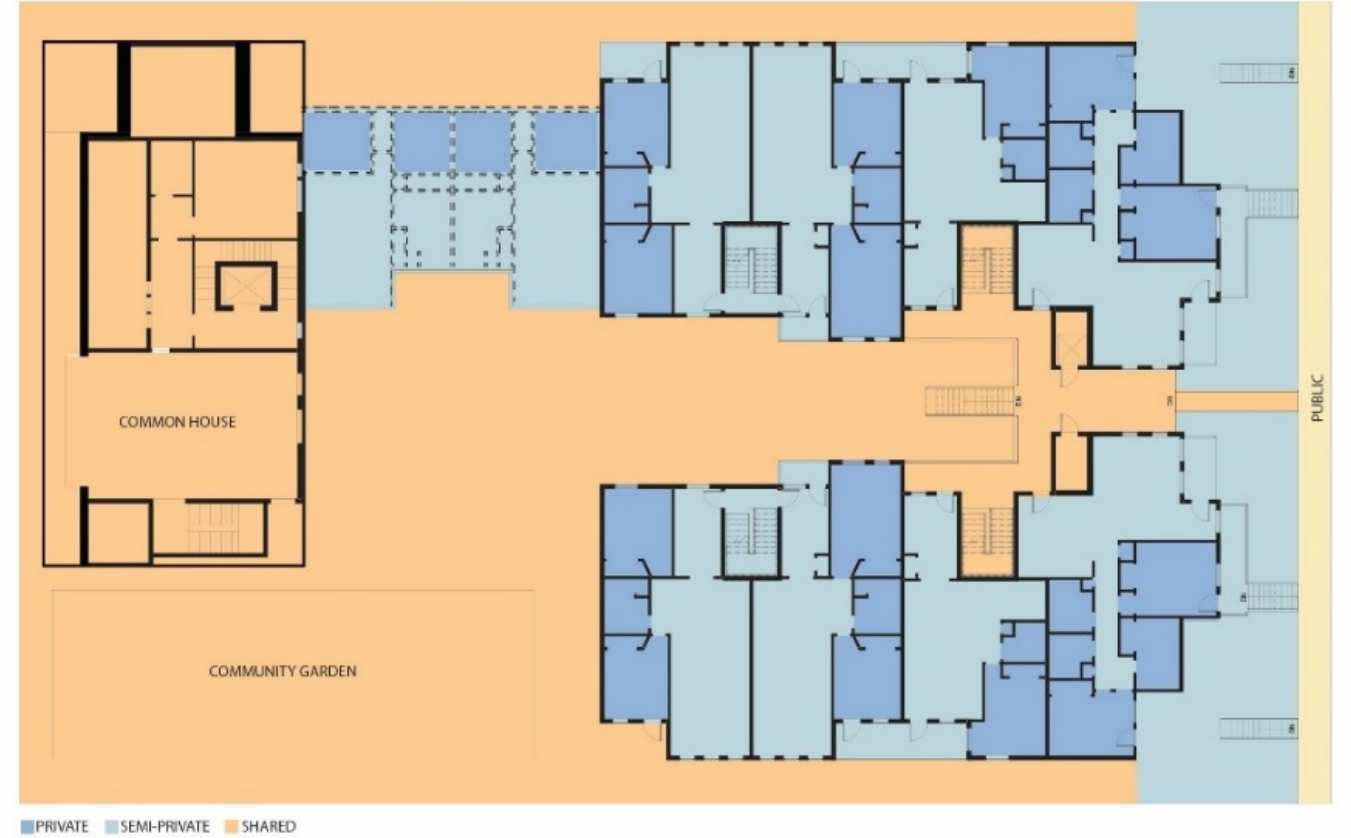

Figure 2-16 Vancouver Co-housing Site Plan

\section{Exposure:}

The formal design encourages a social engagement along circulation paths and within common spaces, although optional access points provide increased control over the exposure of an individual inhabitant (Figure 2-17). 


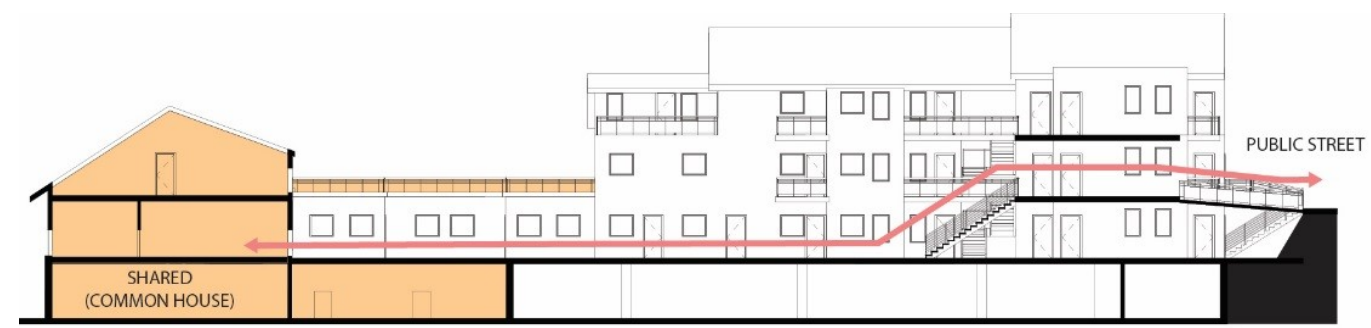

Figure 2-17 Vancouver Co-housing Site Section

Spatial Variability:

The emphasis on creating shared space within the cohousing model demonstrates the capacity for a group of individuals to work together in facilitating the specific needs of the group within the flexibility of a shared environment. These spaces become important places to live that extend beyond the limitations and privacy of their individual dwelling (Figure 2-18).

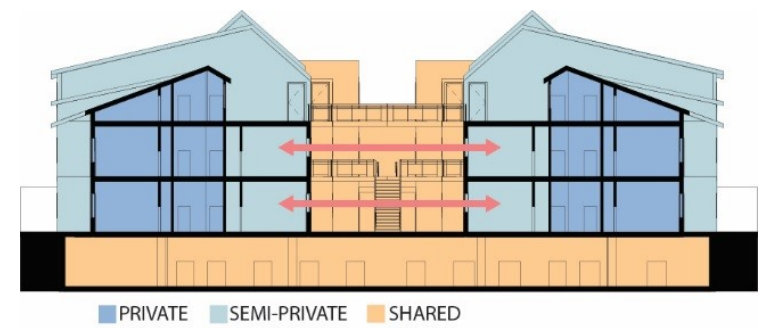

Figure 2-18 Vancouver Co-housing Building Section

\subsubsection{The Assembly of Socio-Material Entanglements}

\section{Architectural framework \& Material Modification}

Light frame construction supports modifiable partitions within the lose spatial enclosure of individual units and the shared space of the 'common house'. These shared spaces can be purposefully designed with flexibility to suite the collective and changing needs 
of the community and are considerably larger in comparison to most co-operatives and condominium models. In this way, the shared architecture can sustain supportive spaces for the community through time.

\section{Setting System}

The 'common house' is designed to accommodate a wide variety of uses, with the intent that time spent over the preparation of shared meals and proximity of work will further encourage a sense of community. This approach is now informing affordable housing in the United States; where agency for the inhabitants is supported by use of a common house and deviates from the association of an 'intentional community' which is typical of a cohousing organization.

The first all-rental cohousing for low income households was completed in 2009 in Sebastopol, California (Figure 2-19). Additional projects in the United States have had similar success in collaboration with government housing agencies; these groups include the South Side Park Group in Sacramento and the Puget Ridge Group in Seattle. Together, these projects demonstrate that typical ownership models are not always the case, specifically in a housing market that prefers the rental option.

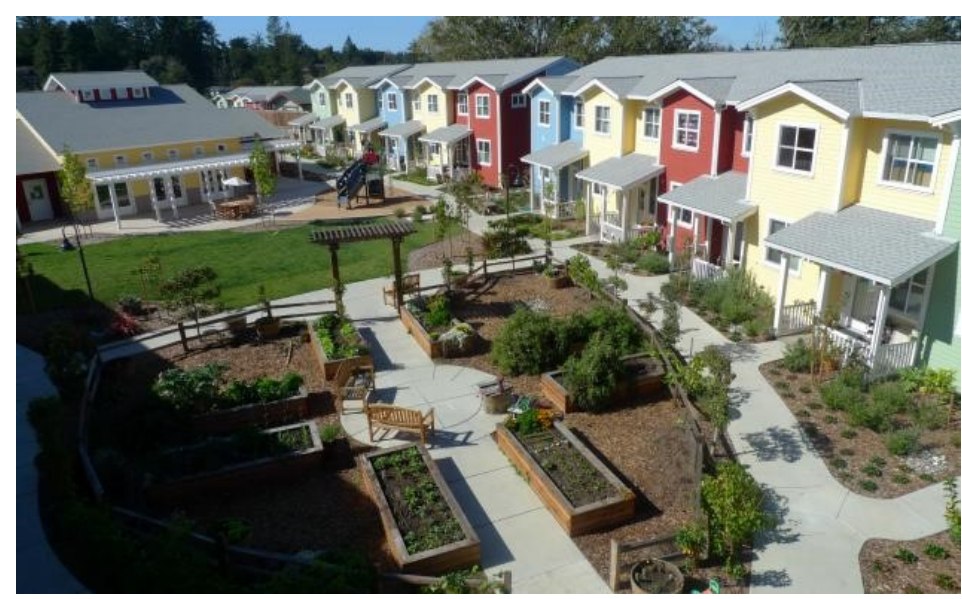

Figure 2-19 Sebastopol Co-housing Site Arial 


\subsection{Case Study: Co-operative Housing / Group Build / Integrated Living}

\subsubsection{Inscription of Metabolic Infrastructures}

Material and Energy Processes:

These co-operative housing models seek to optimise the use of urban sites through the adaptive reuse of existing buildings and infill strategies that seek to incorporate the design of spaces and special features that support social interaction. baugruppe is German for 'building group' and is identified as a group of people working together with an architect to share the responsibility of designing and creating housing without the influence of a developer. The mixed-use German baugruppe project located in Berlin at 56 Oderberger Str., was designed by BAR Architects and completed in 2008; this project demonstrates the successful revitalization of an underutilized site through a small footprint infill strategy that was suitable for the needs of future residents. Similarly, the mixed-use Integrated living project located in Vienna, Austria was envisioned by a group of residents that established themselves as a real estate development association, resulting in the eligibility to receive subsidies and exemption from rigid policies related to normal state-subsidized housing. This allowed the association to procure an industrial state-owned property, with an urban location that was revitalized through the adaptive reuse of the existing structures. In both instances, the need to acquire under utilized or brownfield sites contributed to the effective use of materials in the design and construction of these projects. 


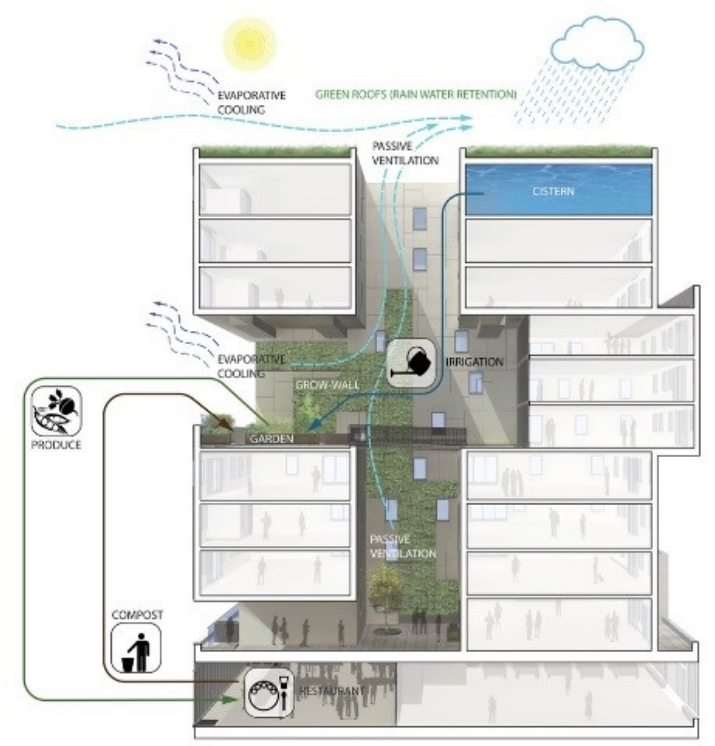

Figure 2-20 Toronto Co-operative Building Section

Looking to Toronto, 60 Richmond Street East is the first housing co-operative to be built in many years and incorporates many sustainable strategies relating to material and energy processes. Unlike many residential buildings of this size, the design considers an increase in highly insulated rainscreen cladding and a decrease in glazed surfaces. In doing so, the building form achieves an optimal balance between natural light and cross ventilation without the overheating effects of excess solar gain. It has been identified that the architecture acts as a filter to condition the air, cultivate vegetation, and absorb storm water through green roofs that further insulate the building while reducing the heat island effect in the urban context (Figure 2-20). Additionally, a self-sustaining condition known as "urban permaculture" is created on site through the composting of organic waste that is then used in a centrally located community garden to produce food (Canadian Architect, 2011).

\section{Boundaries and Areas}

In all three examples of the co-operative housing model, there are more dwellings with above average areas to accommodate families and groups of individuals living together. 
This is best demonstrated in the Austrian Integrated Living example, where the site could support a form of living that offered more than the fulfillment of functional demand per measured area (Figure 2-21). In both the baugruppe and Integrated living examples, there are both physical and spatial boundaries that separate an individuals private living area from a common kitchen and dining area. Partition walls with controlled access and split-level conditions are used to promote social interaction without compromising individual privacy (Figure 2-22).

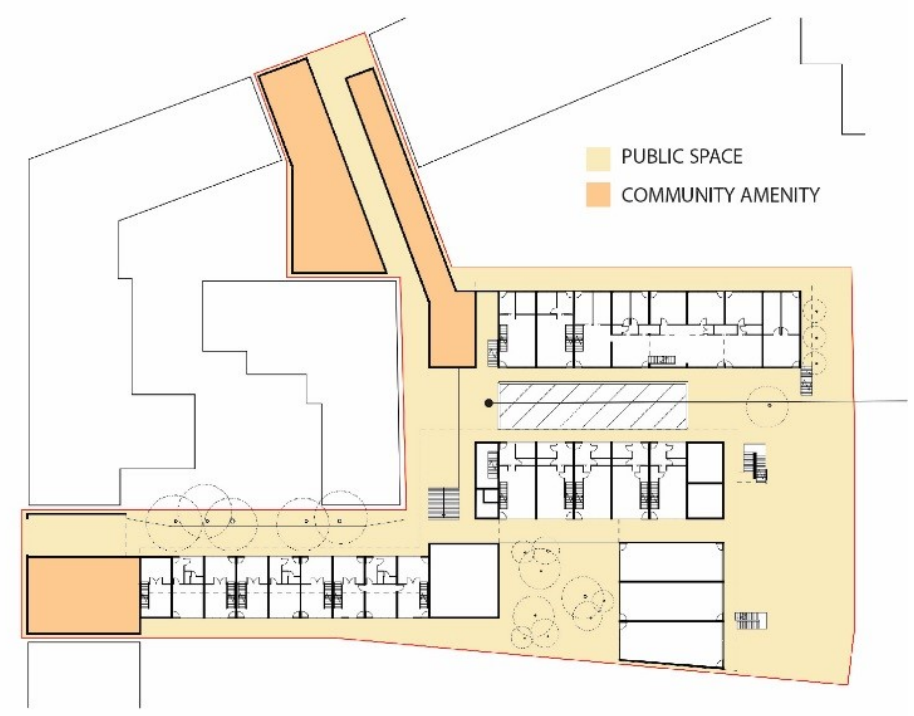

Figure 2-21 Vienna Integrated Living Site Plan

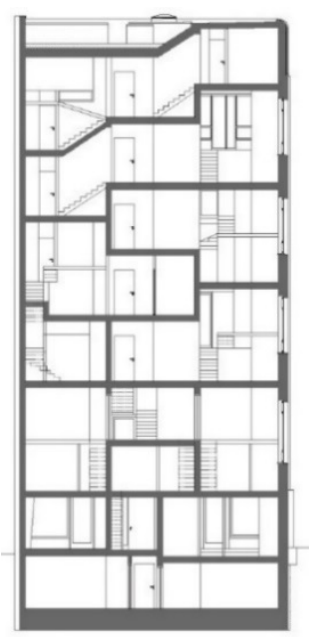

Figure 2-22 Berlin Baugruppe Building Section 


\section{Local Effect}

In all three examples of the co-operative housing model, small groups of people identify a problem and innovate applicable solutions that can be introduced into the broader social discourse. This is demonstrated through a common interest to support a sense of community on site and is demonstrated in varying degrees through the design and use of shared public and semi-private space. Within the baugruppe project there is increased potential for social interaction between residents and the public through shared use of live work collaboration space located in the base of the building. This is typical of most baugruppe projects in Berlin in that shared gardens are also open to the public so that the entire neighborhood can enjoy the exposure to nature (Eidner \& Ring 2013).

In North America, the housing co-operative located in Toronto demonstrates a more private approach to designing for a live-work culture where all residents are employed in the hospitality industry and are members of a local union called Unite Now. This livework culture is supported by both the programming and formal aspects of the architecture, in that a self-sustaining condition known as "urban permaculture" is created on site. This is accomplished through the composting of organic waste that is then used in a centrally located community garden; which in turn, produces food for the union operated practice kitchen and restaurant located on the ground floor (Canadian Architect, 2011).

The local effect is most strongly demonstrated in the Austrian Integrated living project where there is an objective to improve neighborly support between different generational groups and those with specific needs related to varying disabilities. It has been identified that the exchange of mutual support measures can then ease the burden of specific groups while minimising the tendencies toward isolation (Schittich, 2007). In this example, there is an equal measure of both independence without 
isolation, where mixed families and those affected by disability can benefit from the safety and security of an informal community. In addition to the shared semi private space, the resident community can experience an increased potential for social interaction with the public through shared use of recreation facilities, meeting rooms and a café. The architecture in all three examples demonstrate how the design of architecture can support the option for informal human interaction, which is either encouraged or prevented by what is built.

\subsubsection{Disruption of the Sensible}

\section{Proximities}

The measure of proximity varies between the residents of all three co-operative models. In the baugruppe model, the approach to have shared circulation limited to a vertical stairwell and elevator core emphasises the compact clustering of units from where residents have optimal access to a collaborative live work environment. Within the baugruppe model there is an increased proximity for residents with access to shared semi-private living space. This differs from a further proximity between residents living in separate units within the housing co-operative located in Toronto where there is both horizontal corridors and elevators that provide access to shared common space at the base and mid-portion of the building. In contrast with the previous examples, the integrated living arrangement provides a balanced proximity amongst individual residents through the design and use of transition spaces between individual units (Figure 2-23). 


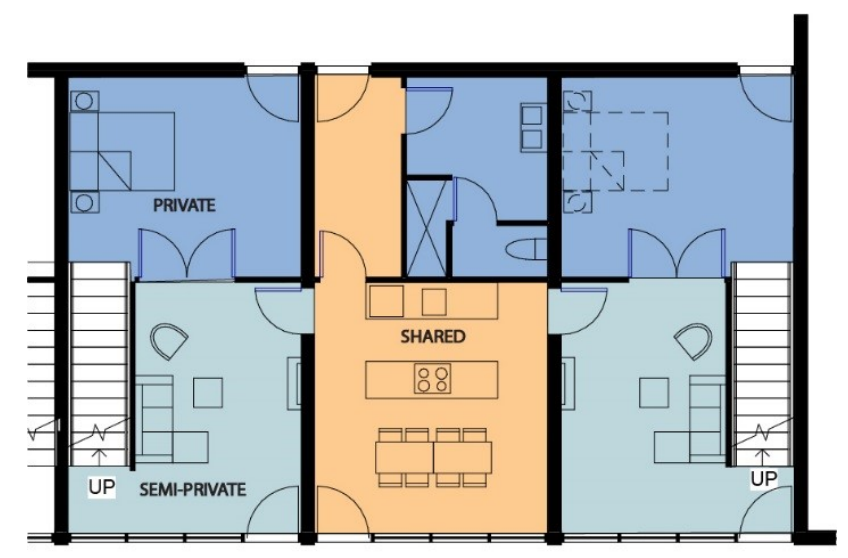

Figure 2-23 Vienna Integrated Living Unit Plan

\section{Exposure}

An individual's exposure within the semi-private and shared spaces of all three cooperative models considers the barriers that divide an individual's dwelling and access to shared semi-private space. In both the baugruppe and integrated living examples, multiple points of access to an individual's dwelling provides control over their exposure to exterior and interior shared space (Figure 2-24, 2-25). Whereas Toronto's cooperative housing model provides single points of access to shared space which decreases the control over exposure between shared and private space.

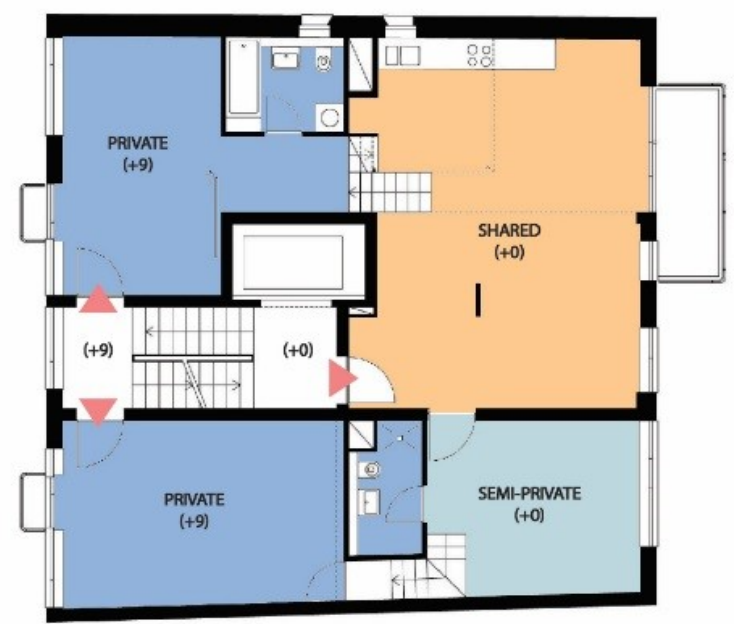

Figure 2-24 Berlin Baugruppe Unit Plan 


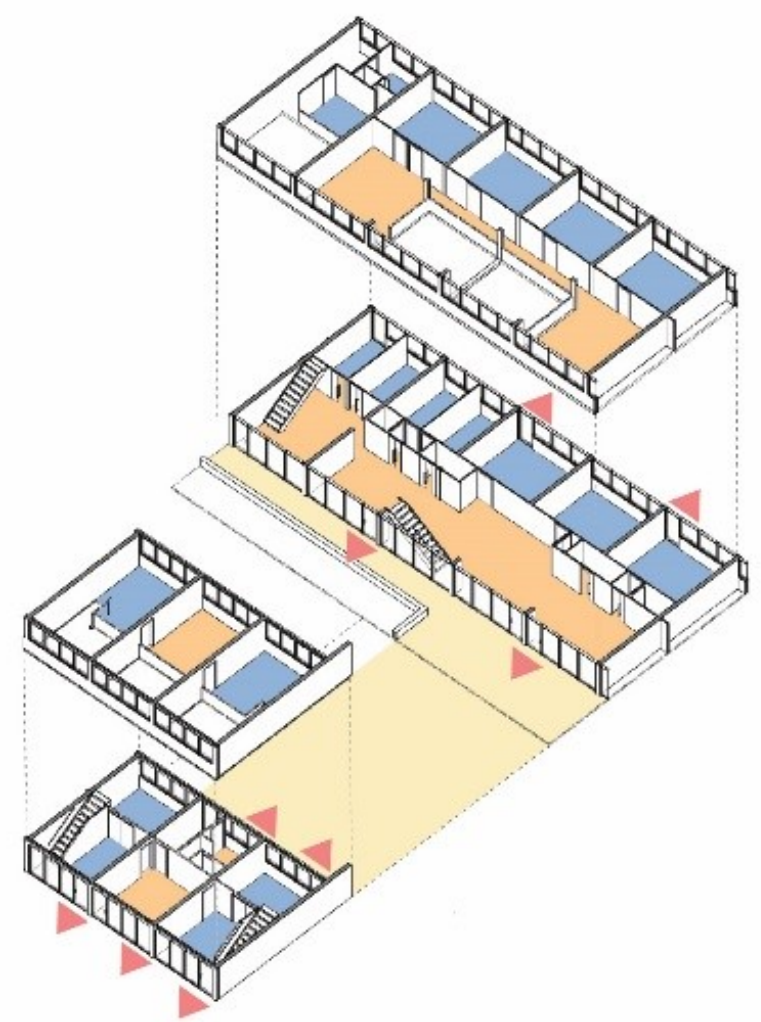

Figure 2-25 Vienna Integrated Living Sectional Building Axonometric

\section{Spatial Variability}

The spatial variability of shared semi-private spaces and within private dwellings is greatest in both the baugruppe and integrated living examples. Where the split-level condition and atypical floor to ceiling heights in both dwellings and live-work spaces provide spatial variation in the vertical dimension (Figure 2-27). Shared public, and semi-private spaces are unique from one another in all three examples, where there is an attempt to provide variation between an individual's private space and those spaces that are shared between the resident group (Figure 2-28). 


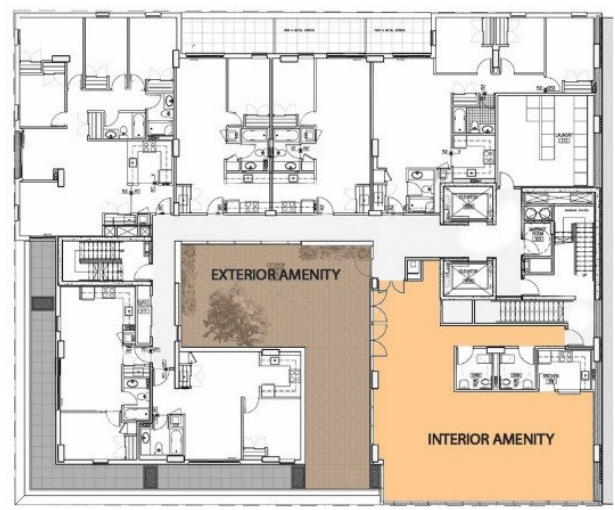

Figure 2-26 Toronto Co-operative Private Resident Amenity

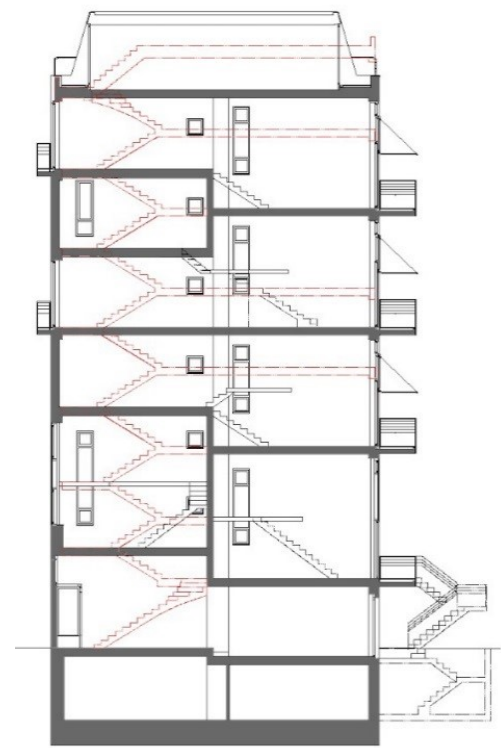

Figure 2-27 Berlin Baugruppe Building Section

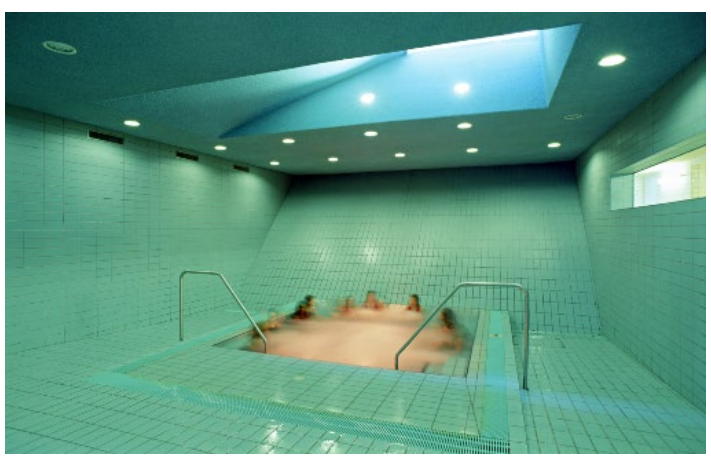

Figure 2-28 Vienna Integrated Living Public Amenity 


\subsubsection{The Assembly of Socio-Material Entanglements}

\section{Architectural Framework}

The architectural framework of all three buildings is comprised of a concrete superstructure with stick frame partitions and decking to enclose the individual dwelling units.

\section{Material Modification}

In all three examples, stick frame partitions can be added or modified within the tight spatial enclosure of a private dwelling unit. The material finish of the dwelling units within the baugruppe example are left purposefully raw so that residents can modify these surfaces to suite their preferences (Figure 2-29, 2-30).

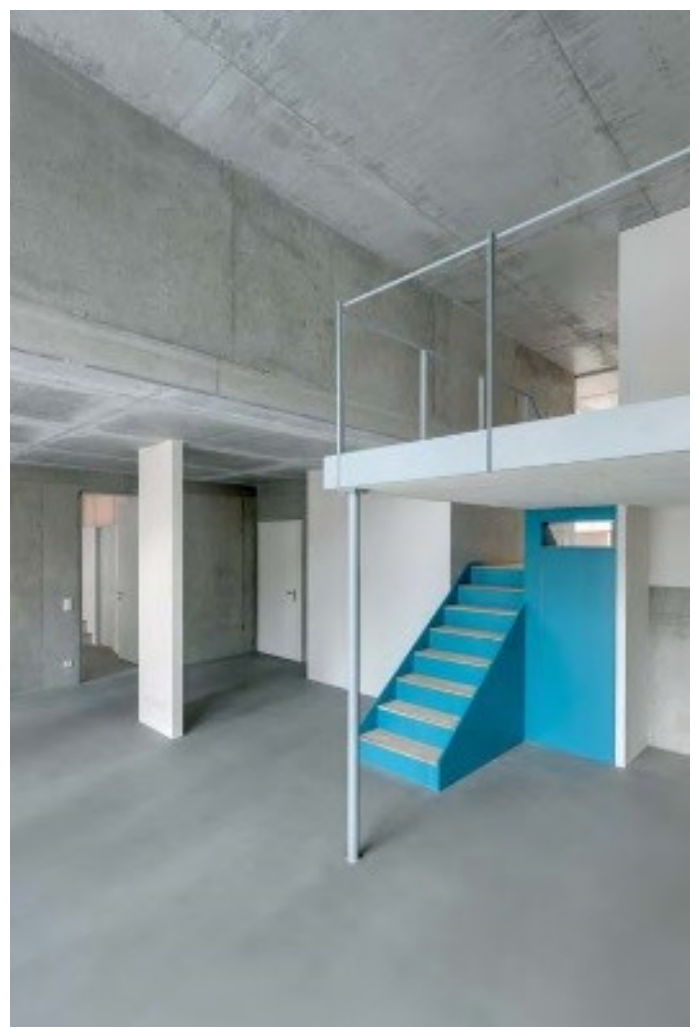

Figure 2-29 Berlin Baugruppe Raw Finish 


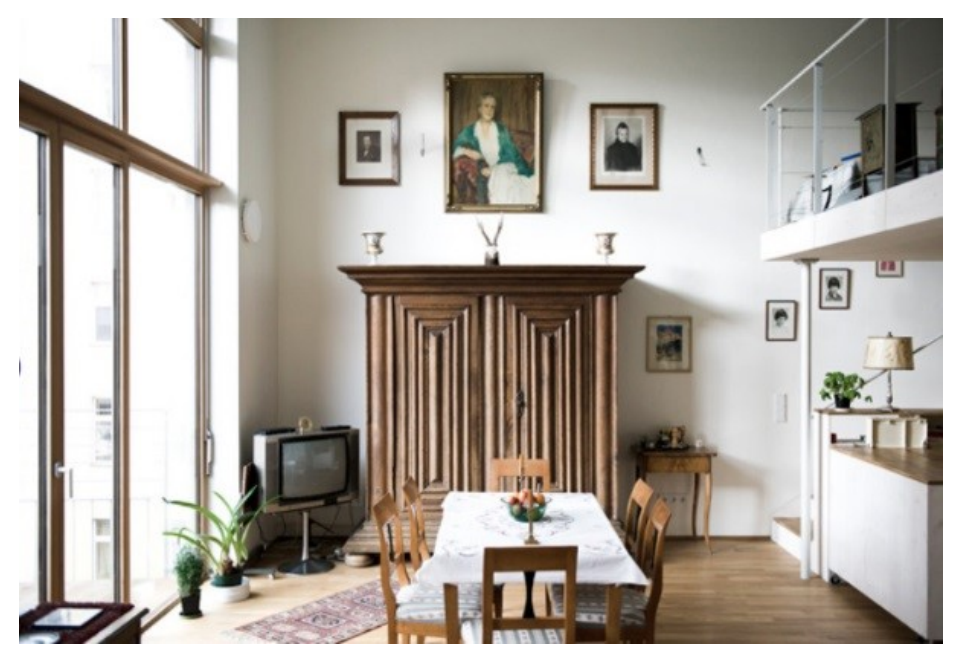

Figure 2-30 Berin Baugruppe Completed Finish

\section{Setting System}

The setting systems of all three examples are demonstrative of the mixed-use approach whereby public and semi-private spaces become an extension of one's private living space through varying degrees of access. In the Toronto example these spaces are primarily limited to the resident group with separation between the live and work environments (Figure 2-31). Whereas the baugruppe and integrated living examples provide greater flexibility in the use of space to support variations of public use, livework and communal living arrangements (Figures 2-32, 2-33).

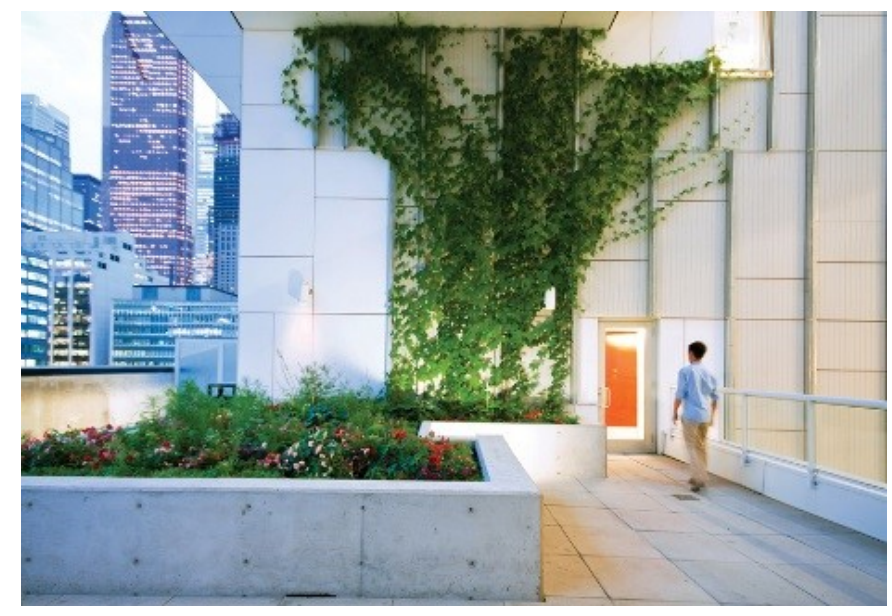

Figure 2-31 Toronto Co-operative Private Resident Gardens 


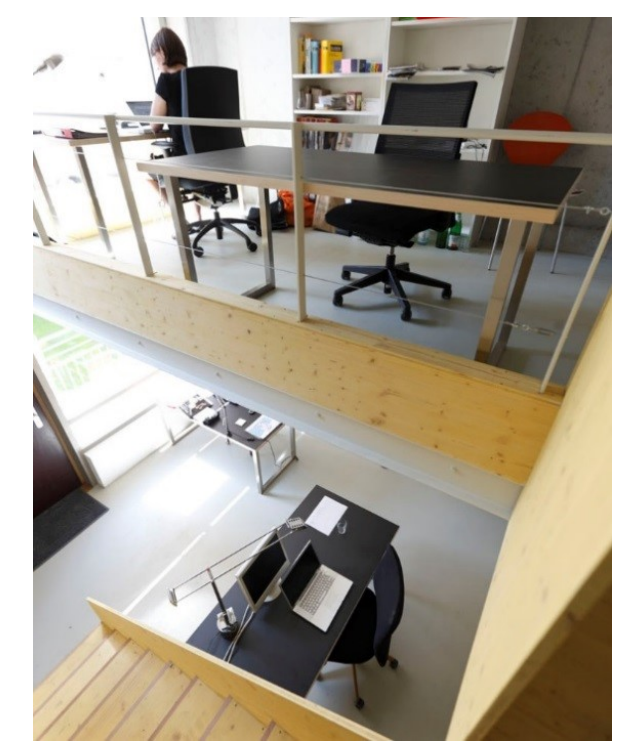

Figure 2-32 Berlin Baugruppe Live-work Space

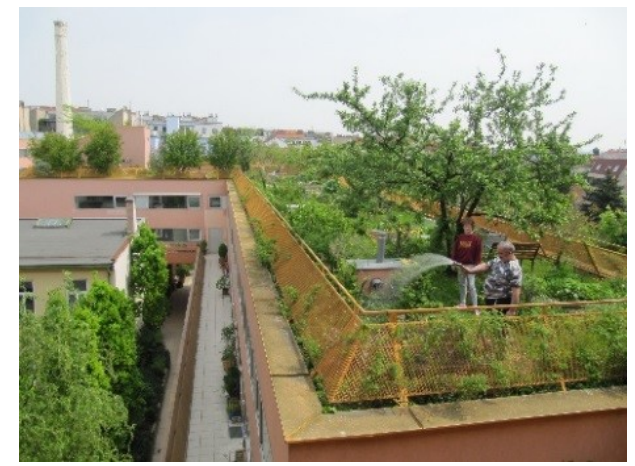

Figure 2-33 Vienna Integrated Living Community Gardens

\subsection{Case Study: Typical and Micro Condominiums}

\subsubsection{Inscription of Metabolic Infrastructures}

Material and energy Processes

Both examples of condominium development demonstrate a revitalization approach that utilizes optimal land, while in many condominium developments, strategies relating 
to the adaptive reuse of existing buildings is often limited to the reuse of exterior facades. Strategies relating to material and energy processes are often limited by use of standardized materials that meet the minimum requirements and regulations for energy consumption. The micro condominium approach to smaller living areas reduces an individual's carbon footprint through reduced energy and material consumption.

\section{Boundaries and Areas}

The typical condominium provides a variety of dwelling units with average or above average square footage, with shared amenity spaces at both the top and bottom floor levels. It is typical to have physical divisions that separate the use of common space which limits the interaction between residents. Unlike the typical condominium, the emergence of the micro condominium redefines the boundaries and areas that are commonly associated with this dwelling type. Unit areas that are $25 \%$ smaller than the prescribed minimum for affordable housing are now growing in acceptance. Evidence shows that the smaller unit areas necessitate an increase in shared amenity space that is accessible throughout the building (City of Vancouver, 2014).

\section{Local effect}

A local effect within the condominium type is challenged by the moderate potential for interaction between residents that use shared recreation space, but this interaction is reduced by limited access to social amenity space. In the micro condominium example, there is increased potential for interaction between residents that use unlimited access to shared semi-private space which is necessitated by the smaller unit areas (Figure 234). 


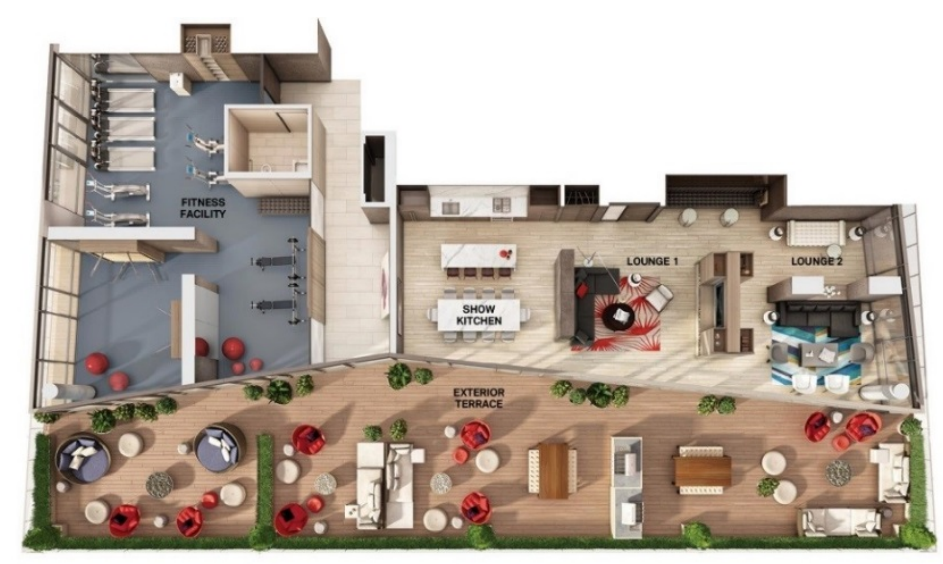

Figure 2-34 Toronto Micro Condo 3rd Level Amenity Space

\subsubsection{Disruption of the Sensible}

\section{Proximity}

Private dwelling units have an increased proximity to one another and are separated by interior corridors and vertical circulation which provide access to limited semi-private space that is often in far proximity.

\section{Exposure}

Control over an individual's exposure is limited by the single access points to private dwelling units that typically have an outward facing exposure. Limited access and physical boundaries that separate semi-private space further reduce the exposure of an individual resident (Figure 2-35). However, the shared amenity space within the micro condominium example demonstrates a trend toward creating higher visibility and exposure within shared spaces. 


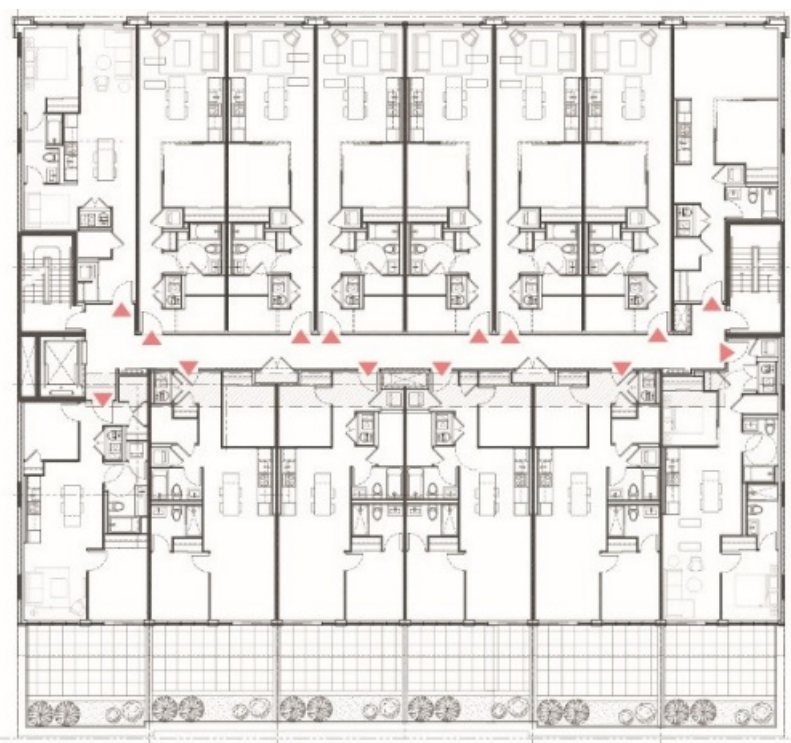

Figure 2-35 Toronto Mid-Rise Condominium Floor Plan

\section{Spatial Variability}

A flat unit type is typical for all floors with spatial variation in the vertical dimension limited to the ground floor (Figure 2-36). Shared amenity space is like the individual unit design but often provides a greater area.
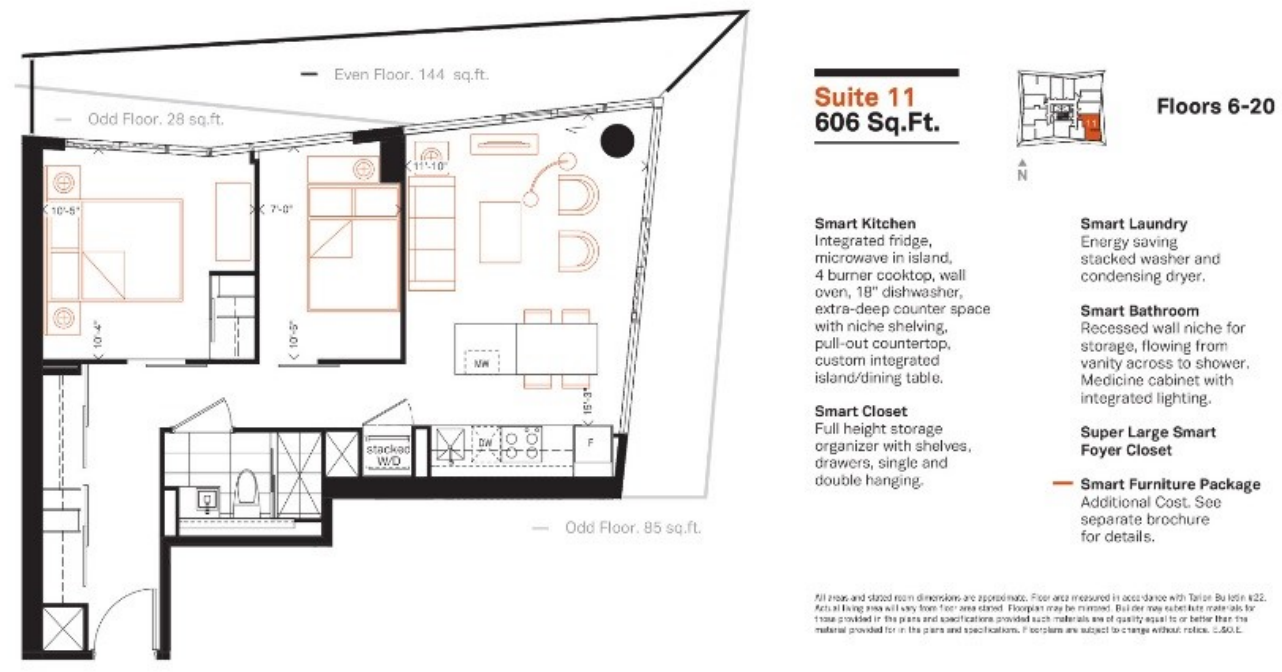

Figure 2-36 Toronto Micro Condominium Unit Plan 


\subsubsection{The Assembly of Socio-Material Entanglements}

Architectural Framework and Material Usage

The architectural framework of both buildings is comprised of a concrete superstructure with stick frame partitions to enclose the individual dwelling units. In both examples, stick frame partitions can be added or modified within the tight spatial enclosure of a private dwelling unit.

\section{Setting System}

The setting systems of both examples are demonstrative of the mixed-use approach whereby private commercial spaces occupy the base of the building and semi-private space to be shared by the residents is located on top and lower levels of the building (Figure 2-37). Regarding the micro condominium example, it is proposed that residents will not only have shared semi-private space on site but will also occupy settings that are not within the building (Figure 2-38).

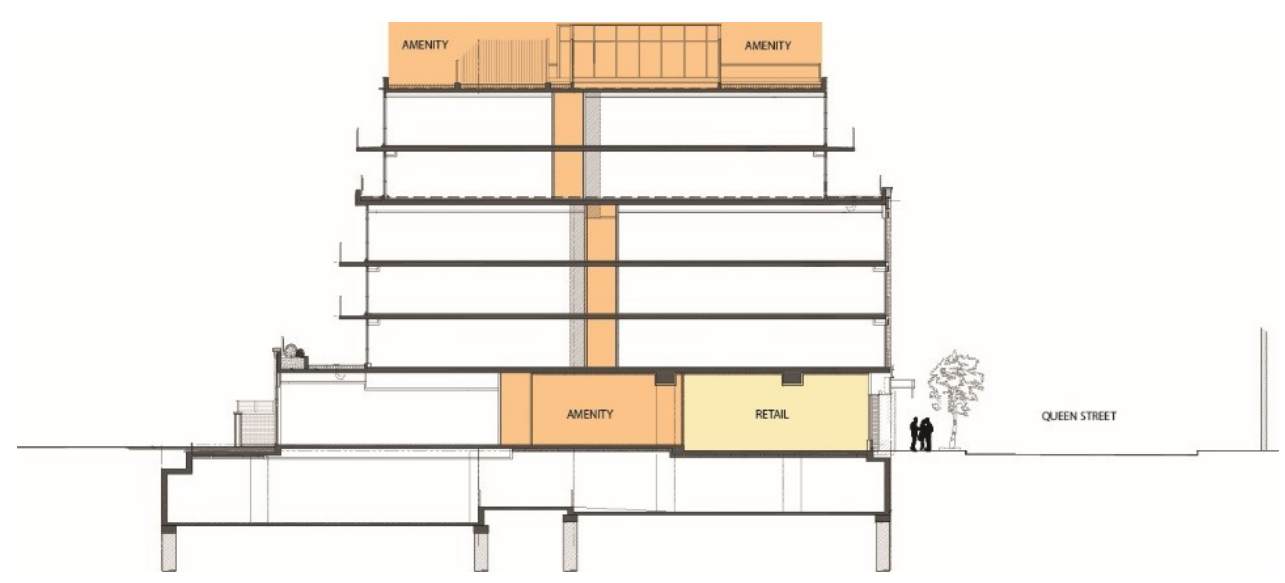

Figure 2-37 Toronto Mid-Rise Condominium Setting System 


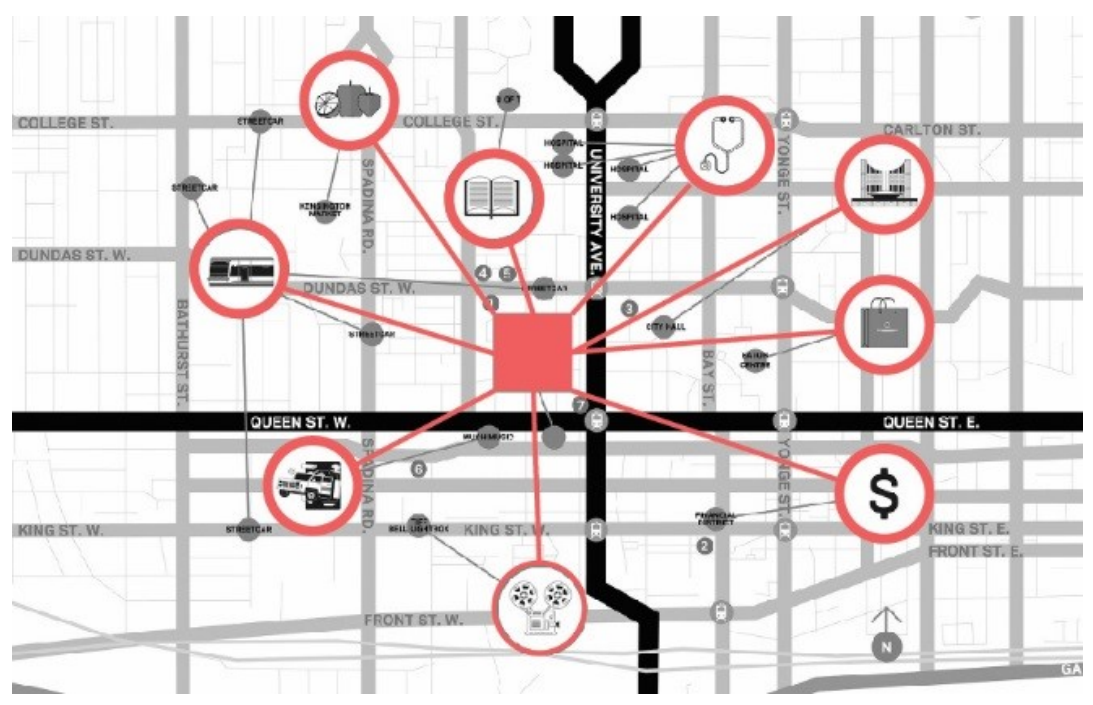

Figure 2-38 Toronto Micro Condominium Setting System

\subsection{Case Study Summary and Design Development}

\subsubsection{Inscription of Metabolic Infrastructures}

The inscription of metabolic infrastructures that influence the sum total of the technical and socio-economic processes that occur within buildings and cities, resulting in growth, production of energy and the elimination of waste. It is proposed that this inscription is demonstrated in how material composition and energy consumption within the setting system of an architectural design can support a local effect amongst residents and neighboring communities.

\subsubsection{Material and Energy Processes}

All the case studies, excluding the rural and suburban bungalow type, demonstrated a design approach that optimized the use of urban sites through the adaptive reuse of existing buildings and infill strategies that extend and 
delineate the metabolic infrastructures within an urban context. It is purpose of this design research to further investigate how an approach to urban infill can influence the sum-total of technical and socio-economic processes within a localized area of Toronto's urban core; where a convergence of housing culture and the need for additional housing is at its greatest. This approach is not meant to exclude the rural and suburban condition altogether, but rather to align with emerging socio-material trends that are affecting housing culture within the city. Design research will seek to demonstrate how the infill of underutilized sites can improve the perception of an affective density through the creation of sociomaterial connections that emulate co-operative and co-housing strategies which best represent social values associated with the communal consumption of material and energy.

Three potential in-fill sites have been identified within existing Toronto neighborhoods which present opportunities to test how architectural form can extend and delineate the metabolic infrastructures of the city. All sites are currently used for at grade commercial parking and located at the peripheries of established neighborhoods and avenues in the downtown core. Where the surrounding built form is defined as low to midrise and primarily comprised of detached and semi-detached houses. The chosen sites are larger in comparison to the surrounding lots and are therefor good candidates to demonstrate how the theories of material politics can create an alternative perspective of an increased affective density at the periphery of established neighborhoods. In this context, micro housing can offer higher density while proposing an increase in shared interior and exterior space for both the inhabitants and surrounding community. Similar sites are often grounds for contentious development in the city, where materiality is often politicised by neighbors, developers and of course politicians. The following investigations demonstrate how increased density can frame an extension of the shared urban environment. 


\section{Site One:}
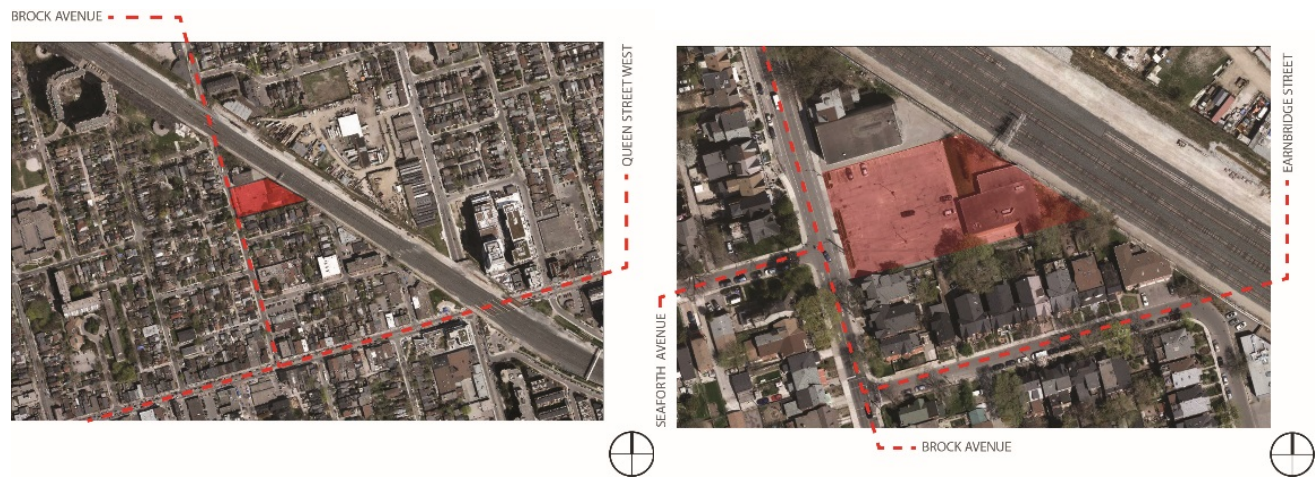

Figure 2-39 Arial photographs of Test Site One 57 Brock Avenue, Toronto

Site One is located at 57 Brock Avenue and is three blocks north of Queen Street West in Toronto's Parkdale neighborhood (Figure 2-39). This site is predominately empty with most of the area covered by surface parking and a one-storey industrial building located to the rear of the site. A current proposal by a developer to have a condominium constructed on site is currently under review by the Ontario Municipal Board and will inform the re-territorialisation of this in-fill site. In late 2016 an application was submitted to have the City' Official Plan and zoning amended to suite the proposed development. This document provides the following description of the existing conditions surrounding the site and the proposed project (City of Toronto, 2016, pg3).

\section{Surrounding Area Description}

North: A two-story industrial building, followed by other industrial uses in semidetached house forms. To the north of the above-noted semi-detached buildings, is a small piece of industrially-zoned open space, and the Canadian National Railway/Canadian Pacific Railway rail corridor, oriented in a northwest/southeast diagonal manner. 
South: Two Pairs of three-storey semi-detached residential buildings, and a threestorey detached building fronting onto Brock Avenue. Also, abutting the south side of the site, are the rear yards of two-storey and three-storey semi-detached and detached residential buildings fronting on to Earnbridge Street

East: The Canadian National Railway/Canadian Pacific Railway Rail Corridor.

West: Detached and semi-detached residential buildings ranging in height from two to three stories. Two of these houses, located at 60 and 62 Brock Avenue, respectively, are listed on the City's inventory of heritage properties.

Proposed Development Description

A seven-storey condominium containing 106 residential units of which 61 are one-bedroom units, 26 are two-bedroom units, and 19 are three-bedroom units. Towards the rear of the site, separating the rail corridor from the residential component is a proposed two storey, above grade parking structure providing 73 parking spaces.

\section{Site Two:}
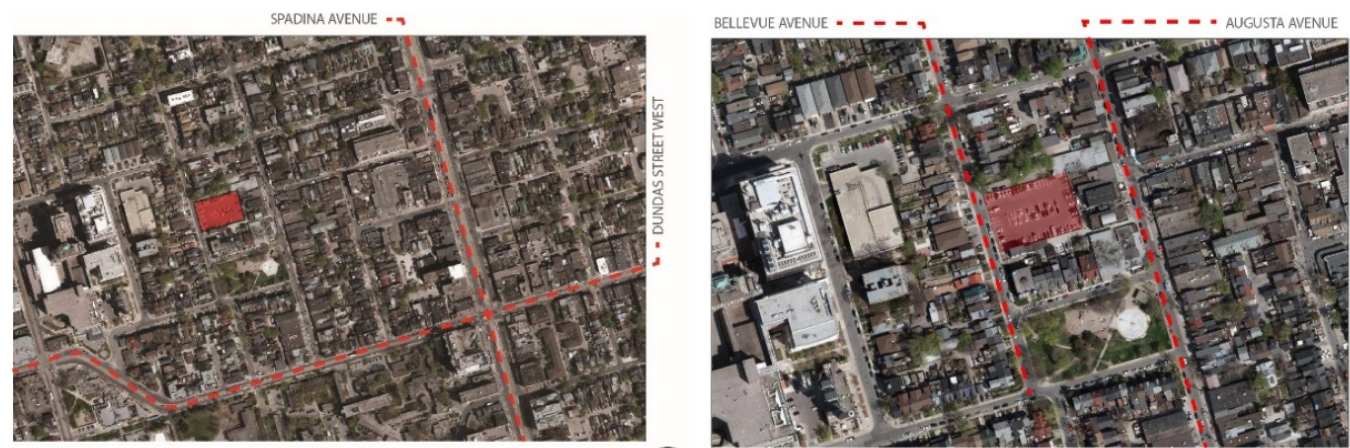

(1)

Figure 2-40 Arial Photographs of Test Site Two, 35 Bellevue Avenue, Toronto 
Site Two is in the Kensington Market neighborhood located at 35 Bellevue Avenue which is three blocks north of Dundas Street West, and between the major avenues of Bathurst Street and Spadina Avenue (Figure 2-40). This site is also predominantly empty in that it is currently used as surface parking. Recent initiatives by the Kensington Market Community Land Trust (KMCLT) have identified that the site can better serve the community if the parking were to be removed and that the space could be reimagined with the local community in mind. It is the aim of the KMCLT to remove land from commercial speculation by using it for community benefit through the creation of entry level housing and mixed-use spaces that maintain the eclectic, multi-ethnic, and multi-socioeconomic nature of the Kensington Market Neighborhood (KMCLT, 2018)

\section{Surrounding Area Description}

North: Adjacent to the site is a vacant property serving as a five-meter public drive aisle followed by a series of detached and semi-detached residential buildings that maintain a consistent height of three stories for the remainder of the city block.

South: A single three-storey detached house with a lot that extends to half the depth of the proposed site. The remaining space adjacent to the site serves as a public access between the current parking lot and Augusta Avenue to the East.

East: Seven mixed use residential and commercial properties that front Augusta Avenue and with rear exposure to the East side of the proposed site. These mixed-use forms are between three and four storeys in height and are between five and ten meters in width. 
West: Detached and semi-detached residential buildings ranging in height from two to three stories.

\section{Site Three:}

Site three is located adjacent to the north side of site two and assumes all of site two's surrounding contextual characteristics. This single lot is the lowest common parcel to all three sites, in that it represents the grounds for Toronto's low-rise residential vernacular that is pervasive through Toronto's established neighborhoods. The original house (Figure 2-41), constructed in 1884, was built for Abraham and Jane Charlton who ran a small dry-goods business from the storefront (Hudson, 1993). Having been left vacant for many years, this house was demolished in 2011. The now vacant site is atypical to most lots on Bellvue Avenue because the overall width of the lot is 8.2 meters versus the typical 7 meters and has south exposure inscribed by laneway access to the south (Figure 2-42).

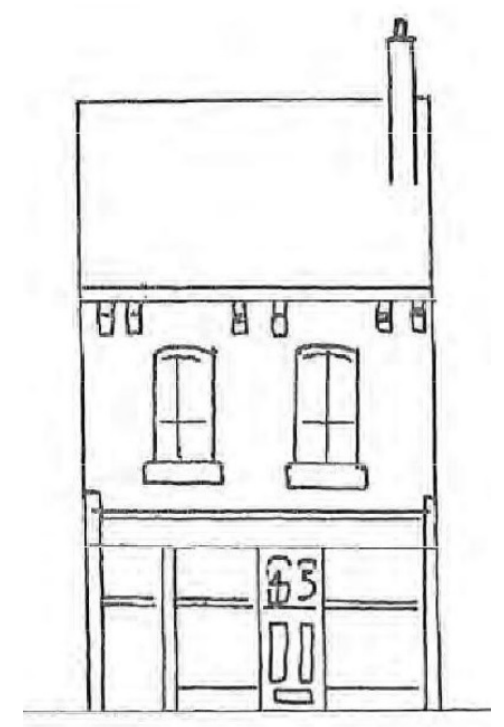

No. 45

Figure 2-41 Elevation of original house at 45 Bellevue Avenue 


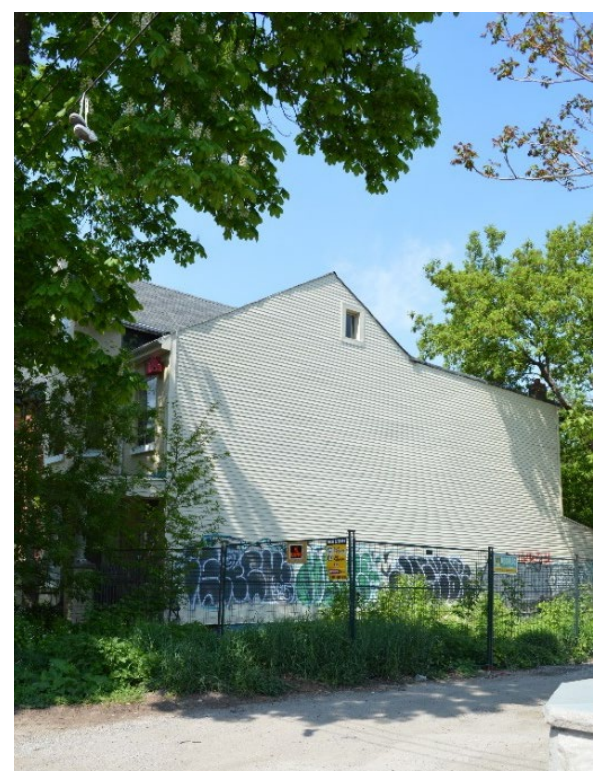

Figure 2-42 Vacant lot at 45 Bellevue Avenue

All three sites are presented as viable grounds to investigate how architectural form relates to the metabolic infrastructures of the city, through physical and virtual connections that support the conscientious and collective use of material and energy. These connections are demonstrated in the physical creation of a 'missing middle' housing typology that fills gaps within the urban fabric, while expanding a virtual network of people that are more closely associated through a ground related environment. This is demonstrated in an investigative cross section for a proposal at 45 Bellevue avenue (Figure 2-43), where a shared thoroughfare leads residents and neighbors from the public street to both interior and exterior semi-private spaces.

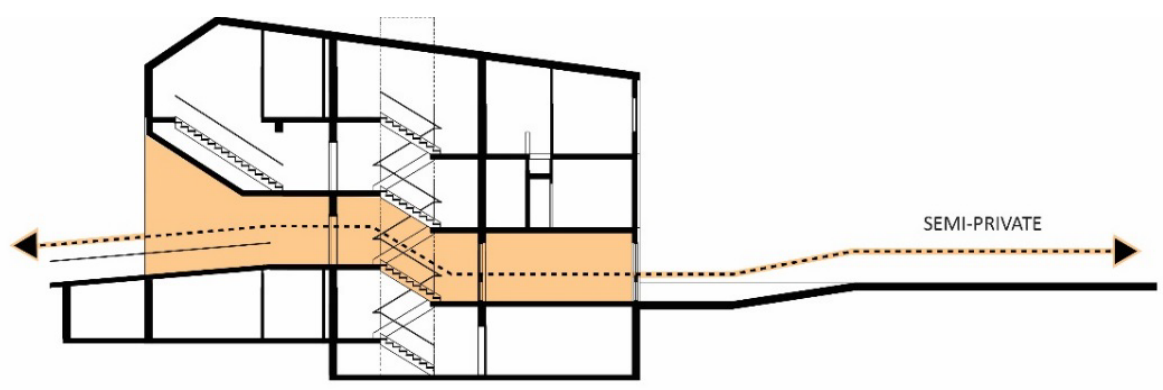

Figure 2-43 Reterritorialization of the residential base 
Through the reterritorilization of urban and domestic spaces there is opportunity to improve pedestrian movement while providing spaces that support community use and the sharing of physical and virtual resources. The provision of shared interior and exterior spaces that maximize exposure to natural daylighting can provide equitable use by the community throughout the year and during climatic change. Within these spaces, sustainable energy and material strategies are enacted at the individual, group and community level; and provide the opportunity to gain a sense of social inclusion and ownership over community initiatives. For example, community workshops with natural daylighting (Figure 2-41)
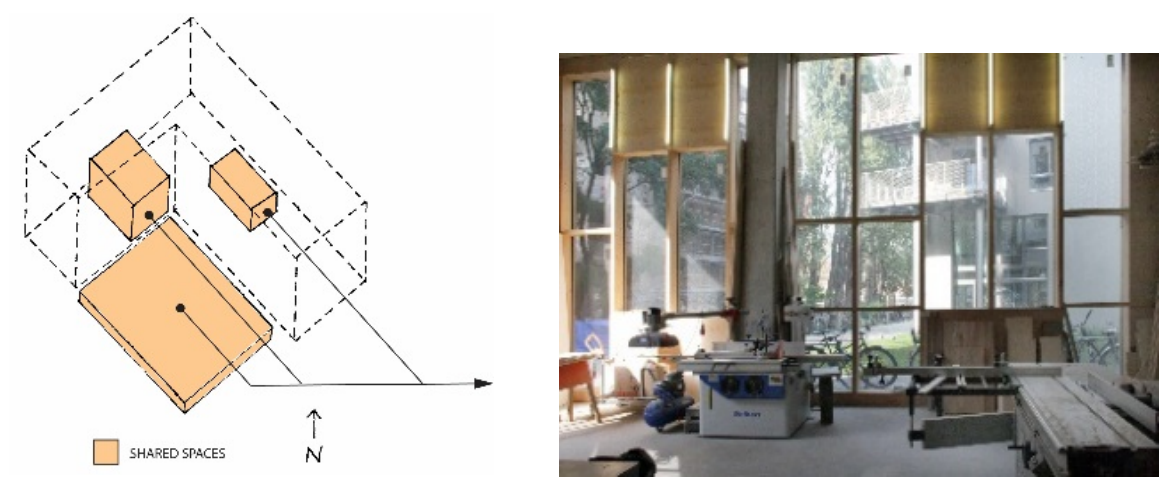

Figure 2-44 Sustainable Energy and Communal Consumption Strategies

The previously mentioned condominium proposal for Site 1 and the subsequent amendments which are now under review by the OMB represent how the architectural form of residential infill sites can either separate or extend and the metabolic infrastructures of an existing neighborhood. The site plan of the proposed condominium development represents a preference for the separation of the ground related environment through an enlarged building footprint that extends across the site, while providing limited access to public space and an increase in vehicular traffic near the site. All of which has contributed to concerns regarding the lack of socio-material benefits for the community (City of Toronto, 2016). Superimposed on this site plan is an alternative footprint that 
represents a micro unit arrangement to maximise the potential for surrounding shared community space while attempting to reduce the shared consumption of space and resources (Figure 2-45).

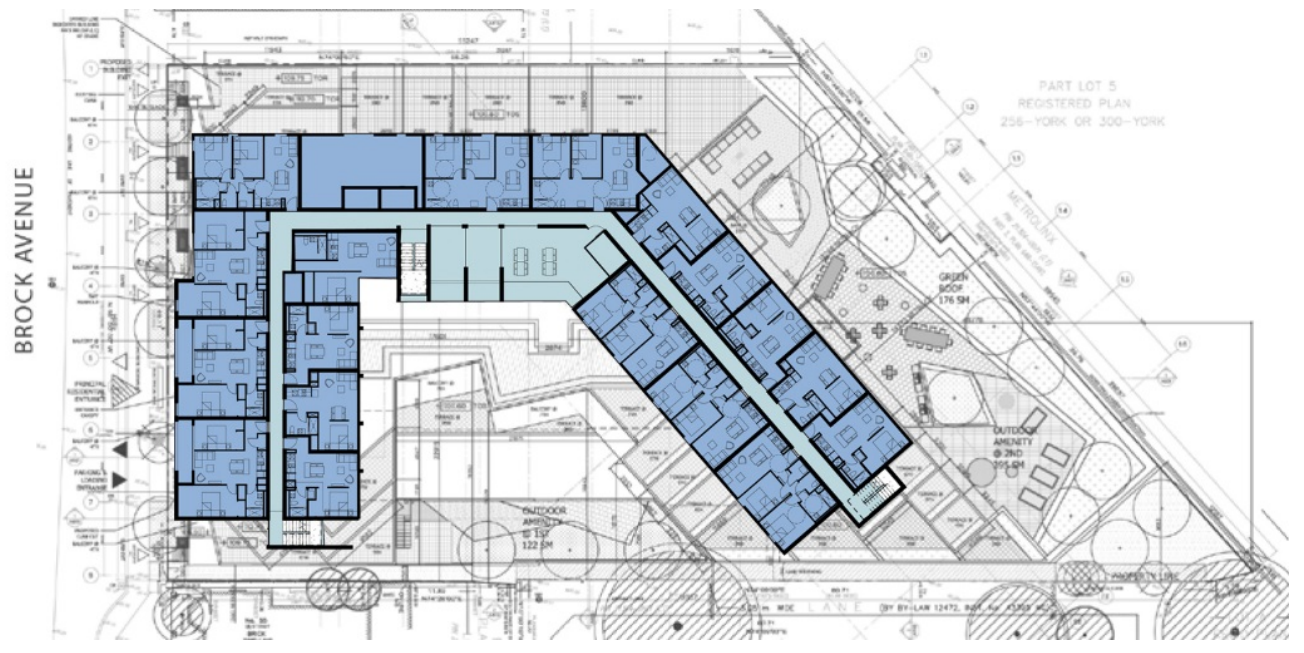

Figure 2-45 Developer proposed site plan with micro unit configuration overlay

\subsubsection{Boundaries and Areas}

As previously identified, both sites have been chosen for their viability to support socio-economic processes occurring on and near the site through the reterritorialization of domestic and urban space. Interrelationships between a local and the greater city infrastructure are demonstrated in (Figure 2-46). Through the added provision of shared interior and exterior space there is opportunity to support a mixture of programable areas that offer a variety in localized experiences and encourage interaction amongst residents and the surrounding community. These interrelationships are further reinforced by the walkability of both sites and their proximity to existing city infrastructure. 

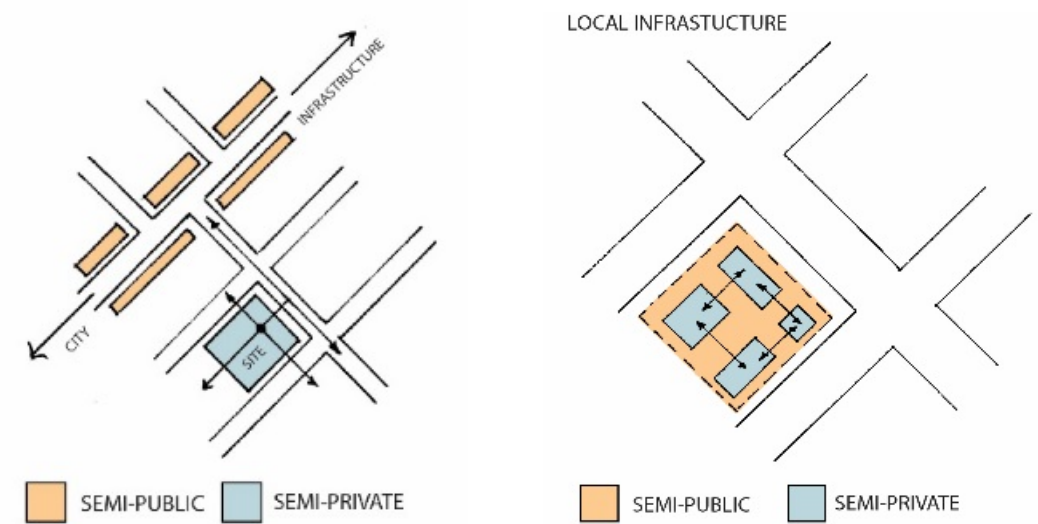

Figure 2-46 Relationship to City and Local Infrastructure

Preliminary design explorations in the development of massing for both sites have investigated how the added provision of shared interior and exterior space can be implemented in to design of a midrise housing typology. This was achieved on all three sites by minimizing the allotment of private space to maximize the potential use and engagement with a shared environment (Fig 247). This approach reduces the footprint of the building to approximately fiftypercent of the site area, which more closely aligns with the design guidelines for apartments within the City of Toronto (Regulations Applying to the Residential Zone Category, City of Toronto, 2018). On test site one the unit count was near parity with the current development proposal at 101 dwellings, while accommodating public interior space along Brock avenue and a shared interior courtyard (Figure 2-48).
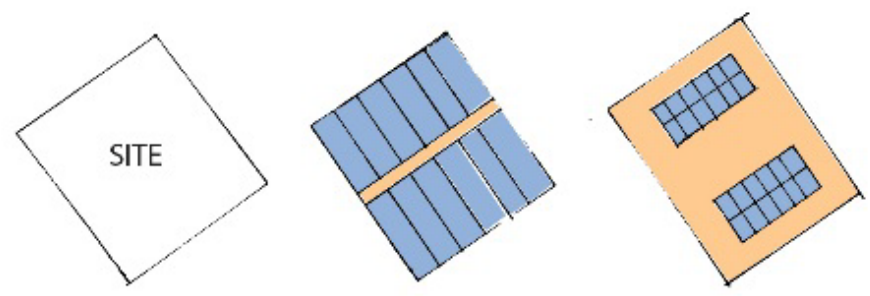

SEMI-PUBLIC

PRIVATE

Figure 2-47 Reduced Private Space 


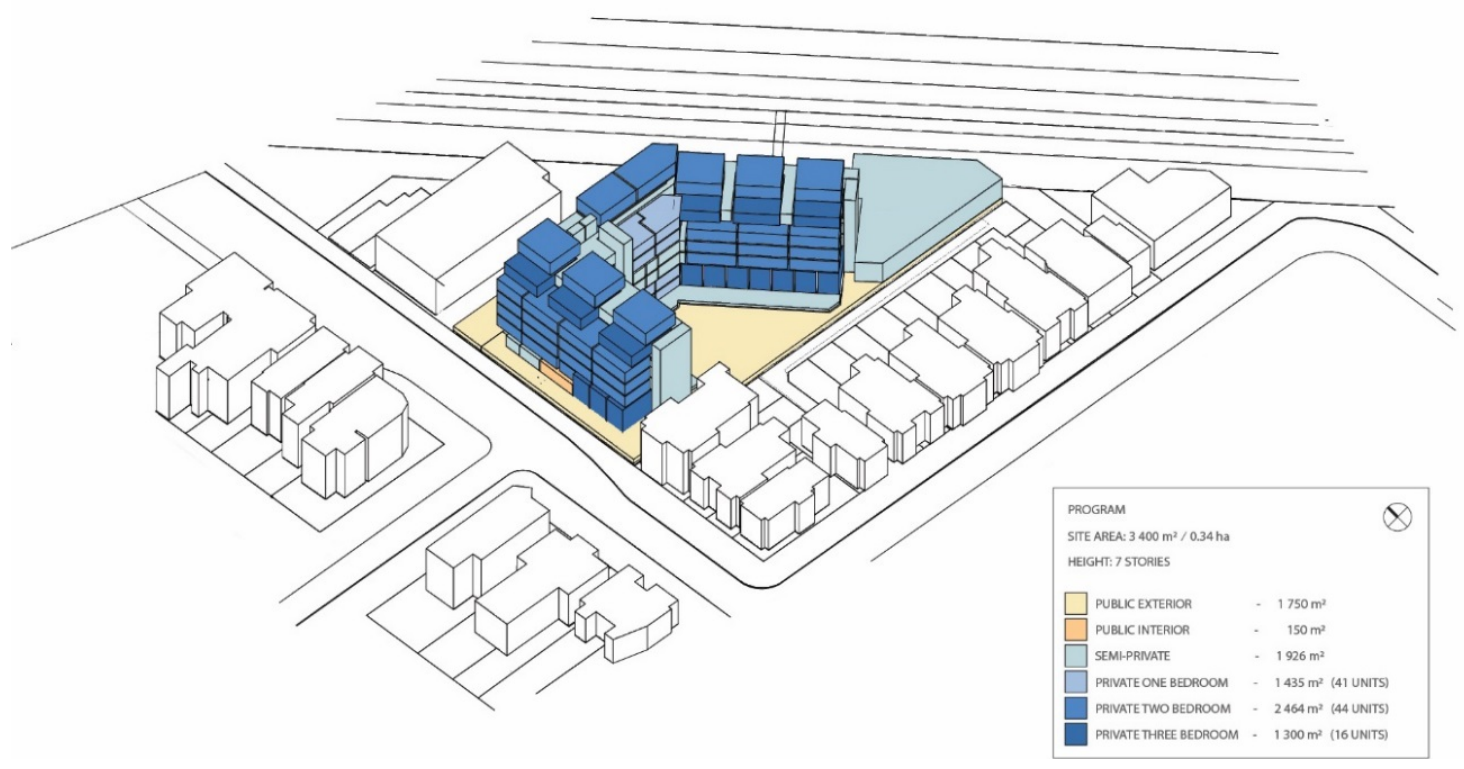

Figure 2-48 Massing on Site One to test boundaries and areas

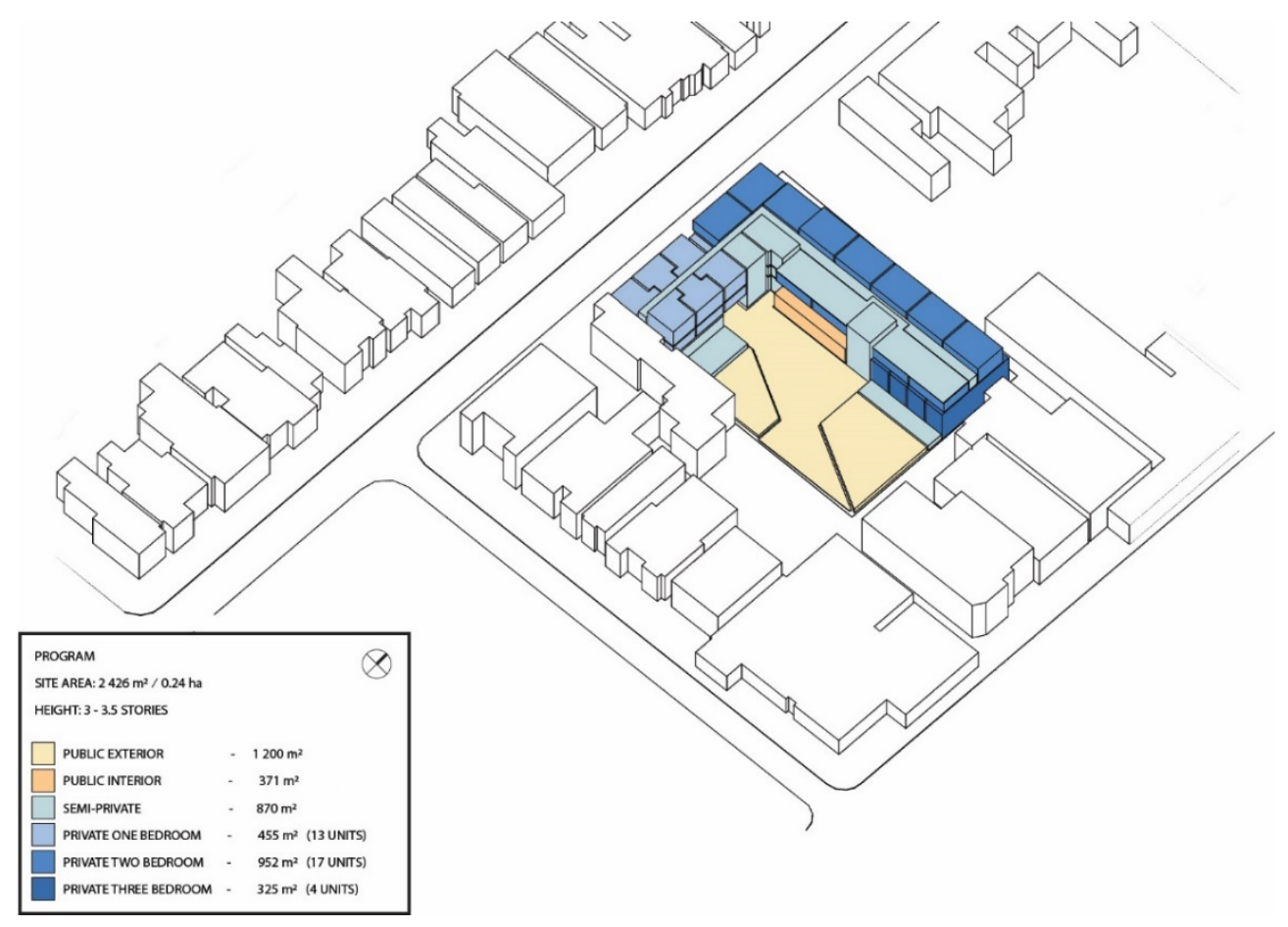

Figure 2-49 Massing on Site Two to test boundaries and areas

On test site two, 34 dwellings are provided while investigating the possibility of creating shared amenity space and an interface with community or temporary public workspace 
on the ground floor (Figure 2-49). This unit count maintains the desired unit density adopted from the massing of test site 1 , whereby the area of site two is $30 \%$ smaller than site one and with half the maximum height restriction, 7 vs. 3.5 stories.

Within the boundaries and areas of test site one, it is proposed that three $950 \mathrm{ft}^{2}$ threebedroom dwellings be provided in a four-storey split-level configuration (Figure 2-50).
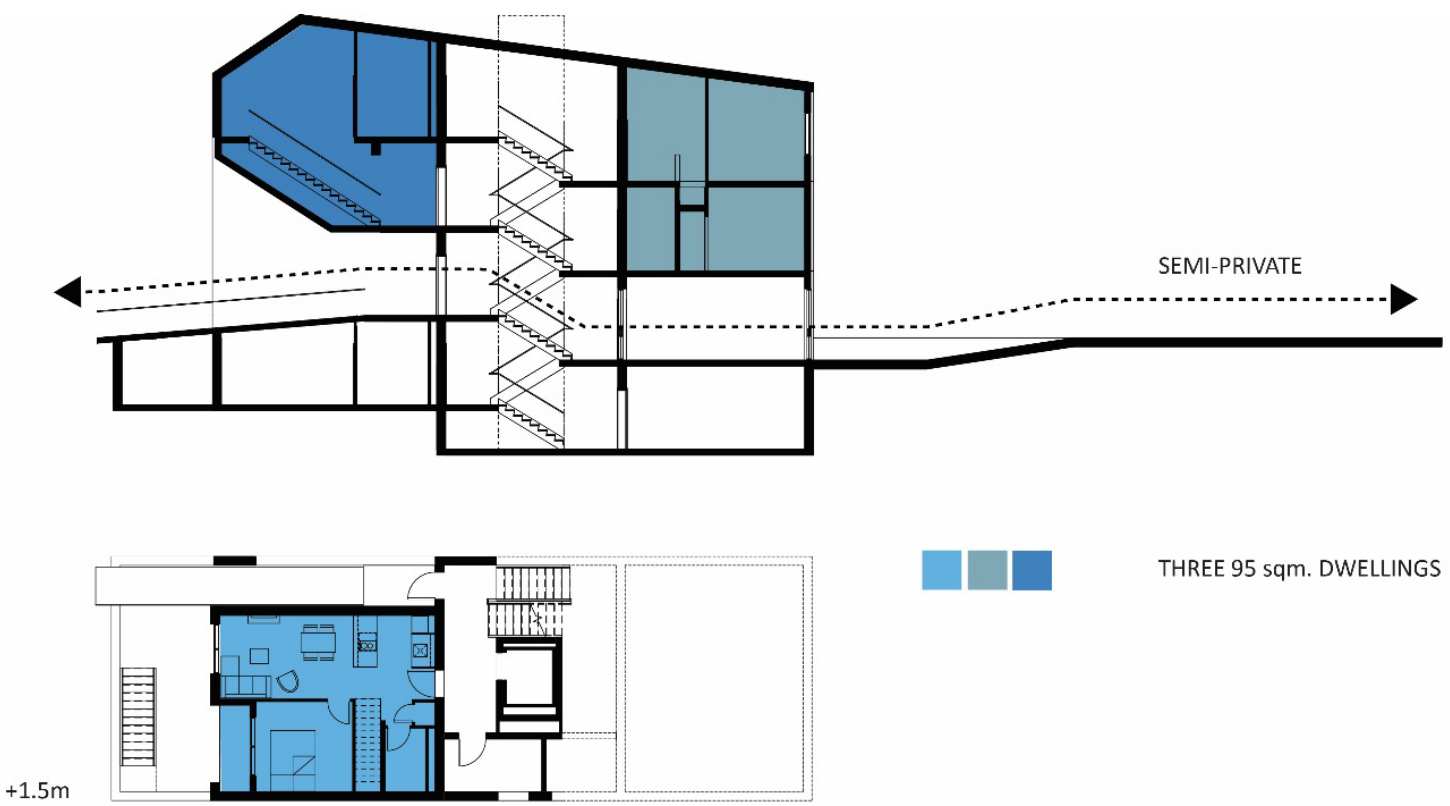

Figure 2-50 Three three-bedroom micro dwellings at 45 Bellevue Ave.

\subsubsection{Local Effect}

It is proposed that a local effect is supported by the added provision of shared interior and exterior spaces within the architectural base; where instances in preliminary design explorations sought to maximize the potential interaction amongst the local group at thresholds and convergent points of circulation. Here the architecture can mediate public and private interaction without compromising resident privacy (Figure 2-51). 


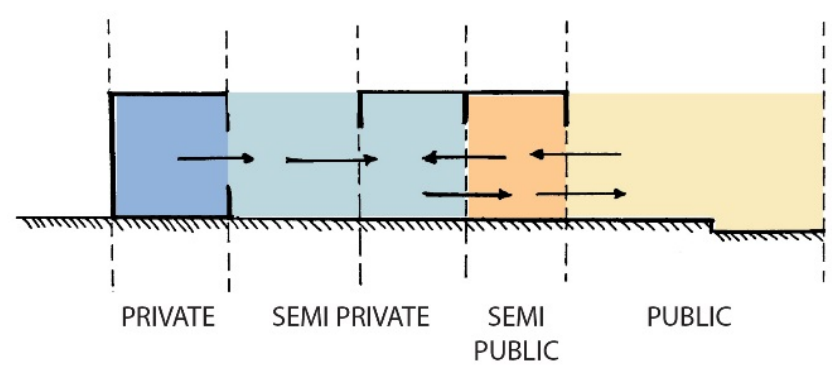

Figure 2-51 Controlled Interaction

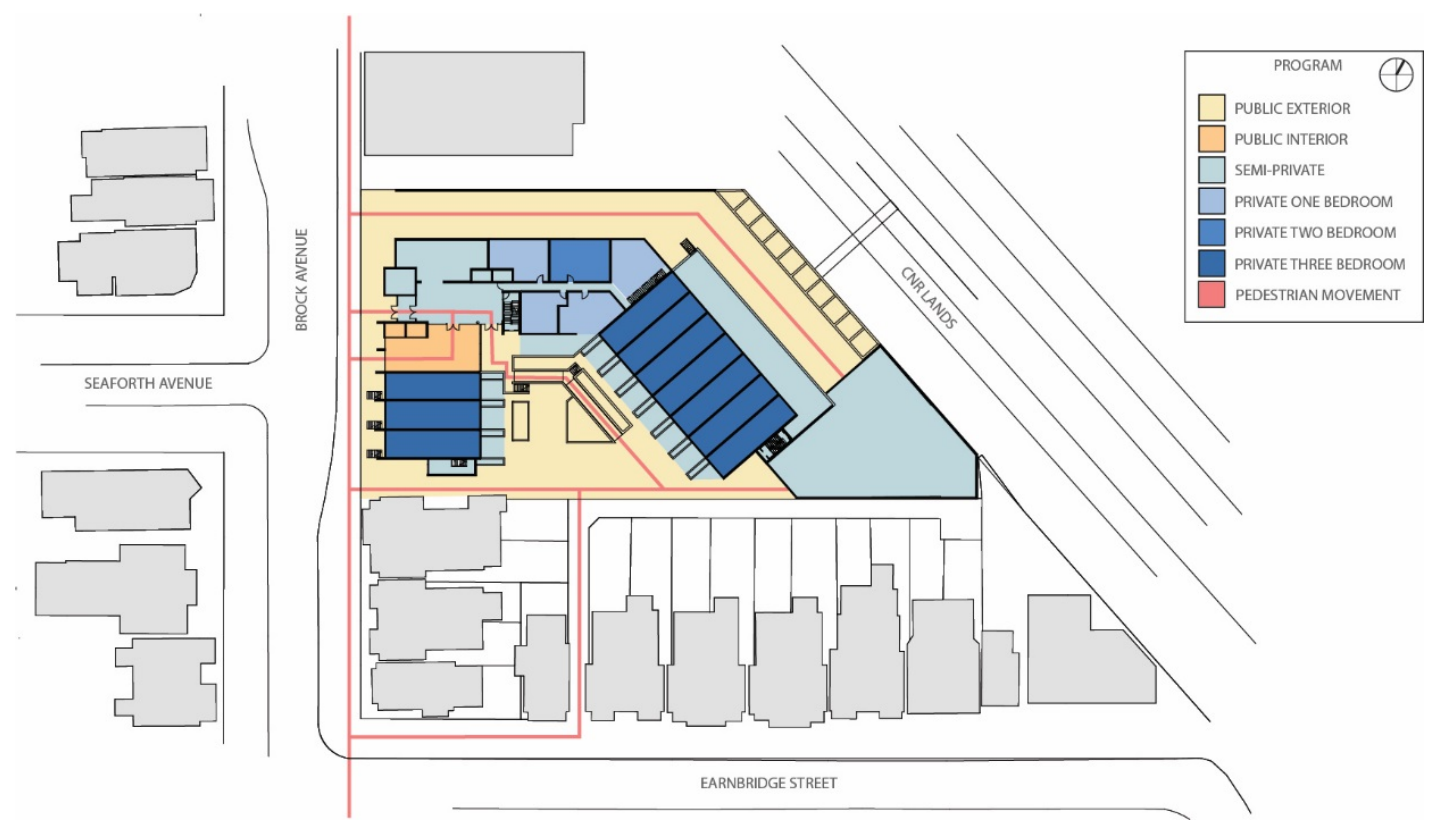

Figure 2-52 Site Plan Investigation of Site One

On site one the support for a local effect is tested by extending public access throughout the site with a prominent entrance in parallel with the private community access. This approach is limited by the physical barrier of the CNR lands to the East, a non-desirable condition that also created limitations in the programming of that space for either private or residential use (Figure 2-52). 

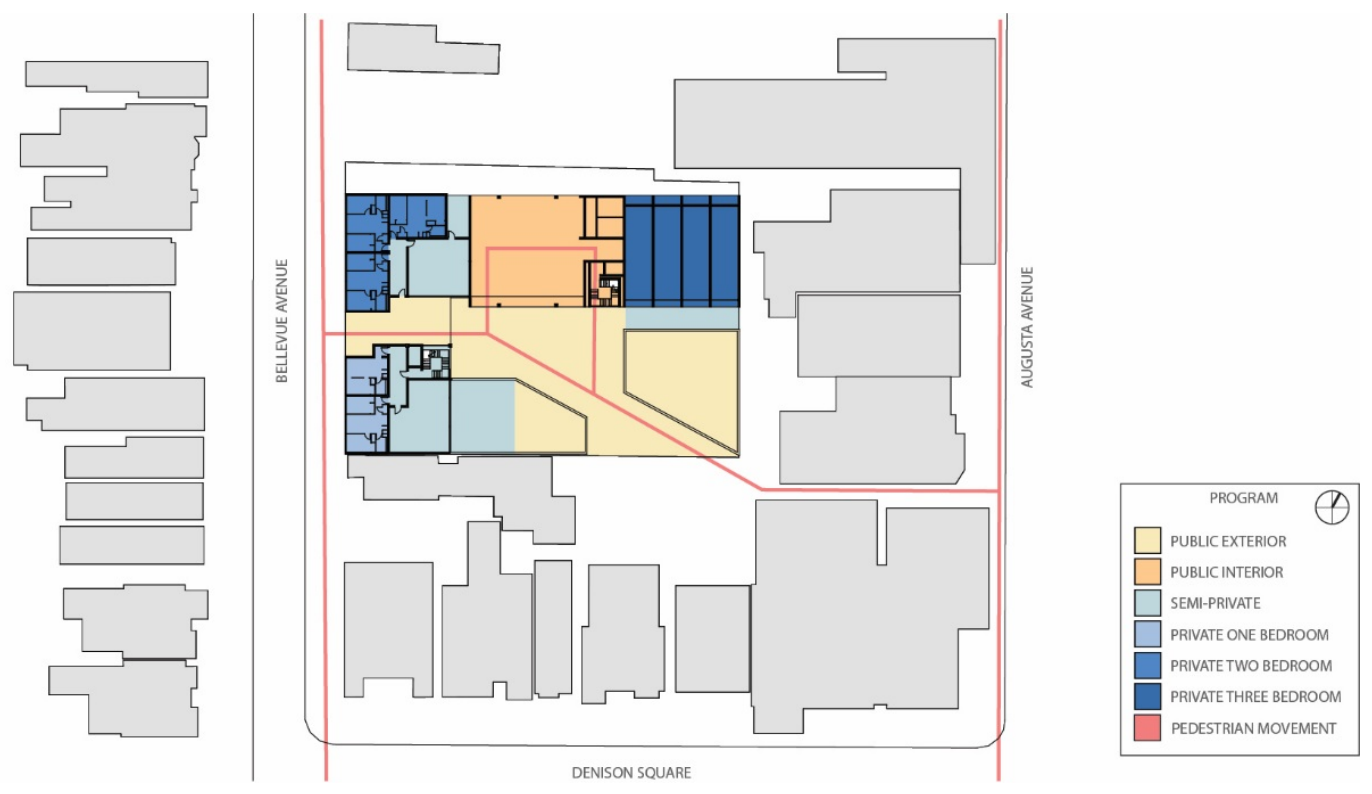

Figure 2-53 Site Plan Investigation of Site Two

On site two the support for a local effect is tested by providing continuity of pedestrian movement through the site and linking the residential context of Bellevue Avenue with the market place along Augusta Avenue (Figure 2-53). In between there is potential for the design of an interior courtyard with adjacent interior semi-public space in parallel with semi-private space that supports both resident and community activity (Figure 2$54)$.

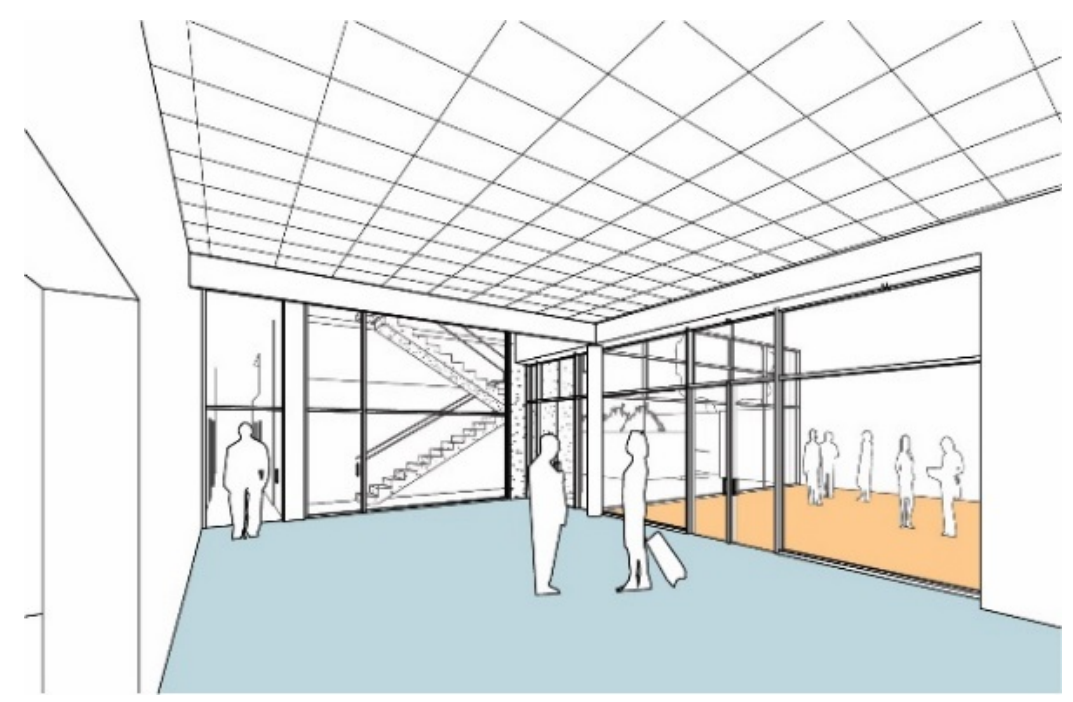

Figure 2-54 Investigation of semi-private and public interior interface 
A local effect is achieved on site three by providing a variety of shared spaces half a level below grade while maintaining continuity with access to both the rear and front yards. These spaces are to be used to supplement the resident's limited private space while potentially supporting visitors and group activities (Figure 2-55).

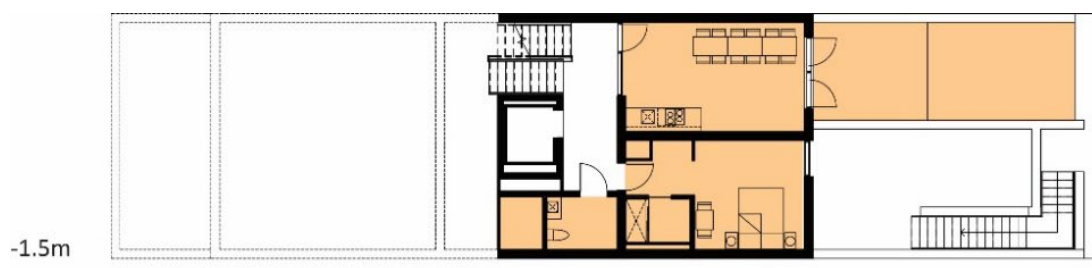

COMMON: DINING ROOM

GUEST ROOM

LAUNDRY ROOM

REC. ROOM

TERRACE

Figure 2-55 Common space supporting a local effect at 45 Bellevue avenue

Further design explorations will consider how the size of a network comprised of individuals, groups, and a surrounding community informs the design of shared spaces that support social inclusion and the exposure to community initiatives (Figure 2-56).

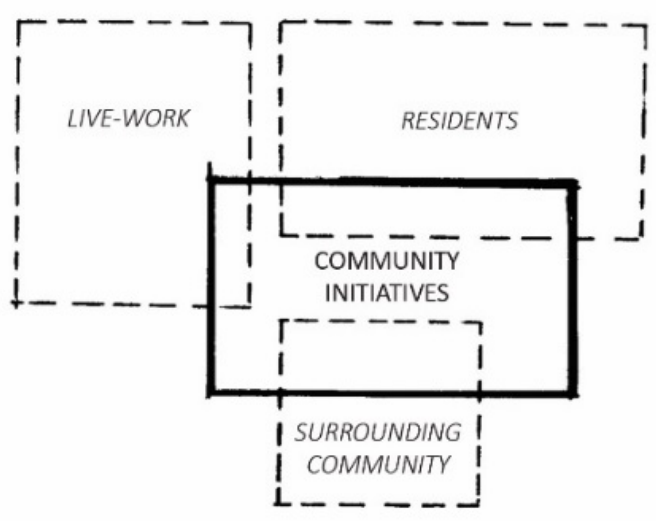

Figure 2-56 Identification of a Local Network 


\subsubsection{The Disruption of the Sensible}

The disruption of the sensible considers the agentic properties of materials and their capacity to disrupt established social and technical assumptions and regulations. It is proposed that the properties of materials and how they are assembled in place provides agency to the user through the mediation of proximities and exposures within spatial variability which ultimately informs our experience of affective density.

\subsubsection{Proximities}

Again, proximity is the sensed measurement between private, semi-private, and public space (Figure 2-57). The increased proximity between units on test site one resulted in a double loaded corridor condition and the potential perception of over crowding by constraining the exposure and activity within this primary access route. The design of a partitioned common space and south facing exposure to the interior courtyard explored the potential for providing equitable access to additional open space in near proximity to private dwellings (Figure 2-58).

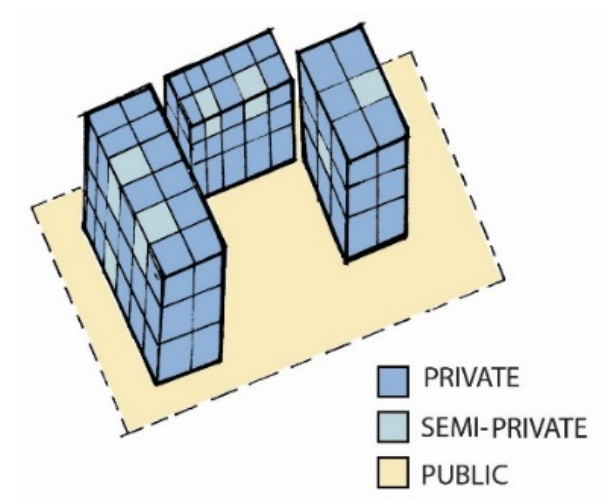

Figure 2-57 Clustering of Units Around Various Shared Spaces 

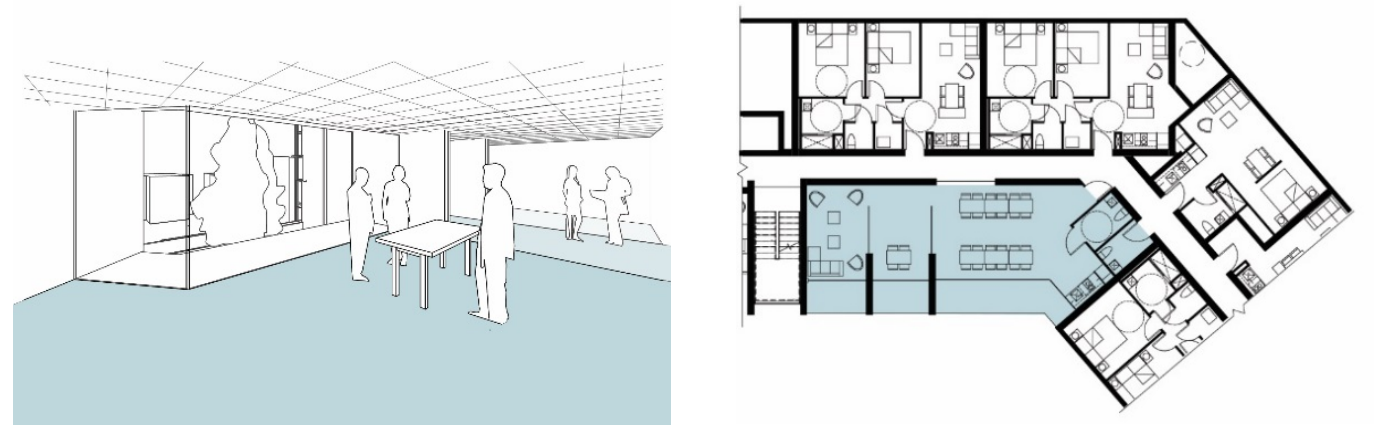

Figure 2-58 Equitable access to additional open space in near proximity to private dwellings

\subsubsection{Exposure}

Provide a circulation network that increases the exposure of inhabitants but consider the design of optional access points and the limited inclusion of physical barriers to provide control over this exposure. It is proposed that for site two, one of the vertical stairwells be made external and accessible for public access to shared green roofs that provide views down into the central courtyard (Figure 2-59).
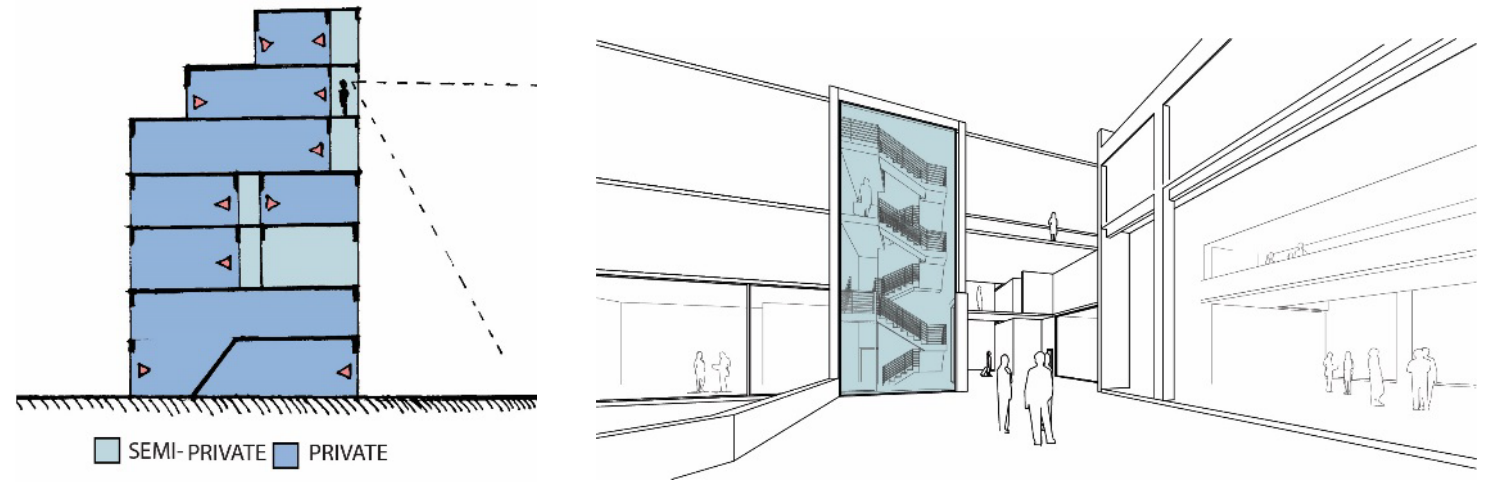

Figure 2-59 Circulation with exposure variability 


\subsubsection{Spatial Variability}

Provide variation in both the horizontal and vertical dimensions to create a variety of spatial experiences in both private and shared settings to create cues in the sensory modality that filter environmental information and minimize the sense of isolation or overcrowding. On test site two, access to a shared mezzanine that expands the common corridor, overlooks the public activities occurring below, and provides a shared spatial experience that extends beyond the limitations of an individual dwelling unit (Figure 2-60).
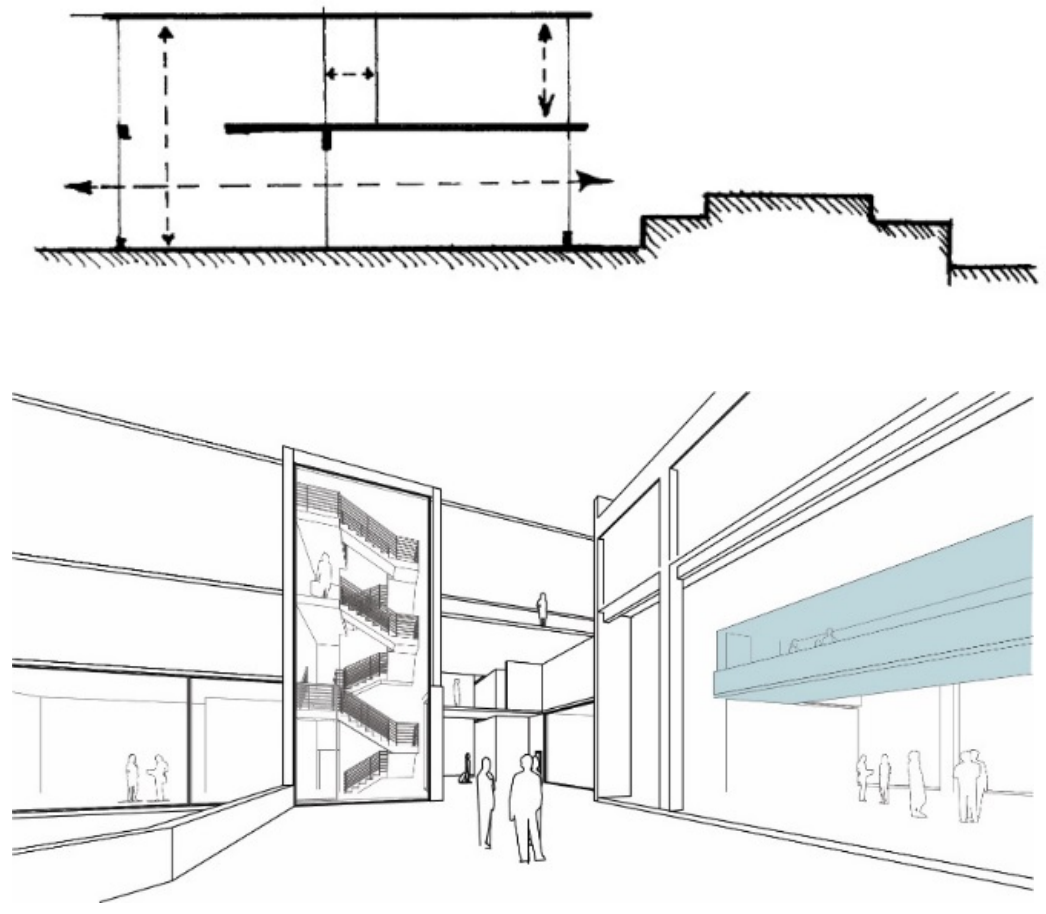

Figure 2-60 Spatial Variability in the Vertical and Horizontal Dimension

Variety in the composition of dwellings is maintained in the development of various micro unit floor plans that align with a variety of lifestyles and living arrangements, including accessible and live work units with the potential for multi level expansion (Figure 2-61). 

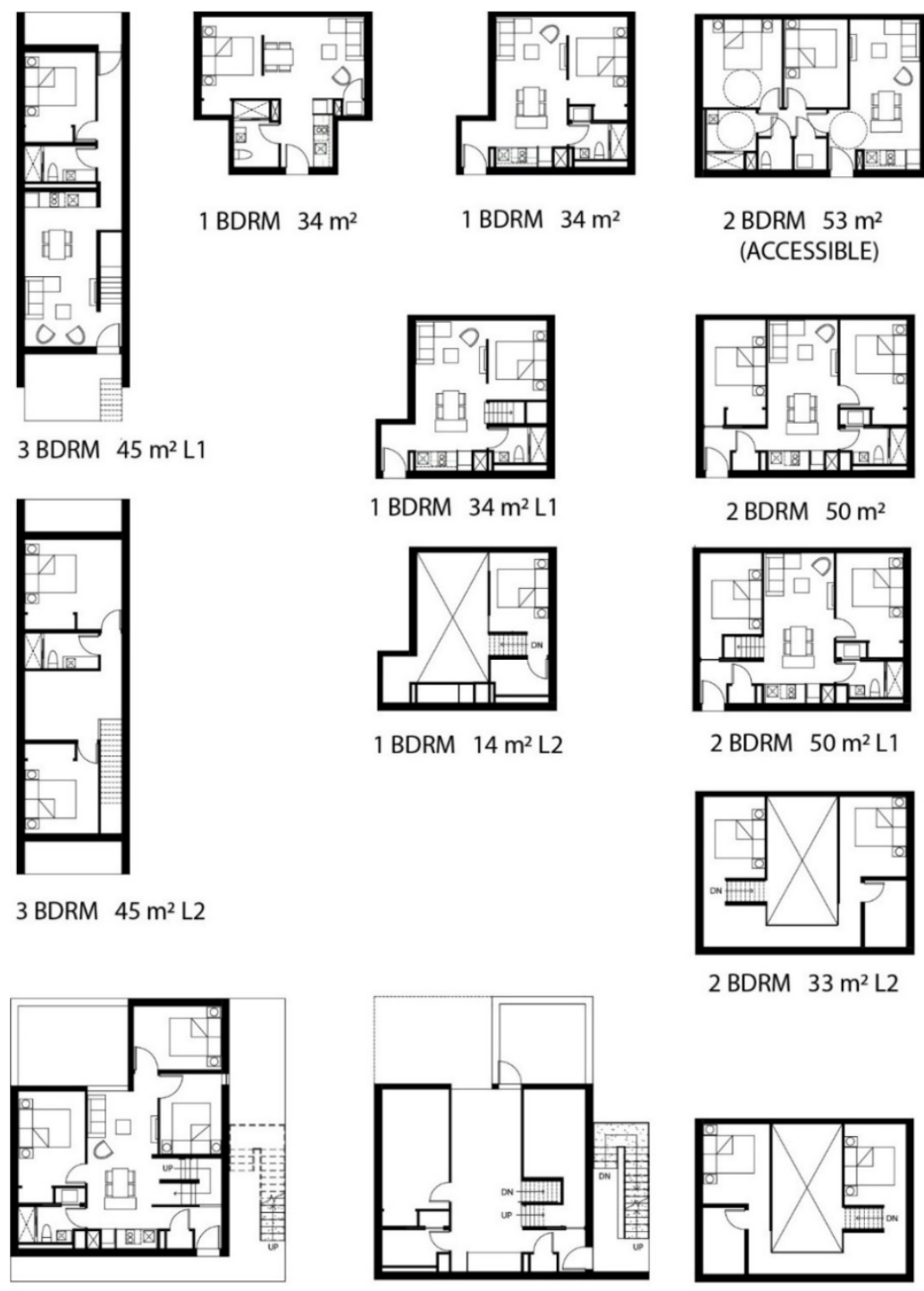

3 BDRM $63 \mathrm{~m}^{2} \mathrm{~L} 1$

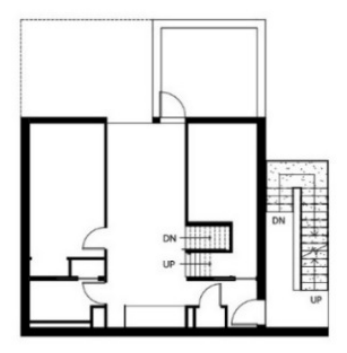

2 BDRM $33 \mathrm{~m}^{2} \mathrm{~L} 2$

0 5 10

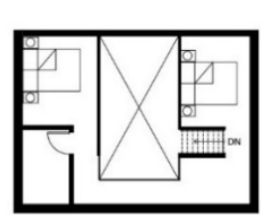

+2 BDRM $33 \mathrm{~m}^{2}$

Figure 2-61 Investigation of variable unit composition

\subsubsection{The Assembly of Socio-Material Entanglements}

The assembling of socio-material entanglements considers the design flexibility of space in relation to socio-material processes that reposition materials into new function; which in turn, 
alter and redefine local practices and experiences. It is proposed that the assembling of sociomaterial entanglements is demonstrated in how an architectural framework, can support material modification and the flexible configuration of a setting system to align with emerging trends in housing.

\subsubsection{Architectural Framework \& Material Modification}

The consideration of how an architectural framework can support future flexibility options is tested in the stacking of three private dwellings and the possible modification to link them vertically or maintain multiple access points to each through an exterior circulation network (Figure 2-62).

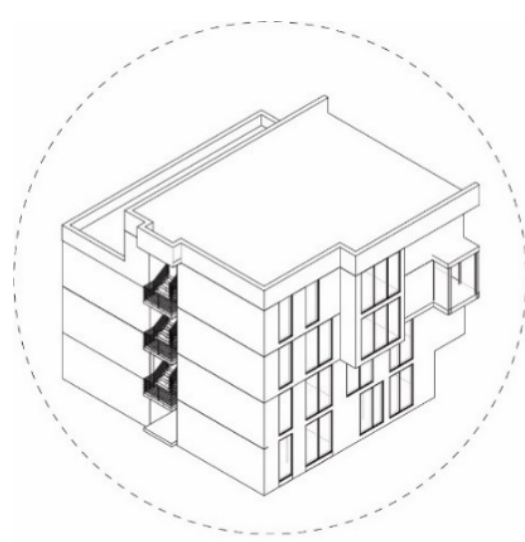

23 M2 - SINGLE ROOM OCCUPANCY

85 M2 - THREE OR FOUR BEDROOM DWELLING WITH FLEXIBILITY TO CREATE TWO SEPARATE DWELLINGS

$52 \mathrm{M} 2$ - TWO BEDROOM DWELLING WITH FLEXIBILITY TO CREATE ACCESIBLE DWELLINGS

$68 \mathrm{M} 2$ - LIVE/WORK DWELLING WITH FLEXIBILITY TO CREATE A THREE BEDROOM DWELLING OR TWO SINGLE BEDROOM DWELLINGS

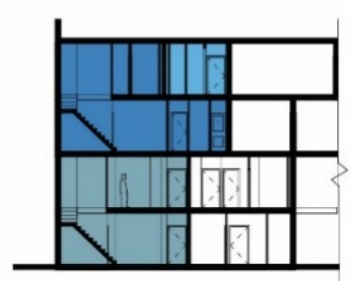

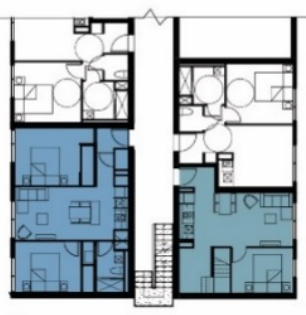

2.

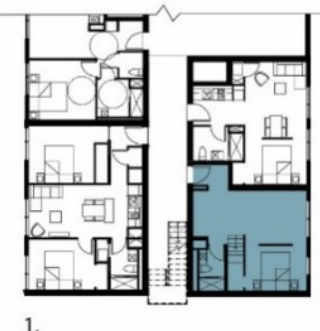

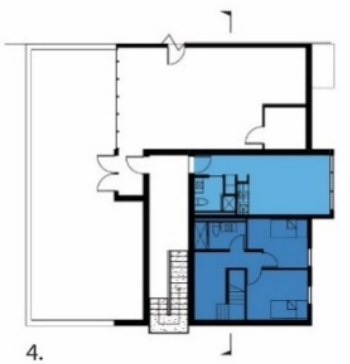

4.

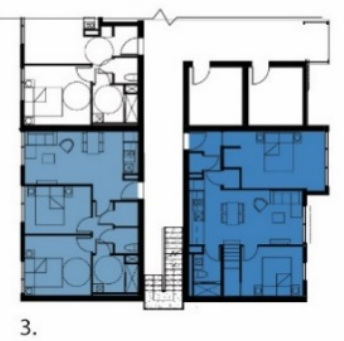

Figure 2-62 Flexible Architectural Framework investigation 


\subsubsection{Setting System}

There is a preference to create an on-site, open access, setting system that limits the deferring and translation of activities to external sites (Figure 2-63). Design for transitions between settings and consider how this supports continuity within a system of activities. A public threshold condition was investigated on test site two, that transitions from a residential context to the shared mixed-use space of the interior courtyard (Figure 2-64).

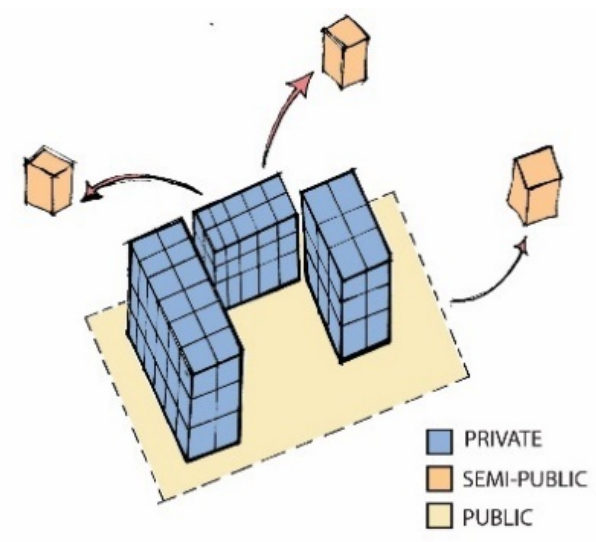

Figure 2-63 Limit the differing to off-site activities

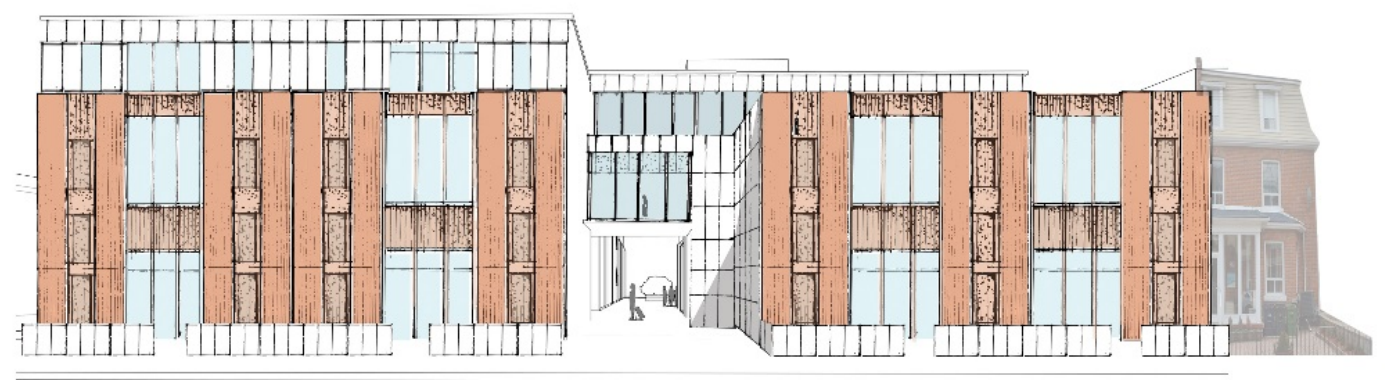

Figure 2-64 Open access within a setting system at 35 Belleview Ave. (site two) 


\section{Design}

\subsection{Project Description}

Multi unit micro housing for Site Two located in the Kensington Market neighborhood with a unit composition of approximately 34 dwellings and open access to semi-private and public spaces that support live-work, aging in place and family-oriented lifestyles (Figure 301). This project is presented as a missing-middle housing alternative, whereby the perception of an increase in affective density is evaluated through the incorporation of the objective comparators that demonstrate Leandro Minuchin's theory strands of Material politics.

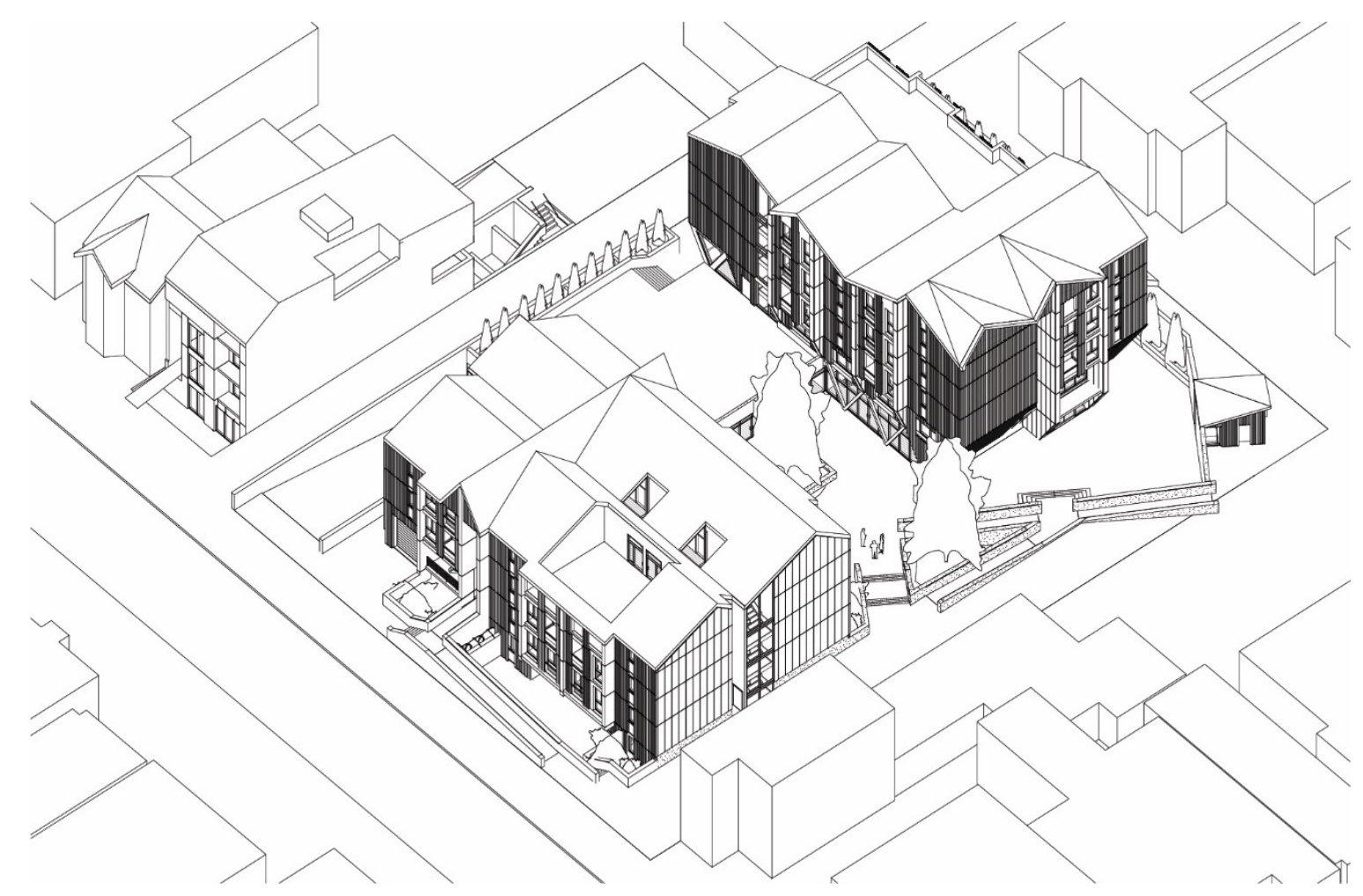

Figure 3-01 South West axonometric of micro housing model 


\subsection{Design for The Inscription of Metabolic Infrastructures}

\subsubsection{Material and Energy Processes}

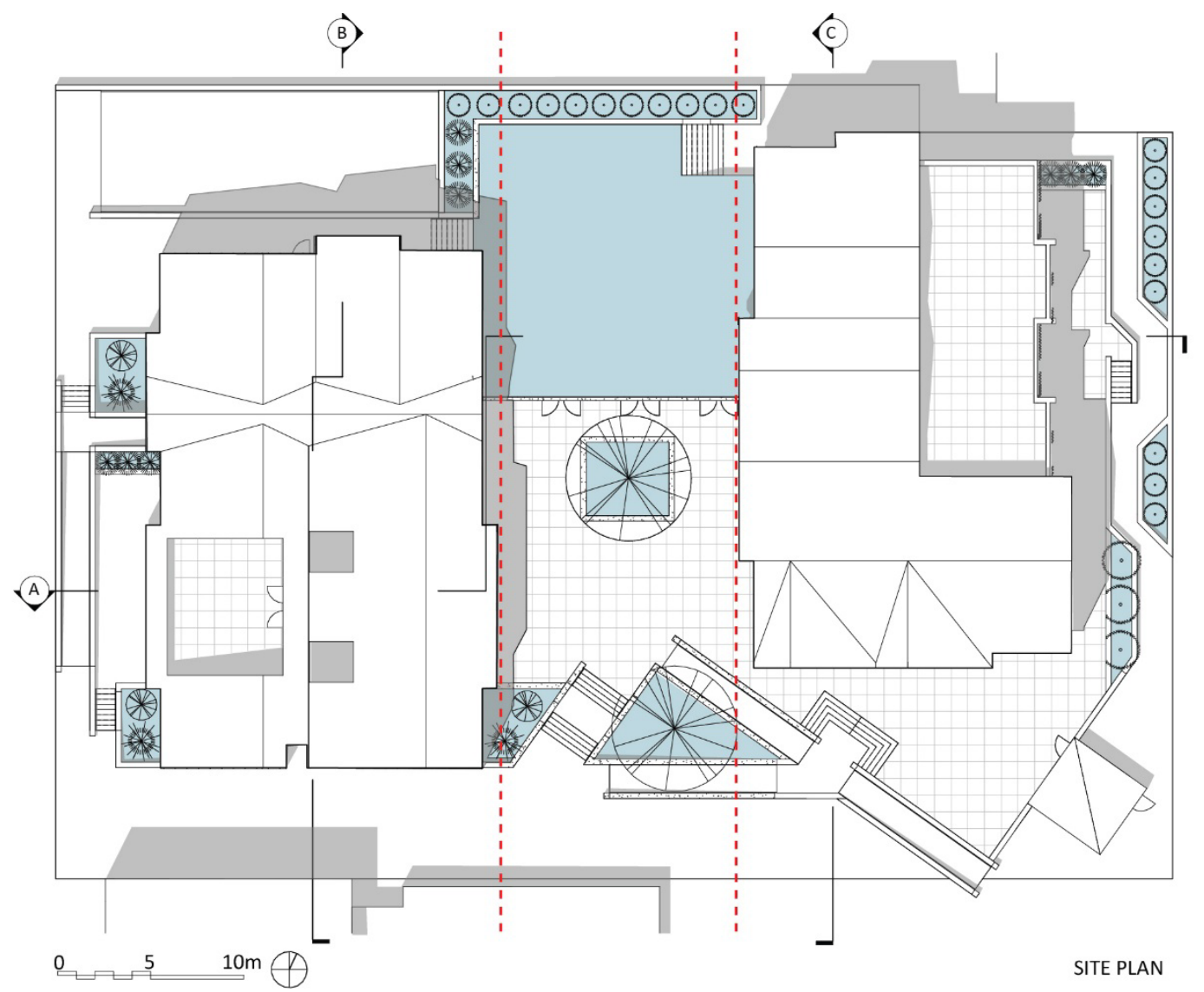

Figure 3-02 Micro Housing Site Plan

Various considerations regarding the consumption of material and energy processes are represented in the siting of architectural components within the Kensington market site. Firstly, all parking for residents, neighbors and visitors to the market neighborhood has been relegated to a subsurface parking area with both entry and exit access to the northwest of the site. Removing the parking at grade is an obvious precursor for this infill strategy and creates a more pedestrian friendly environment above ground which represents improved walkability within the neighborhood and the overall reduction of 
cars that park idly along Bellevue avenue and within the market (Figure 3-02). Public access to the sublevel parking is made available at the south east portion of the site and near market access (Figure 3-03).

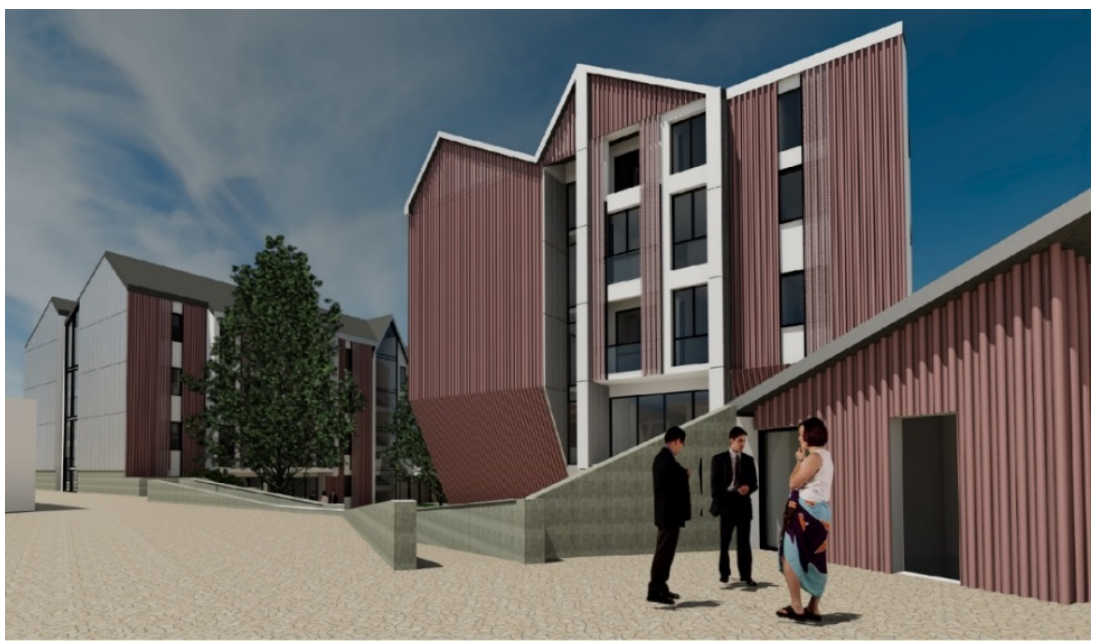

Figure 3-03 Micro Housing South East site access from Market

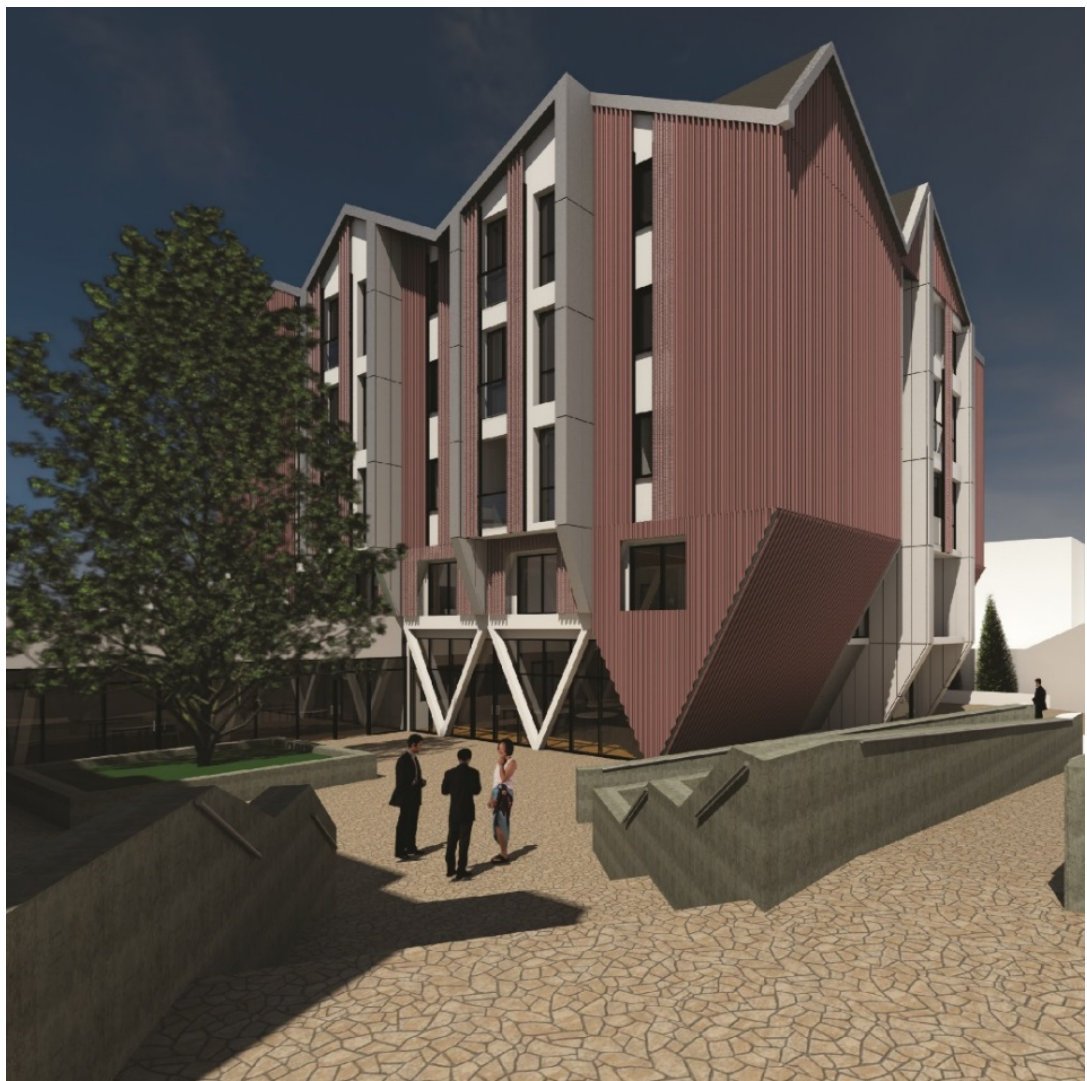

Figure 3-04 Micro Housing access from Bellevue Avenue 
Pedestrian movement is further promoted by creating a thoroughfare along the south edge of the site which represents an extension of the shared public domain that would link the market place to the residential context of the neighborhood. Along this thoroughfare, pedestrians have full accessibility to the sunken courtyards and landscaped areas at the centre of the site (3-04). The centre of the site has been preserved for this purpose to maximize natural daylighting throughout the year in support of outdoor recreational activities which are not limited to social gatherings, gardening or play occurring on site. Micro dwellings are comprised in two architectural components with primarily east-west exposures for residents. With spans not exceeding 8.5 meters, the structural frame of these architectural components could be of heavy timbre construction with stick frame partitions that reinforce the use of renewable building materials.

\subsubsection{Boundaries and Areas}

Design considerations were made regarding the extents of boundaries and areas within the site which are defined by the architecture of the micro housing components. By reducing the provision of private dwelling areas, the overall footprint of the architecture is approximately $800 \mathrm{~m}^{2}$ or $1 / 3$ of the total site area. These parameters allow for the maximum vertical density of the area while creating the opportunity to better define the surrounding urban environment. Separation of the private and semi-public domains is achieved by raising the first level 1.5 meters above grade which is roughly characteristic of the surrounding neighborhood, and loosely secures an exterior terrace of approximately $215 \mathrm{~m}^{2}$ in area with onlooking shared interior spaces to be used exclusively by residents. This terrace overlooks the semi-private domain that is 1.5 meters below grade with primary access from the public thoroughfare to the south of the site (Figure 3-05). The strategy of reducing individual private living areas results in a greater allotment of semi-public and public space to used for shared benefit and 
inscribes greater input into the metabolic infrastructure of the surrounding urban environment.

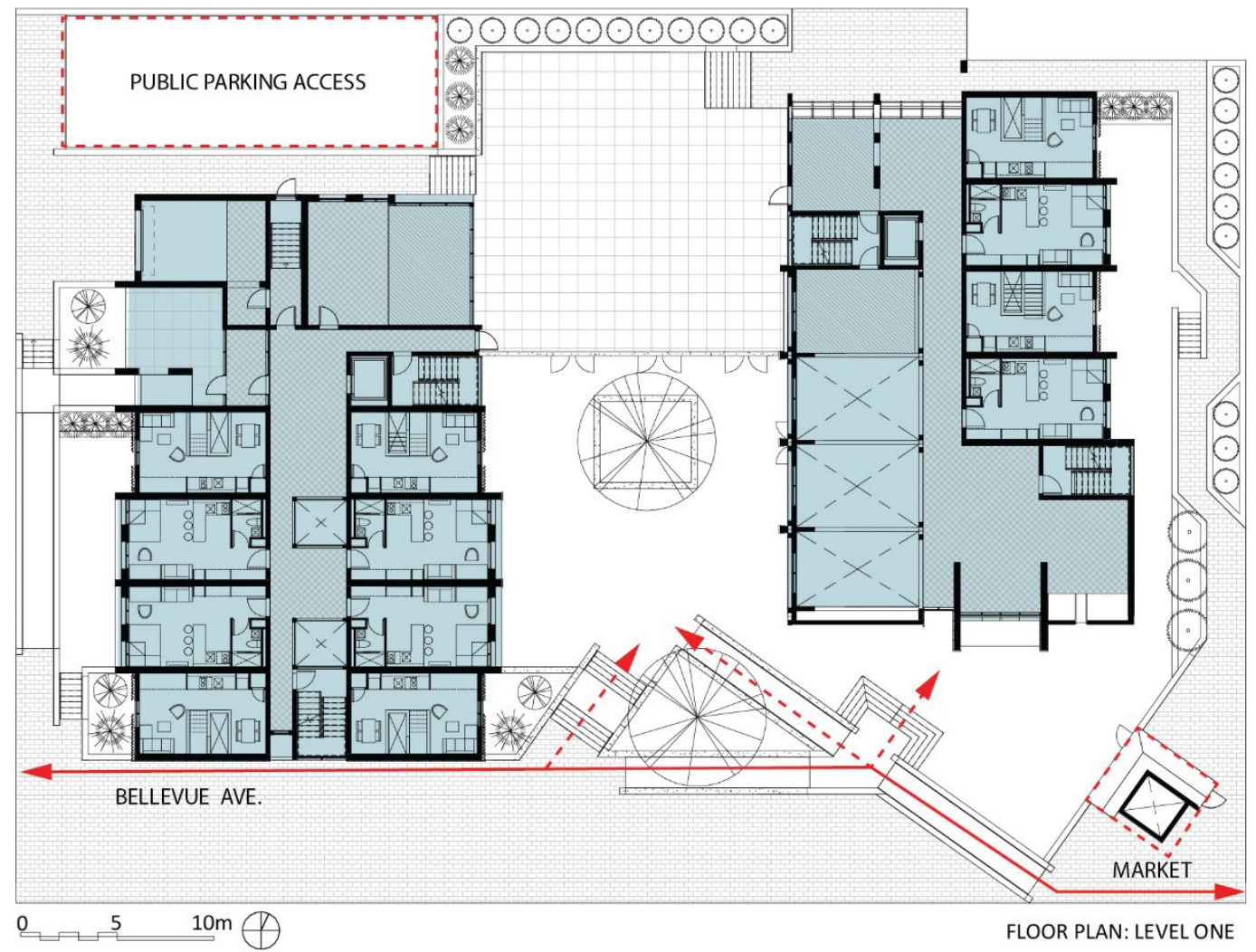

Figure 3-05 Micro Housing Level One 


\subsubsection{Local Effect}

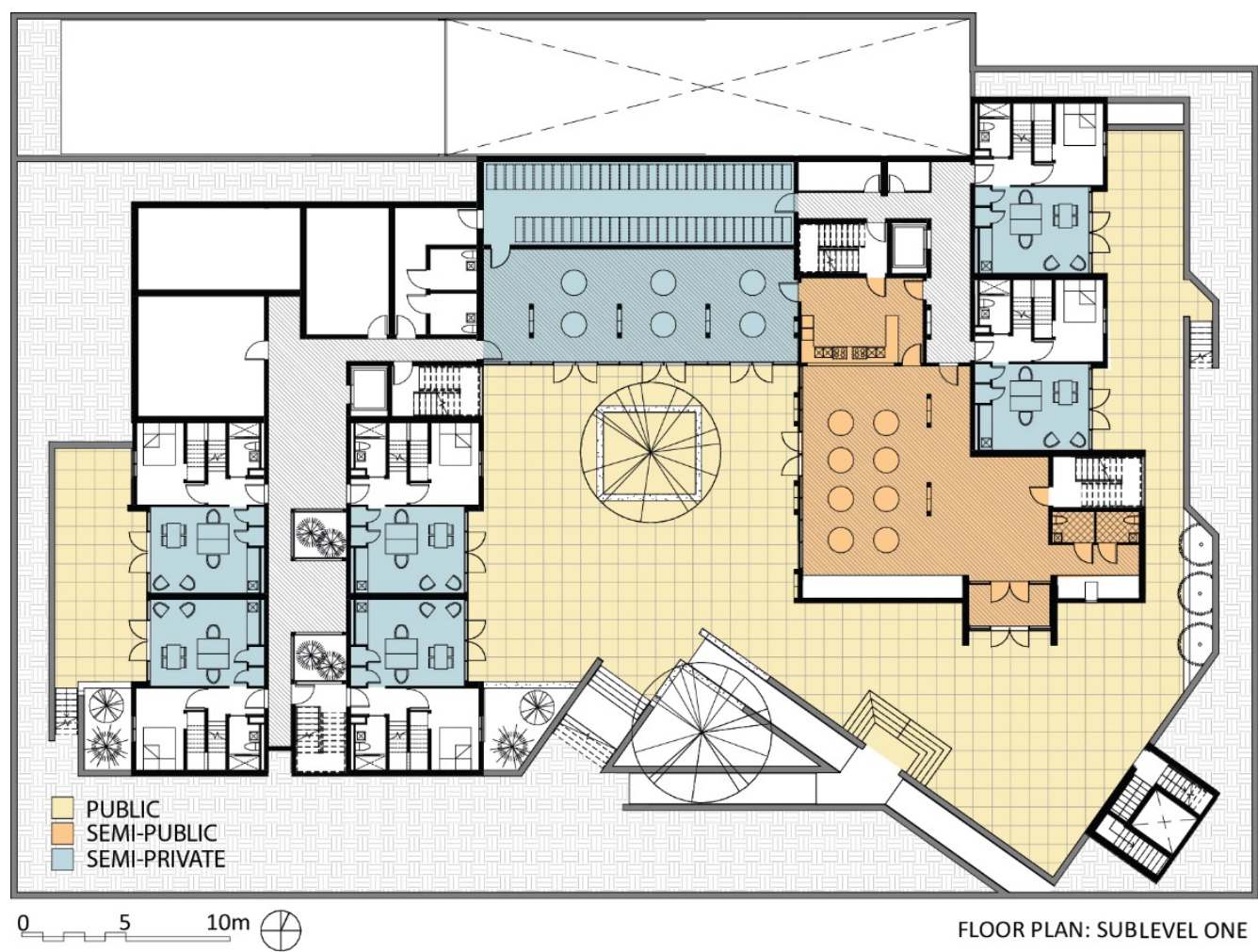

Figure 3-06 Micro Housing Sublevel One

A local affect is supported through an extension of the public and semi-private domain 1.5 meters below grade. At this level the public has access to both interior and exterior spaces that promote local activities and shared experiences with residents on site. The lower level of six micro dwellings are located at this level and offer the possibility of operating a small business in support of a live/work life style that offers direct access to the public domain (Figure 3-06). Additionally, to the east of the central courtyard, approximately $115 \mathrm{~m}^{2}$ of interior space is allotted for use by local organizations and community groups. This interior space is fully accessible and provides access to a large kitchen amenity that can be shared by the residents of the micro dwelling on site (Figure 3-07). North of the courtyard, and adjacent to the interior storage for 62 bicycles, is an additional $80 \mathrm{~m}^{2}$ of interior open space to be used exclusively by micro dwelling residents, where access to the enlarged kitchen amenity and south facing exposures of 
the interior courtyard are shared with other residents and members of the outside community.

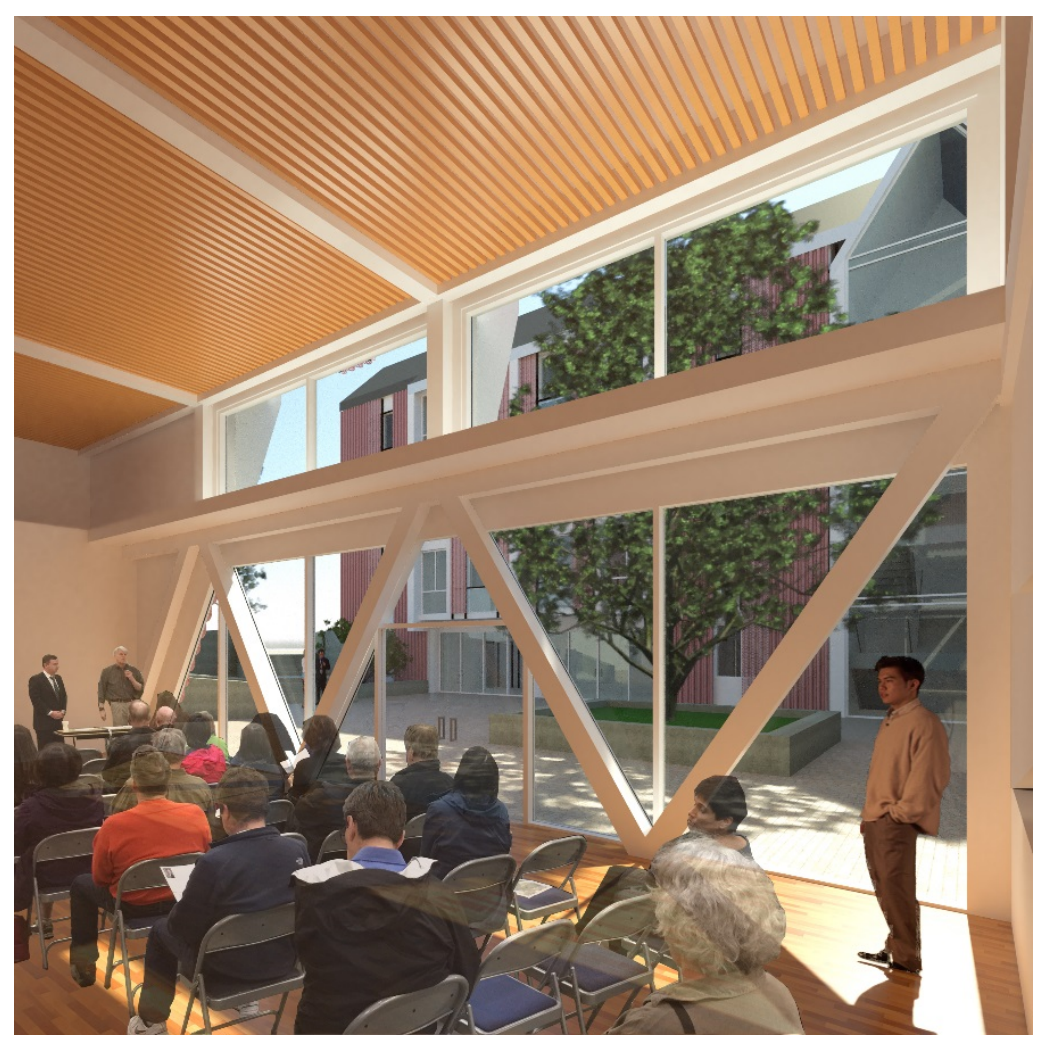

Figure 3-07 Public Interior Space

\subsection{The Disruption of the Sensible}

\subsubsection{Proximities}

The disruption of the sensible considers the agentic properties of materials and their capacity to disrupt established social and technical assumptions and regulations. Agency is provided to the resident of a micro dwelling through the provision of minimum areas of private enclosure, that offer a sustainable and economically viable 
housing alternative without compromising individual privacy. Consequently, there is an increased proximity between those that share an individual dwelling unit and between separate dwellings. Access is provided to six micro dwelling per floor in both architectural clusters to minimize the perception of over crowdedness (Figure 3-08).
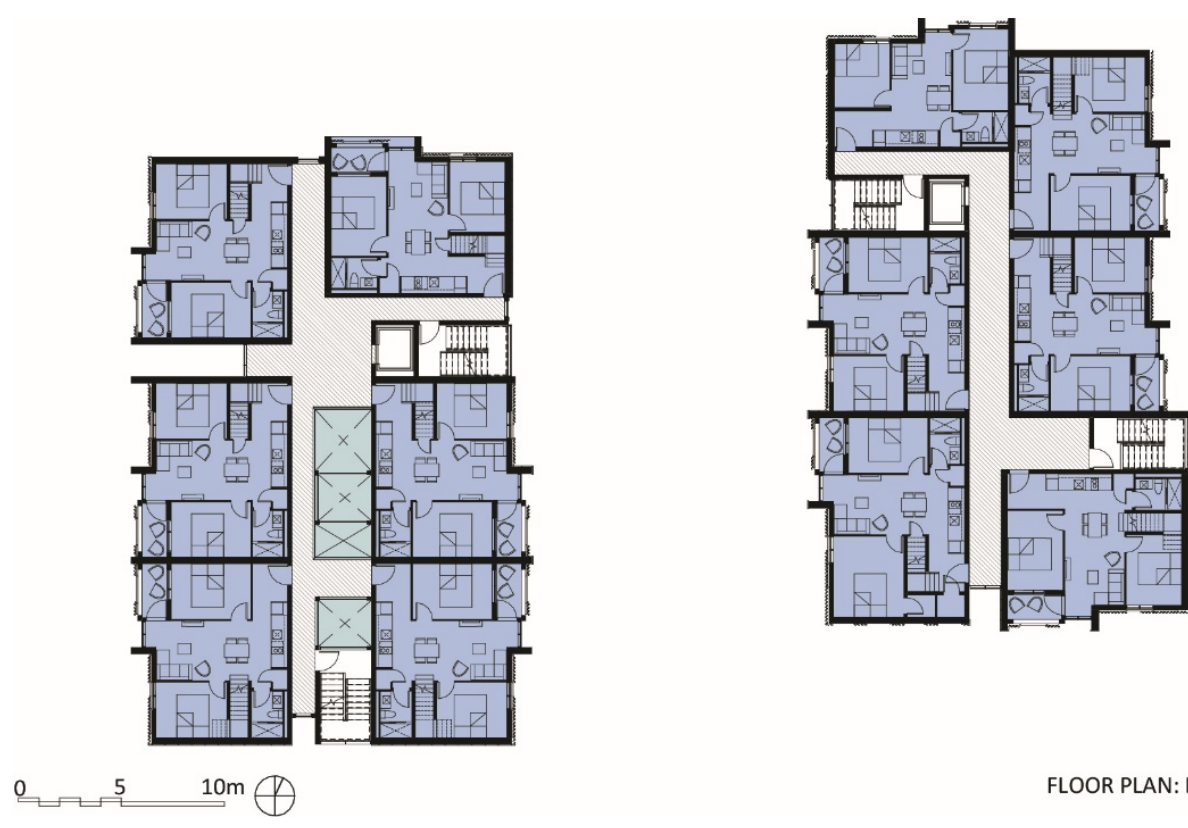

Figure 3-08 Micro Housing Level Two
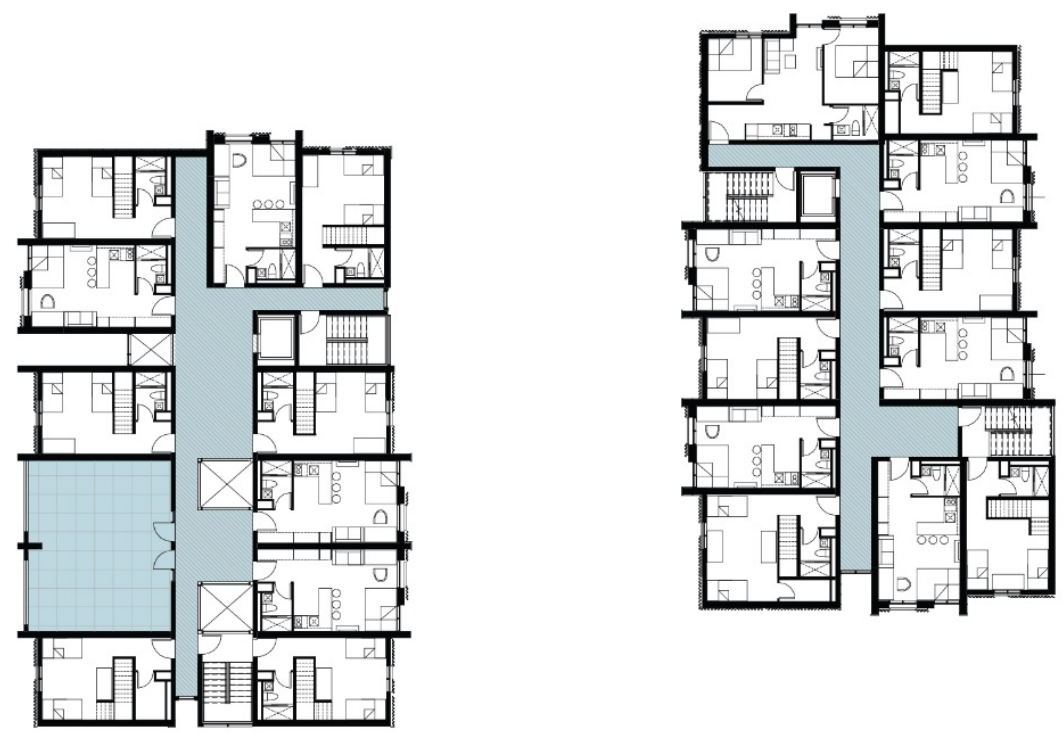

$0 \quad 5 \quad 10 \mathrm{~m} \oplus$

FLOOR PLAN: LEVEL THREE

Figure 3-09 Micro Housing Level Three 
Further design considerations attempt to mediate the ill effects of this increased proximity by providing close access to shared interior and exterior spaces at nearly every resident level. These spaces are accessible through wide interior corridors (Figure 3-09), with natural daylighting to promote potential social interaction and the possibility of shared storage (Figure 3-10).

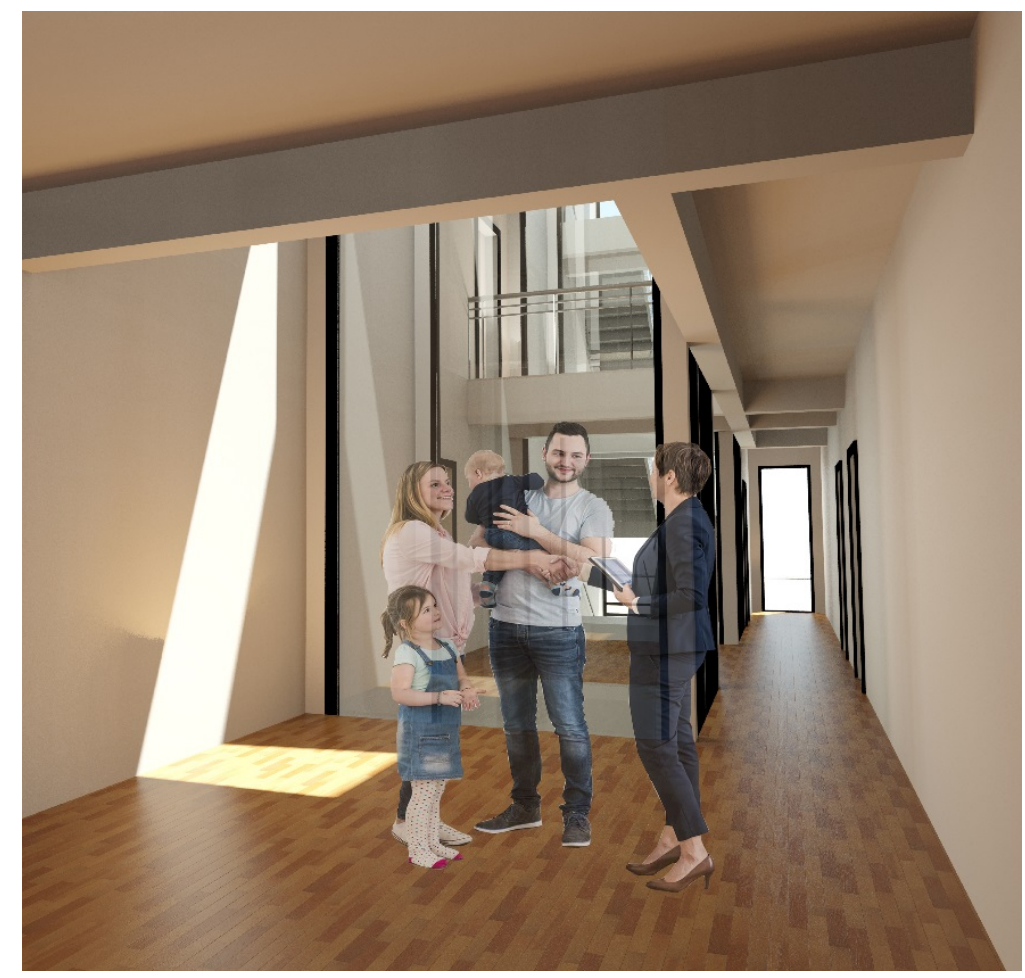

Figure 3-10 Interior corridor with natural day lighting

These shared spaces include exterior terraces with overlooking laundry lounges and an oversized kitchen amenity with adjacent dining areas for gatherings that require more space than any individual micro dwelling (Figure 3-11). 


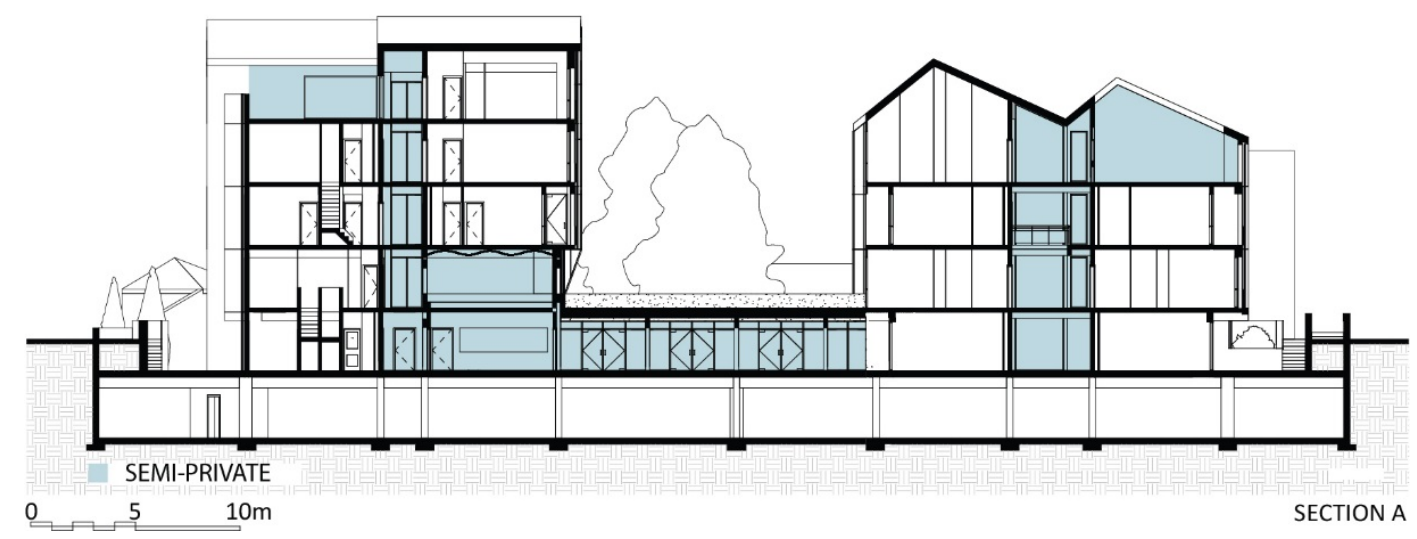

Figure 3-11 Micro Housing Section A with emphasis on semi-private space

\subsubsection{Exposure}

Circulation throughout the micro housing model allows individual residents to control their exposure within the local group. Although all vertical circulation and common spaces are naturally daylit, the choice between multiple access points between interior and exterior allow residents to choose their level of engagement in activities with other residents and members of the surrounding community. Optional access points to semiprivate space are provided at each level where micro dwellings are in two level stacked configuration. This allows greater control of exposure between residents that share a single dwelling which may be suitable for tenant or extended family living arrangements. Exterior glazing is used in spaces where an increased exposure is desirable, namely the laundry lounges located at the north of each housing cluster which overlook the raised exterior terrace (Figure 3-12). 


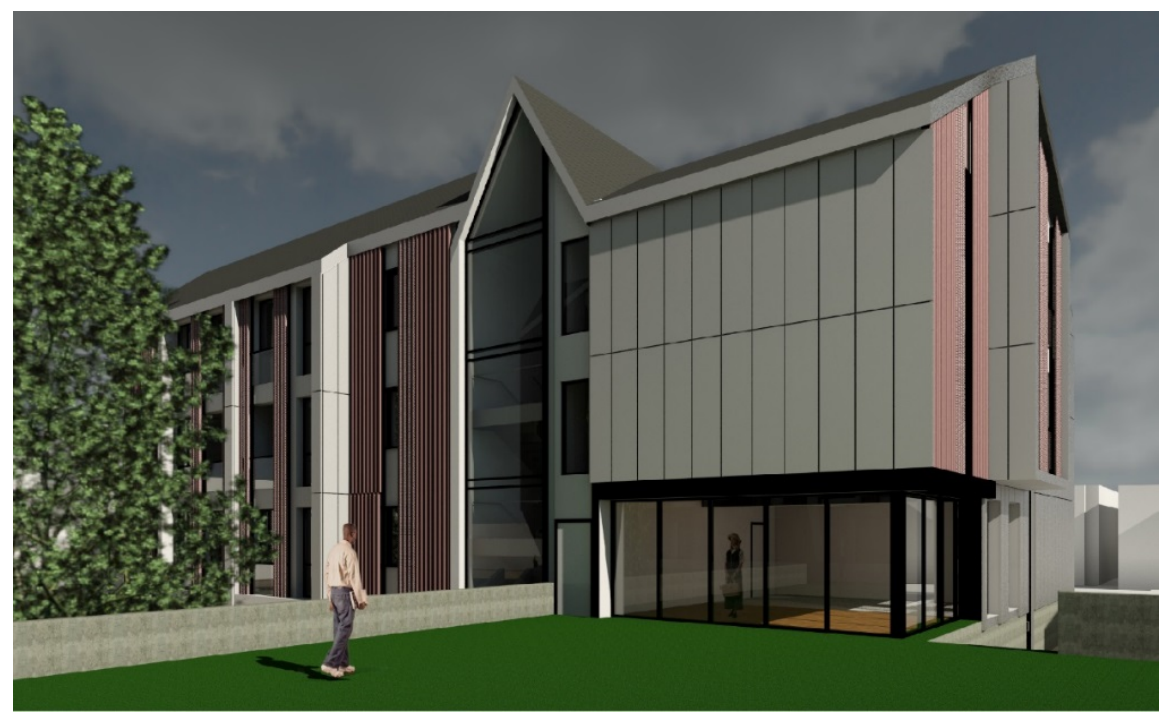

Figure 3-12 Exterior perspective of laundry lounges from elevated terrace

This allows residents to supervise the activity of children within the semi-private space while accomplishing domestic or professional work. Exposure is also increased within the semi-public domain of the courtyard below, where the activities occurring within this shared space are in view of the residents that reside above and by those residents that are occupying the interior common space below (Figure 3-13).

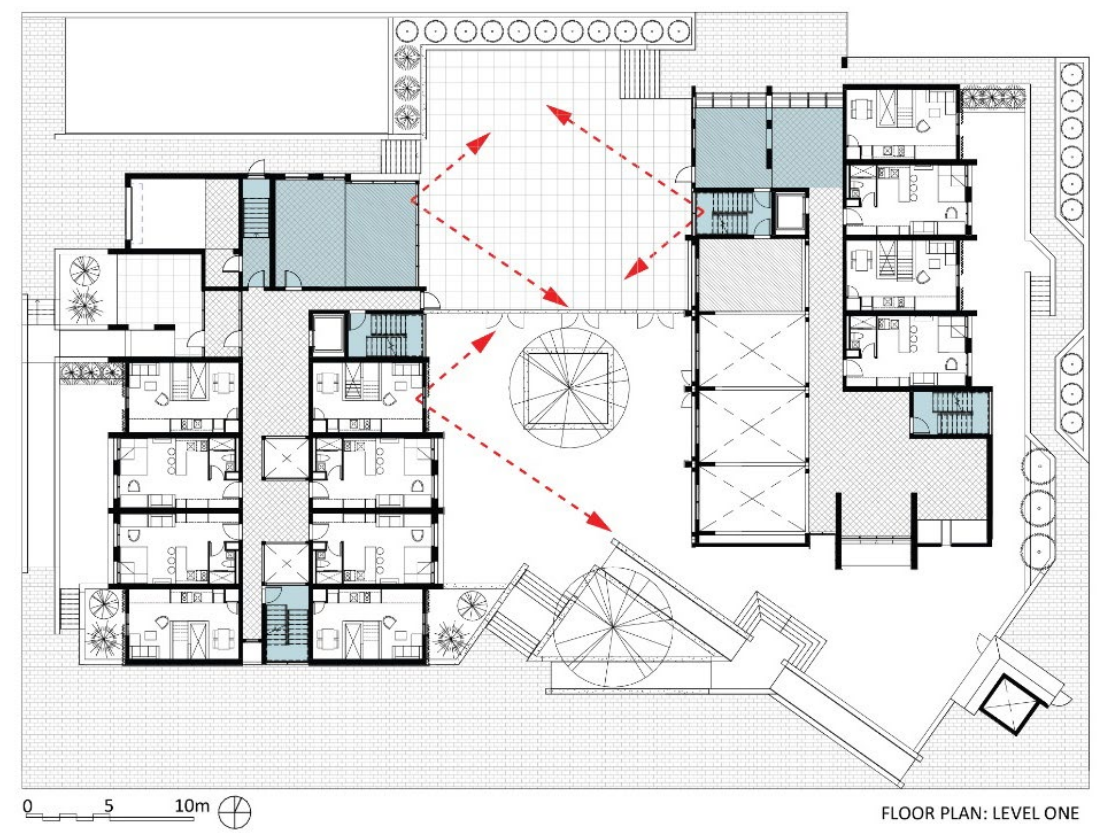

Figure 3-13 Resident supervision of exterior spaces 


\subsubsection{Spatial Variability}

Agency is provided for the residents of the micro dwelling model and members of the surrounding community through the spatial variability of the design. Preliminary design investigations considered a micro housing at the scale of a single semidetached house to the north of the site and adjacent to an existing 3.5 story residence. It was determined through this process how three individual micro dwellings with the agency of shared space could be integrated into the existing neighborhood fabric, specifically the width and height parameters of an individual micro dwelling. These parameters then informed the design development of the Bellevue Avenue elevation, where the scale, materiality, and fenestration compliment the rhythm of the existing residences along Bellevue Avenue. Maintaining the spatial qualities of the streetscape establishes a sensibility in the design that can be perceived as agency for the surrounding neighbors while creating a point in the design process from which a disruption is sensed through instances of spatial variability. This disruption is revealed upon entry to the thoroughfares that access the interior of the site (Figure 3-14).

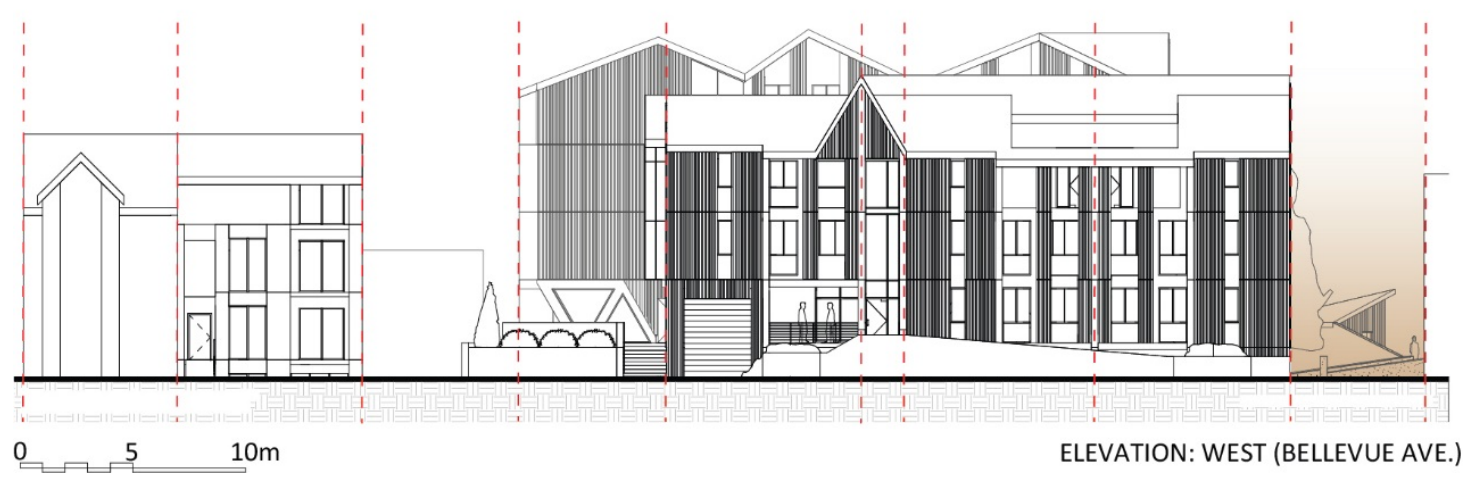

Figure 3-14 West Elevation at Bellevue Avenue 
At the centre courtyard residents and members of the surrounding community sense a contrast in the west elevation of the micro dwelling cluster to the east of the site. This contrast is created through a disruption in in the structural framework and in both the height and orientation of the roof line. A trussed frame at the base of the dwelling cluster defines an open access to the interior shared public space of the micro housing model. This disruption to the sensible is an act of agency for those that reside in the repeatable configuration of the modular micro dwellings, where the repetition breaks for a moment of contrast (Figure 3-15).

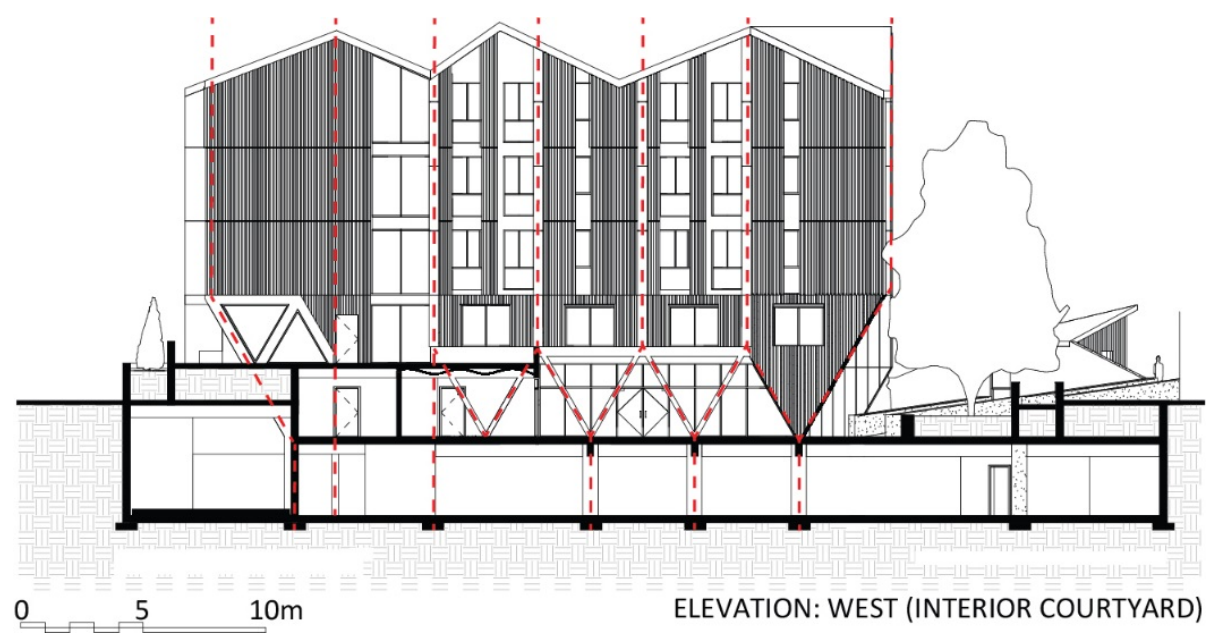

Figure 3-15 West Elevation at interior courtyard

Cross sections of both micro dwelling clusters reveal strategies for the disruption of the sensible through spatial variability in the creation of a mezzanine conditions that overlook the double heighted interior public space and within the corridors of the micro dwelling cluster to the west of the site (Figure 3-16). This spatial variability is further emphasized through the design of lightwells that allow nature and daylight to penetrate the centre of the housing cluster (Figure 3-17). 


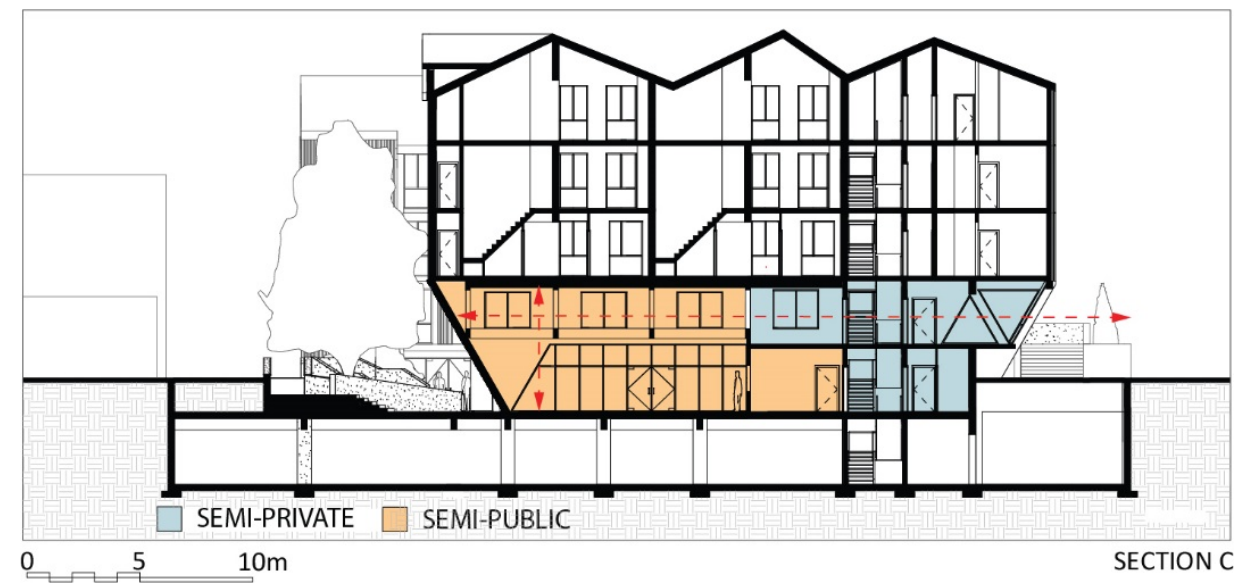

Figure 3-16 Section C

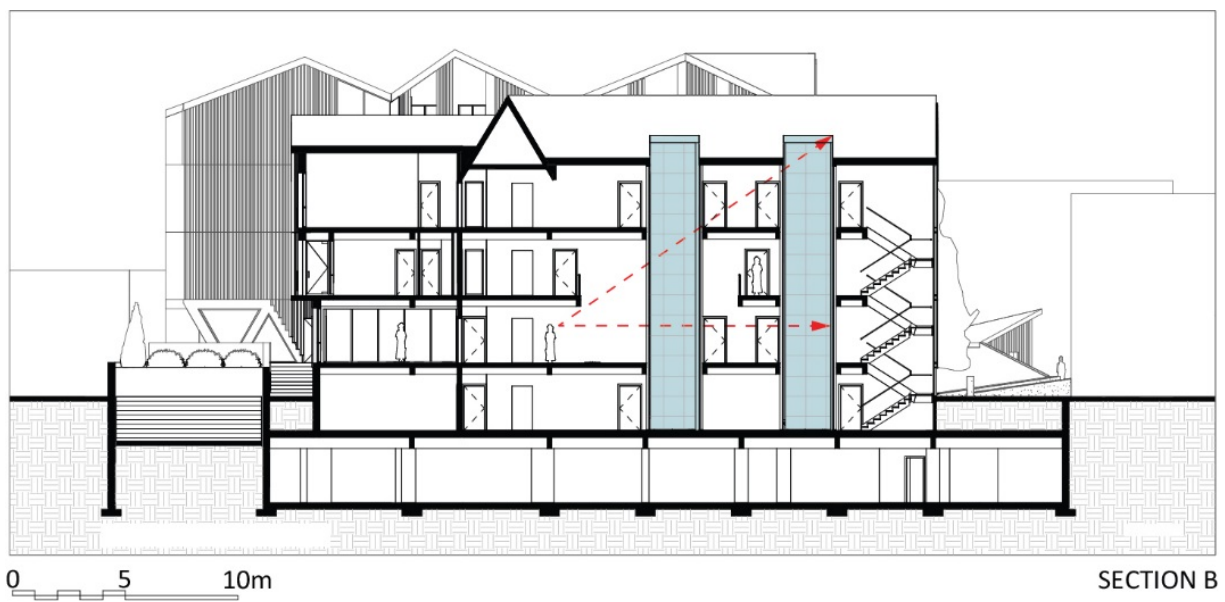

Figure 3-17 Section B

Spatial variability in the horizontal dimension is created within the shared space that is exclusive to the residents of the micro housing model. Here the plan is partitioned into three structural bays to serve as flexible living space to supplement the minimum areas of individual micro dwellings. Transparency of the exterior wall provides views into the interior courtyard and exposure to sunlight throughout the year (Figure 3-18). 


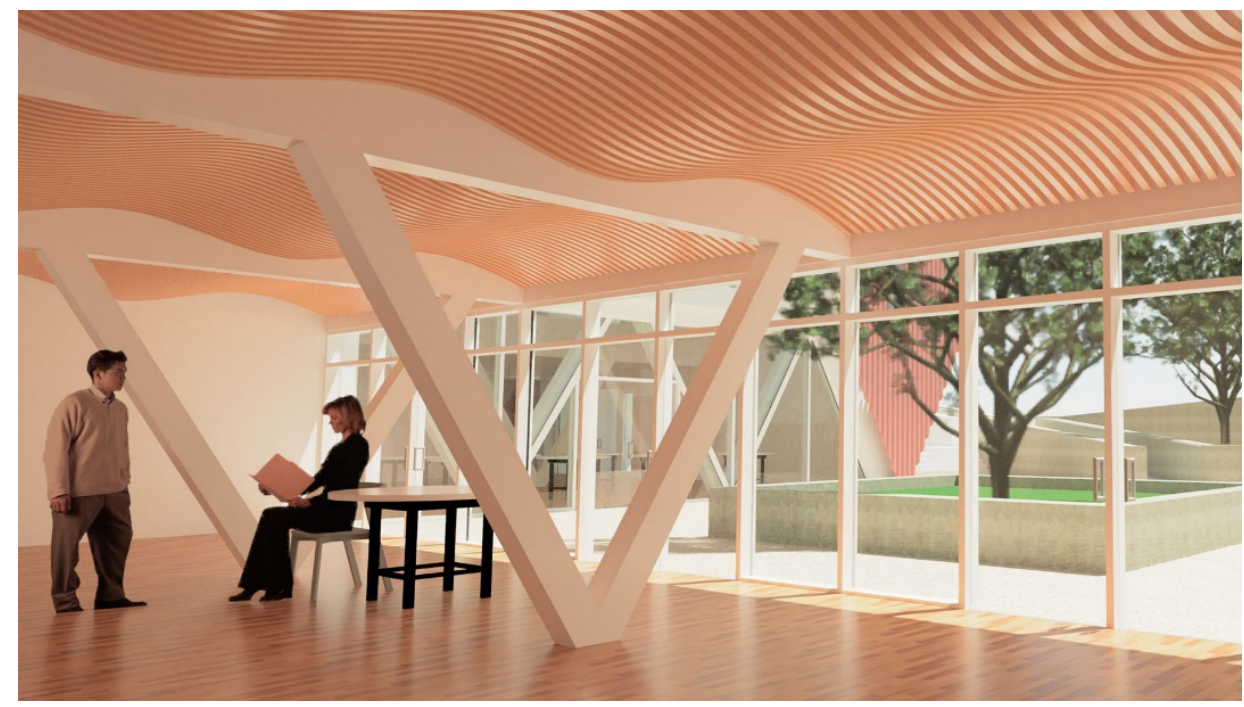

Figure 3-18 Resident Shared Space

\subsection{The Assembly of Socio-Material Entanglements}

\subsubsection{Architectural Framework and Material Modification}

The assembly of socio-material entanglements contemplates the design flexibility of space in relation to socio-material actions that translate materials into new function; which in turn, alter and redefine local experiences and practices. Design flexibility of space is achieved through the stacked configuration of a modifiable stick frame module. Where the residents of the micro housing model can renovate their module through time to support changes in life-style and the expansion and contraction of the family unit to promote aging in place (Figure 3-19). Section D represents how the $47 \mathrm{~m}^{2}$ base module can be sub-divided to create a familiar $27 \mathrm{~m}^{2}$ single room occupancy micro dwelling although the micro dwelling concept has been applied here to live/work, family oriented, and fully accessible life-styles (Figure 3-20). 

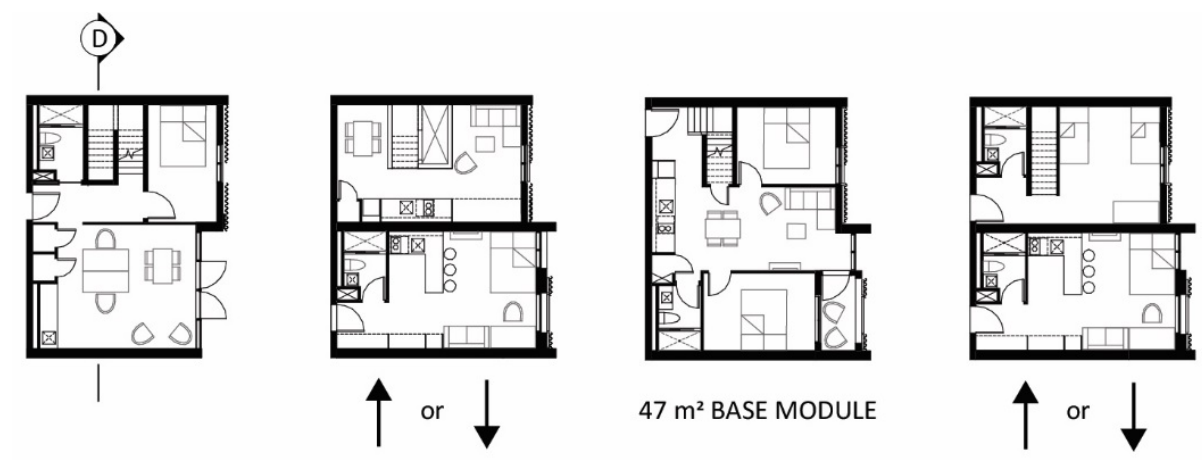

$47 \mathrm{~m}^{2}$ BASE MODULE

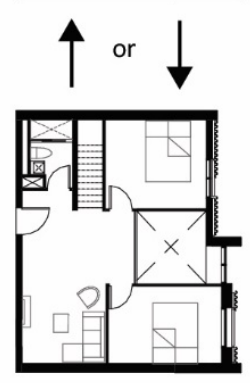

LO

L1

L 2

L3

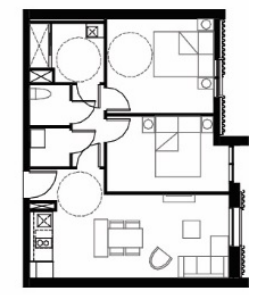

居 $10 \mathrm{~m}$

UNIT PLANS

Figure 3-19 Modular Micro Unit Floor Plans

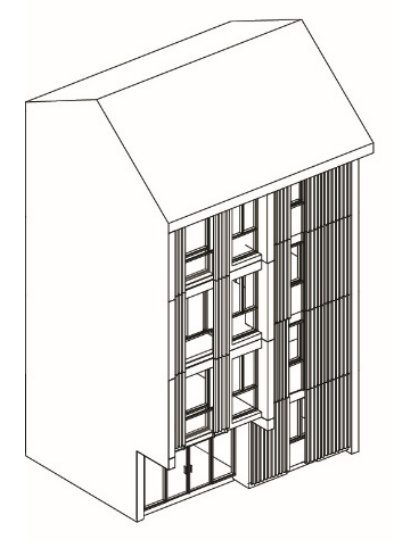

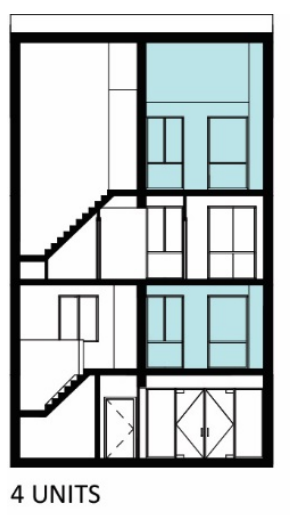

$0 \longdiv { 5 }$

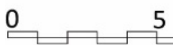

5 $10 \mathrm{~m}$

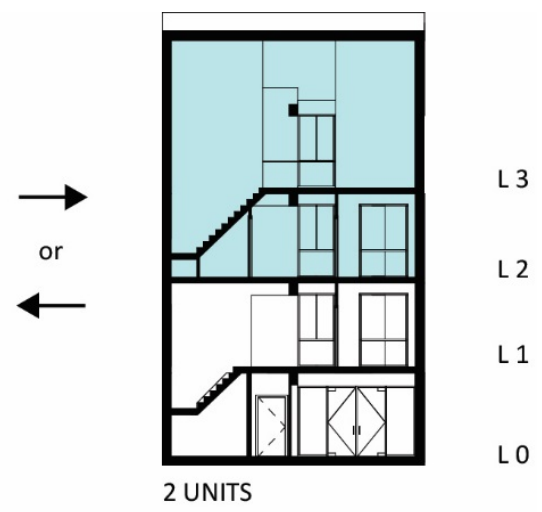

SECTION D

Figure 3-20 Section D 


\subsubsection{Setting System}

The provision of shared rooms of indeterminate use are designed to emphasize qualities of space that contrast the minimum private areas of the micro dwellings. Natural daylighting throughout the year and an open plan in the horizontal dimension are the parameters for the resident shared space, to provide a temporal flexibility that creates an on-site setting system that defers the translation of activities to external sites (Figure 3-21). This provides an alternative option for those that chose to conserve resources in support of a more familiar and local life style.
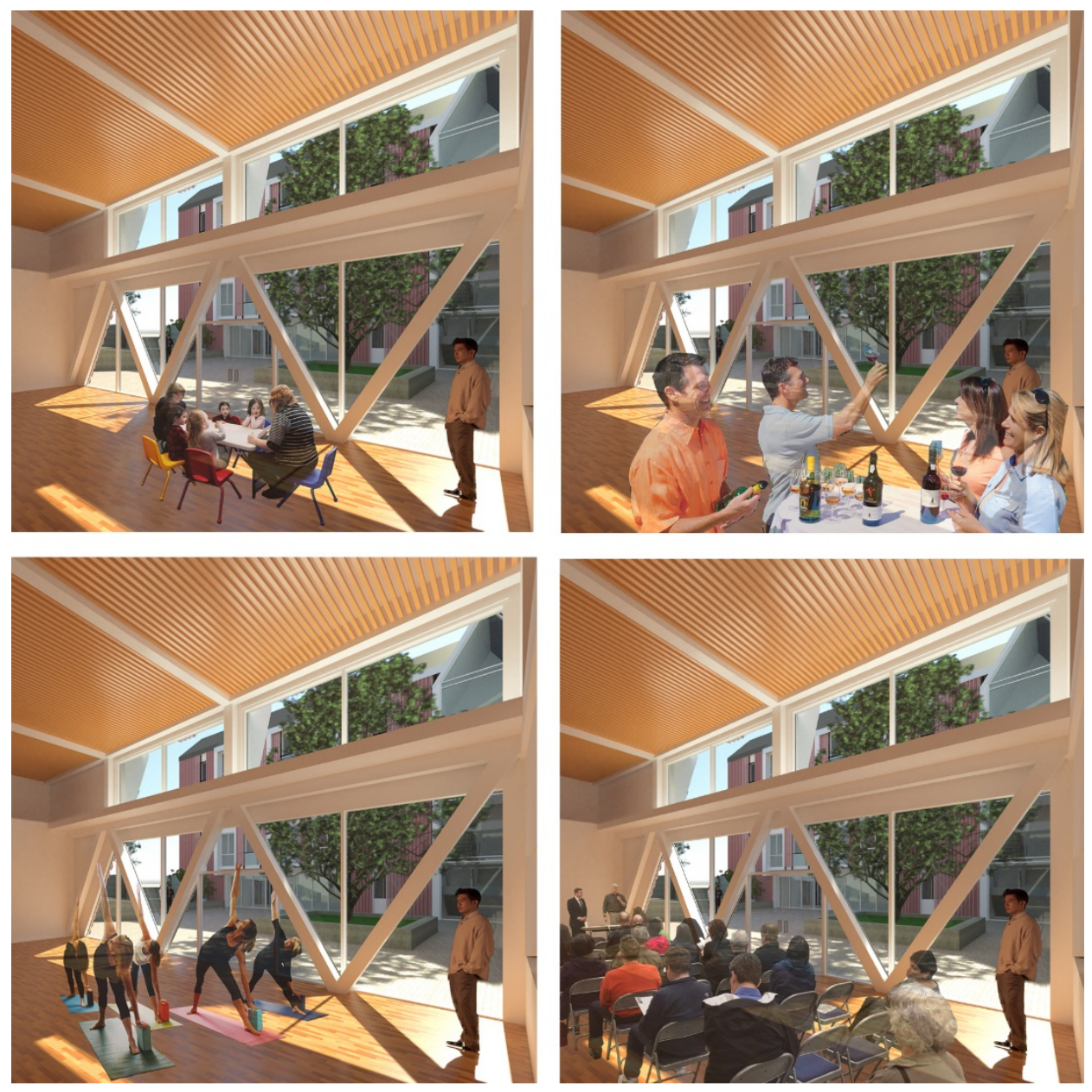

Figure 3-21 On-site setting system to defer the translation of activities to external sites 


\subsection{Conclusion}

The material politics of micro urban living demonstrates how theories on urbanization can inform the design of architecture as components to our shared urban and domestic environments. In the context of micro urban dwelling, these theories create an alternative perspective of an affective density within an increasingly densified urban environment. It is my hope that this perspective aligns with Amos Rapport's definition of affective density, which is neither overcrowding nor isolating but simply satisfactory. This thesis attempts to create an alternative housing model that fits the description of the 'missing-middle' to mediate the socio-material divisions that are reinforced by the homogenous design of housing within Toronto's urban core. As an architect, it is my intent that through design we can reterritorialize the urban and domestic spheres to create architecture that supports the option for informal human interaction, which is either encouraged or prevented by what is built and be all together pertinent to the rising socio-material implications of the $21^{\text {st }}$ century.

In many ways, Leandro Minuchin's theories relating to material politics are not so unfamiliar. The inscription of metabolic infrastructures contemplates the need for sustainable design of architecture in support of sustainable lifestyles to further encourage greater participation in these efforts to ensure a better life for future generations.

Disruption of the sensible considers how the configuration of materials in architecture can provide agency for the user and could automatically consider a sustainable approach but that which is often at odds with the interest of individual design ambitions. Therefore, the disruption of the sensible often becomes a matter of professional ethics to which all architects must familiarize themselves.

The assembly of socio-material entanglements is an acknowledgment of the shortcomings of architecture that is presumably static and often compromised by rapid changes in socio- 
material organization. Therefore, it is of importance that architects continue innovation in flexible design and design for future flexibility whenever possible.

As always, the question is how these theories are implemented into our common reality. It is my hope that this research demonstrates a way for further synthesis of these ideas and the sustained improvement of architectural design and the equitable livability of growing cities. 


\section{Appendix A}

The following tables provide the qualitative and quantitative assessment of the comparators used in the case study analysis of this thesis. Each set of comparators attempt to describe how Minuchin's three theory strands of Material Politics are objectively related to various housing forms. 
METABOLIC INFRASTRUCTURES

MATERIAL / ENERGY

BOUNDARIES AND AREAS

LOCALEFFECT
SEMI-DETACHED HOUSE

\section{sustainable energy and materiat}

strategies implemented by

\section{sustainable energy and}

material strategies

resident with moderate impact to implemented by resident

with low impact to metabolic
infrastructure

Typically physical divisions within
semi-private living spaces to suite various lifestyles without

compromising individual privacy.

Both spatial and physical

divisions within semi-private

iving spaces to suite various

lifestyles without

Higher than average unit areas

compromising individual

privacy.

sustainable energy

material strategies

mplemented by residents

metabolic infrastructu

Both spatial and physical

divisions within semi-private

living spaces to suite various

lifestyles without

compromising individual

privacy. Higher than average

unit areas

small resident community in a low

rise condition with minimal

setbacks. transition spaces for

ngagement with the gener

public

\section{mall resident community in optimal size of resident}

a low rise condition with

optimal size of residen
community in lowrise

condition. Maximum

maximum transition spaces

for minimum interaction w

the public realm

residents with decreased

interaction with the gener public

MICRO HOUSING optimal tandardized material a regulation of energy

consumption

Spatial divisions within shared

\begin{tabular}{l|l} 
Spatial divisions within shared & $\begin{array}{l}\text { Physical divisions within shar } \\
\text { spaces that increase }\end{array}$ \\
spaces that limit interaction \\
interaction between residents. & between residents. Average
\end{tabular} variation

\section{(a)}

highrise condition. Increased tontion. Increased botween residents through the use of limited shared

the use of limited shared

recreational space. Increased
interaction with general public off site

regulation of

consumption unit areas with variation drise condition. Moderate pontial or social interaction tween resdients through th use of limited shared ecreational space revitalization through adaptive revitalization through adaptive Productive rooftop gardens

Physical divisions within shared

$$
\begin{aligned}
& \text { lar } \\
& \text { mi } \\
& \text { po } \\
& \text { be } \\
& \text { use } \\
& \text { rec }
\end{aligned}
$$

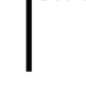

Physical divisions within shared
spaces to promote a variety of
interaction between residents.
Average unit areas with limited
variation
large resident community in
midrise condition. Increased
potential for social interaction
between residents and the
general public through the use
of shared recreational space

\section{BAUGRUPPE}

revitalization through small footprint in-fill. Sustainable energy and material strategies

by resident group.

Spatial divisions within shared semi-private communal living spaces to suite various lifestyles without compromising individual privacy. Average and below average unit areas with variation

\section{optimal size of resident} community in midrise conditio Increased potential for social interaction between residents an the general public through the us ive-work collaboration space 
DISRUPTION OF THE SENSIBLE

The agentic properties of materials and their capacity to disrupt established social and technical assumptions and regulations

SEMI-DETACHED HOUSE

PROXIMITES

EXPOSURE

SPATIAL VARIABILITY

\begin{tabular}{|c|c|}
\hline $\begin{array}{l}\text { Interior circulation routes } \\
\text { providing access to limited shared } \\
\text { recreation space with private } \\
\text { spaces in both far and near } \\
\text { proximity }\end{array}$ & $\mid \begin{array}{l}\text { Interior circulation routes } \\
\text { providing access to an } \\
\text { increase in shared recreatior } \\
\text { space with private spaces in } \\
\text { both far and near proximity }\end{array}$ \\
\hline $\begin{array}{l}\text { Limited access points provide } \\
\text { lower control over exposure, } \\
\text { typically low visability in shared } \\
\text { spaces }\end{array}$ & $\begin{array}{l}\text { Optional access points } \\
\text { provide control over } \\
\text { exposure, both high and low } \\
\text { visability in shared spaces }\end{array}$ \\
\hline $\begin{array}{l}\text { Duplex typology provides spatial } \\
\text { variation in the veritcal dimension } \\
\text { within units. Shared semi-private } \\
\text { spaces are similar to one another }\end{array}$ & $\begin{array}{l}\text { Maxiumum spatial variation } \\
\text { in the horizontal dimension } \\
\text { with variety in the vertical } \\
\text { dimension }\end{array}$ \\
\hline
\end{tabular}

\begin{tabular}{|c|c|}
\hline CO-HOUSING & MICRO HOUSING \\
\hline $\begin{array}{l}\text { Transition spaces provide } \\
\text { comfortable proximity within } \\
\text { and between units }\end{array}$ & $\begin{array}{l}\text { Interior circulation routes } \\
\text { providing access to limited } \\
\text { shared recreation space and } \\
\text { private units in close proximit }\end{array}$ \\
\hline $\begin{array}{l}\text { Optional access points } \\
\text { provide control over } \\
\text { exposure, both high and low } \\
\text { visability in shared spaces }\end{array}$ & $\begin{array}{l}\text { Single access points to private } \\
\text { units with outward facing } \\
\text { exposure, HIGH visability in } \\
\text { shared spaces }\end{array}$ \\
\hline $\begin{array}{l}\text { Duplex typology provides } \\
\text { spatial variation in the } \\
\text { veritcal dimension within } \\
\text { units. Shared semi-private } \\
\text { spaces are unique from one } \\
\text { another }\end{array}$ & $\begin{array}{l}\text { Flat unit typology with spatial } \\
\text { variation in the vertical } \\
\text { dimension limited to the } \\
\text { ground level. Shared space } \\
\text { different to unit design. }\end{array}$ \\
\hline
\end{tabular}

TYP. MIDRISE

$\mid \begin{aligned} & \text { Interior circulation routes } \\ & \text { providing access to limited } \\ & \text { shared recreation space and } \\ & \text { private units in close proximity }\end{aligned}$

INTEGRATED

\begin{tabular}{|l|l|}
$\begin{array}{l}\text { Transition spaces provide } \\
\text { comfortable proximity within } \\
\text { and between units }\end{array}$ & $\begin{array}{l}\text { Limited circulation routes } \\
\text { providing residents and the } \\
\text { general public access to live-work } \\
\text { collaboration space on optimal } \\
\text { proximity. Increased proximity for } \\
\text { residents using semi-private space } \\
\text { for communal living }\end{array}$ \\
$\begin{array}{l}\text { Optional access points provide } \\
\text { control over exposure, high } \\
\text { visability in shared spaces }\end{array}$ & $\begin{array}{l}\text { Optional acces points into units } \\
\text { provide control over exposure, } \\
\text { limited visability in shared and } \\
\text { semi-private spaces. }\end{array}$ \\
$\begin{array}{l}\text { Duplex typology provides spatial } \\
\text { variation in the veritcal } \\
\text { dimension within units. Shared } \\
\text { semi-private spaces are unique } \\
\text { from one another }\end{array}$ & $\begin{array}{l}\text { split levels and atypical floor to } \\
\text { ceiling heights providing spatial } \\
\text { variety within dwellings and live } \\
\text { work collaboration spaces }\end{array}$ \\
&
\end{tabular}




\begin{tabular}{|c|c|c|c|c|c|c|c|}
\hline & SEMI-DETACHED HOUSE & COUNTRY HOUSE & CO-HOUSING & MICRO HOUSING & TYP. MIDRISE & INTEGRATED & BAUGRUPPE \\
\hline $\begin{array}{l}\text { ARCHITEECTURAL } \\
\text { FRAMEWORK }\end{array}$ & \begin{tabular}{|l} 
Light-frame Construction on \\
Concrete Foundation
\end{tabular} & \begin{tabular}{|l} 
Light-frame Construction on \\
Concrete Foundation
\end{tabular} & $\begin{array}{l}\text { Light-frame Construction on } \\
\text { Concrete Foundation }\end{array}$ & \begin{tabular}{|l} 
Concrete superstructure with \\
light frame partitions
\end{tabular} & $\begin{array}{l}\text { Concrete superstructure with } \\
\text { light frame partitions }\end{array}$ & \begin{tabular}{|l} 
Concrete superstructure with \\
light frame partitions
\end{tabular} & $\begin{array}{l}\text { Composite Concrete } \\
\text { superstructure with light frame } \\
\text { partitions and decking }\end{array}$ \\
\hline MATERIAL USAGE & $\begin{array}{l}\text { Modifiable partitions within tight } \\
\text { spatial enclosure }\end{array}$ & $\begin{array}{l}\text { Modifiable partitions within } \\
\text { loose spatial enclosure }\end{array}$ & $\begin{array}{l}\text { Modifiable unit partitions to } \\
\text { support variations within } \\
\text { social groups }\end{array}$ & $\begin{array}{l}\text { Modifiable unit partitions } \\
\text { within tight spatial enclosure }\end{array}$ & $\begin{array}{l}\text { Modifiable unit partitions } \\
\text { within tight spatial enclosure }\end{array}$ & $\begin{array}{l}\text { Modifiable unit partitions to } \\
\text { support variations within social } \\
\text { groups }\end{array}$ & $\begin{array}{l}\text { Raw material palette and loose } \\
\text { spatial enclosure for future } \\
\text { modifcation }\end{array}$ \\
\hline SETTING SYSTEM & $\begin{array}{l}\text { designed spaces for particular } \\
\text { residential uses }\end{array}$ & $\begin{array}{l}\text { designed spaces for a variety } \\
\text { of residential uses }\end{array}$ & $\begin{array}{l}\text { designed spaces for private } \\
\text { live-work use and maximum } \\
\text { shared semi-private space } \\
\text { for communal living }\end{array}$ & $\begin{array}{l}\text { designed spaces for a } \\
\text { maximum variety of } \\
\text { residential uses }\end{array}$ & $\begin{array}{l}\text { Mixed use residential and } \\
\text { commercial with designed } \\
\text { spaces for particualar } \\
\text { residential and commercial } \\
\text { uses. }\end{array}$ & $\begin{array}{l}\text { Mixed use residential with } \\
\text { shared public and semi-private } \\
\text { space for flexible community } \\
\text { programming and communal } \\
\text { living }\end{array}$ & $\begin{array}{l}\text { Mixed use live-work and } \\
\text { commercial with shared semi- } \\
\text { private space for communal living }\end{array}$ \\
\hline
\end{tabular}




\section{Figure Credits}

*All figures not listed below are credited to the author

\section{3-02}

Figure 10: Unit Mix by Construction Period - GTA Source: Urbanation. Ryerson City Building Institute, Bedrooms in the Sky: Is Toronto Building the Right Condo Supply? (2017, Nov 7). Retrieved Nov 27, 2017, Ryerson University City Building Institute website: https://www.citybuildinginstitute.ca/wp-content/uploads/2017/11/FINAL BedroomsInTheSky.pdf

\section{4-03}

Figure 9: Share of units 2 Bedrooms or larger by Construction Period and location Source: Urbanation. Ryerson City Building Institute, Bedrooms in the Sky: Is Toronto Building the Right Condo Supply? (2017, Nov 7). Retrieved Nov 27, 2017, Ryerson University City Building Institute website: https://www.citybuildinginstitute.ca/wp-content/uploads/2017/11/FINAL BedroomsInTheSky.pdf

\section{5-04}

[No Title] Rapoport, A. (1975). Toward a Redefinition of Density. Environment and Behaviour, 7 (2), 133-158. doi: 10.1177/001391657500700202

\section{1-05}

Identification of Differences between Cultures. Kent, S., \& Rapoport, A. (1990). Domestic architecture and the use of space: An interdisciplinary cross-cultural study. Cambridge: Cambridge University Press

\section{1-07}

Comparison of Setting Systems. Kent, S., \& Rapoport, A. (1990). Domestic architecture and the use of space: An interdisciplinary cross-cultural study. Cambridge: Cambridge University Press

\section{1-08}

Comparison of unlike Setting Systems. Kent, S., \& Rapoport, A. (1990). Domestic architecture and the use of space: An interdisciplinary cross-cultural study. Cambridge: Cambridge University Press

\section{1-09}

Differentiation of System Settings. Kent, S., \& Rapoport, A. (1990). Domestic architecture and the use of space: An interdisciplinary cross-cultural study. Cambridge: Cambridge University Press 


\section{2-01}

View from yard Image 2. BARarchitekten (2013). Retrieved February 1, 2019, BARarchitekten website: www. Bararchitekten.de/projects/baseplus.html

\section{2-02}

Figure 1 Downtown Growth. City of Toronto, Downtown Toronto Trends Issues Intensification (2014, May). Retrieved Nov 27, 2017, City of Toronto website:

https://www.toronto.ca/legdocs/mmis/2014/te/bgrd/backgroundfile-69192.pdf

\section{2-03}

Typical floor plan of Carmel Place, New York City, 2016. nARCHITECTS Retrieved Nov 27, 2017, from nARCHITECTS website: http://narchitects.com/work/carmel-place/

\section{2-04}

Shared Space Axonometric of Carmel Place, New York City, 2016. nARCHITECTS Retrieved Nov 27, 2017, from nARCHITECTS website: http://narchitects.com/work/carmel-place/

\section{2-07}

WeWork Space, Toronto. WeWork Retrieved Nov 27, 2017, from Yellow Pages website: https://www.yellowpages.ca/bus/Ontario/Toronto/WeWork-Richmond-StreetWest/101881953.html

\section{2-08}

Co-operative Housing Community Space, Chicago. Brinshore Retrieved Nov 27, 2017, from Brinshore website: http://brinshore.com/dev/dorchester-artist-housing-collaboration/

\section{2-09}

Smart House amenity space, Toronto, 2017. SmartHouse Amenities (2017). Retrieved Nov 15, 2017, from Smart House website: http://smarthousetoronto.com/smart-amenities.html\#

2-10 Typical Cohousing Common House. McCamant \& Durret. Retrieved Nov 15, 2017, from pintrest website: https://www.pinterest.ca/pin/369013763190387959/?lp=true

\section{2-12}

Gregory House Exterior Room. Kiley, D., \& Amidon, J. (2001). DanKiley in his own words: Americas master landscape architect. London: Thames and Hudson

\section{2-14}

Vancouver Co-Housing Gardens. Vancouver Cohousing. Retrieved Nov 15, 2017, from Vancouver co-housing website: https://vancouvercohousing.com/ 


\section{2-15}

Vancouver Co-housing Shared Exterior. Vancouver Cohousing. Retrieved Nov 15, 2017, from Vancouver co-housing website: https://vancouvercohousing.com/

\section{2-19}

Sebastopol Co-housing Site Arial. Satellite Affordable Housing Associates. Retrieved Nov 15, 2017, from Satellite Affordable Housing Associates website:

https://www.sahahomes.org/properties/petaluma-avenue-homes

\section{2-20}

Toronto Co-operative Building Section. Teeple Architects. Retrieved February 15, 2018, from Canadian Architect website: https://www.canadianarchitect.com/features/60-richmond-streeteast-housing-co-operative/

\section{2-22}

Berlin Baugruppe Building Section. BARarchitekten. Retrieved Nov 8, 2017, from BARarchitekten website: http://www.bararchitekten.de/projects/oderberger.html

\section{2-24}

Berlin Baugruppe Unit Plan. BARarchitekten. Retrieved Nov 8, 2017, from BARarchitekten website: http://www.bararchitekten.de/projects/oderberger.html

\section{2-26}

Toronto Co-operative Private Resident Amenity Teeple Architects. Retrieved February 15, 2018, from Canadian Architect website: https://www.canadianarchitect.com/features/60-richmondstreet-east-housing-co-operative/

\section{2-27}

Berlin Baugruppe Building Section. BARarchitekten. Retrieved Nov 8, 2017, from BARarchitekten website: http://www.bararchitekten.de/projects/oderberger.html

\section{2-28}

Badehaus Sargfabrik. Hertha Hurnaus. Retrieved Nov 8, 2017, from Sargfabrik website: https://www.sargfabrik.at/Home/For-Rent/Badehaus

\section{2-29}

Berlin Baugruppe Raw Finish. BARarchitekten. Retrieved Nov 8, 2017, from BARarchitekten website: http://www.bararchitekten.de/projects/oderberger.html

\section{2-30}

Wohnung 2, 4.OG. BARarchitekten. Retrieved Nov 8, 2017, from BARarchitekten website: http://www.bararchitekten.de/projects/oderberger.html 


\section{2-31}

Toronto Co-operative Private Resident Gardens. Teeple Architects. Retrieved February 15, 2018 from Houseporn website:

http://www.houseporn.ca/architecture/article/torontos_60_richmond_east_housing_develop ment_by_teeple_architects

\section{2-32}

Studio B BARarchitekten. Retrieved Nov 8, 2017, from BARarchitekten website:

http://www.bararchitekten.de/projects/oderberger.html

\section{2-33}

Vienna Integrated Living Community Gardens. Sargfabrik. Retrieved Nov 8, 2017, from pintrest website: https://www.pinterest.ca/pin/555490935279361233/?lp=true

\section{2-34}

Toronto Micro Condo 3rd Level Amenity Space SmartHouse Amenities (2017). Retrieved Nov 15, 2017, from Smart House website: http://smarthousetoronto.com/smart-amenities.html\#

\section{2-35}

Toronto Mid-Rise Condominium Floor Plan. Daniels. Retrieved Nov 17, 2017, from city of Toronto website: https://www.toronto.ca/legdocs/mmis/2016/te/bgrd/backgroundfile95749.pdf

\section{2-36}

Toronto Micro Condominium Unit Plan. Smart House. Retrieved Nov 15, 2017, from pintrest website: https://www.pinterest.ca/pin/411868328399332281/?lp=true

\section{2-37}

Toronto Mid-Rise Condominium Setting System. Retrieved Nov 17, 2017, from city of Toronto website: https://www.toronto.ca/legdocs/mmis/2016/te/bgrd/backgroundfile-95749.pdf

\section{2-38}

Toronto Micro Condominium Setting System Retrieved Nov 15, 2017, from Smart House website: http://smarthousetoronto.com/smart-amenities.html\#

\section{2-39}

Arial photographs of Test Site One 57 Brock Avenue, Google Maps, Retrieved February 15, 2018 from google maps website: https://www.google.ca/maps

\section{2-40}

Arial Photographs of Test Site Two, 35 Bellevue Avenue, Google Maps, Retrieved February 15, 2018 from google maps website: https://www.google.ca/maps 


\section{2-41}

Bellevue Avenue, An Architectural and Social Study. Pg. 21. Toronto Region Architectural Conservancy. Retrieved February 1, from ACO Toronto website:

https://www.acotoronto.ca/res_files/Bellevue\%20Compressed.pdf

\section{2-44}

Sustainable Energy and Communal Consumption Strategies in community gardens and workshops. Vancouver Co-housing \& BARarchitekten, Vancouver Cohousing. Retrieved Nov 15, 2017, from Vancouver co-housing website: https://vancouvercohousing.com/ \& BARarchitekten. Retrieved Nov 8, 2017, fromArchdaily website:

https://www.archdaily.com/587590/coop-housing-project-at-the-river-spreefeld-carpanetoarchitekten-fatkoehl-architekten-bararchitekten

\section{2-45}

Site Plan 57 and 65 Brock Avenue. City of Toronto, Retrieved February 15, 2018 from City of Toronto website: https://www.toronto.ca/legdocs/mmis/2016/te/bgrd/backgroundfile97839.pdf 


\section{Bibliography}

Bose, S., \& Architects, M. (2015). Places for Strangers. Zurich: Park Books.

Bost, K. \& Howeler, E. (2013), Ownership to Membership: Collective Consumption as Urban Strategy. MONU Communal Urbanism, Issue 18, p. 27

Canadian Architect, Teeple Architect's Richmond Street Housing Co-operative wins Archdaily Building of the Year Award (2011, February). Retrieved February 15, 2018, from Canadian Architect website: https://www.canadianarchitect.com/architecture/teeple-architects-60richmond-street-east-housing-co-operative-wins-archdaily-building-of-the-year-a/1000402392/

City of Toronto, 57 and 65 Brock Avenue - Official Plan amendment and Zoning Admendment Applications - Preliminary Report (2016, October). Retrieved March 1, 2018, from City of Toronto website: https://www.toronto.ca/legdocs/mmis/2016/te/bgrd/backgroundfile97839.pdf

City of Toronto Affordable Housing Office, Affordable Rental Housing Design Guidelines (2015, January). Retrieved Oct 15, from City of Toronto website: https://www.toronto.ca/wpcontent/uploads/2017/11/8fea-AFFORDABLE-HOUSING-DESIGN-

GUIDELINES.FINAL_.07.06.2017.pdf

City of Toronto, Avenues \& Mid-Rise Buildings Study (2010, May). Retrieved July 11, 2017, from City of Toronto website:

https://www1.toronto.ca/City\%200f\%20Toronto/City\%20Planning/Urban\%20Design/Midrise/midrise-FinalReport2.pdf

City of Toronto, Planning for Children in New Vertical Communities (2017). Retrieved Nov 15, 2017, from City of Toronto website:

https://www.toronto.ca/legdocs/mmis/2017/pg/bgrd/backgroundfile-103920.pdf

City of Toronto, Profile Toronto: Housing Occupancy Trends 1996-2011 (2015, Oct 01).

Retrieved July 11, 2017, from City of Toronto website:

https://www.toronto.ca/legdocs/mmis/2015/pg/bgrd/backgroundfile-84816.pdf

City of Vancouver, Micro Dwelling Policies and Guidelines (2014, March 15). Retrieved February 15, 2018, from City of Vancouver website: http://guidelines.vancouver.ca/D015.pdf

CMHC, Housing Observer 2017 Micro Apartments (2017, June). Retrieved Nov 15, 2017, from Canada Mortgage and Housing Corporation website: https://www.cmhc-schl.gc.ca/en/hoficlincl/observer/upload/micro-apartments-housingobserver-2017.pdf 
Edmunds, S. (2008). Grotesque relations: modernist domestic fiction and the U.S. welfare state. Oxford: Oxford University Press

Eidner, F., \& Ring, K. (2013). Selfmade city: Berlin; self-initiated urban living and architectural interventions. Berlin: Jovis.

Government of Canada, Census in Brief: Young Adults living with their parents in Canada in 2016 (2017, Aug 2). Retrieved August 27, 2017, from Government of Canada website:

http://www12.statcan.gc.ca/census-recensement/2016/as-sa/98-200-x/2016008/98-200x2016008-eng.cfm

Government of Canada, Dwellings in Canada: High-rises stand tall in Toronto and Vancouver (2017, May 3). Retrieved February 15, 2017, from Government of Canada website:

http://www12.statcan.gc.ca/census-recensement/2016/as-sa/98-200-x/2016005/98-200x2016005-eng.cfm

Haas, T. (2012). Sustainable urbanism and beyond: Rethinking cities for the future. New York: Rizzoli.

Hass, T, \& Mehaffy, M (2012). Climate Change and the Differential Evidence of European Urbanism. New York: Rizzoli.

Hudson, E. (1993). Bellevue Avenue, An Architectural and Social Study. Toronto Region Architectural Conservancy. Retrieved February 1, from ACO Toronto website:

https://www.acotoronto.ca/res_files/Bellevue\%20Compressed.pdf

Kennedy, C., Cuddihy, J. and Engel-Yan, J. (2007), The Changing Metabolism of Cities. Journal of Industrial Ecology, 11: 43-59. doi:10.1162/jie.2007.1107

Kensington Market Landtrust (2018, March 01). Come Help Us Dream! [Letter to S.

MacDougall]. Kensington Market, Toronto, Ontario. Kensingtonmarketatclt@gmail.com

Kent, S., \& Rapoport, A. (1990). Domestic architecture and the use of space: An interdisciplinary cross-cultural study. Cambridge: Cambridge University Press

Kiley, D., \& Amidon, J. (2001). DanKiley in his own words: Americas master landscape architect. London: Thames and Hudson

Luhaaru, E., BARarchitekten and atelier lebalto (2013). Base + Urban Living Ideas Workshop. Retrieved August 15, 2017, from BARarchitects website: http://www.bararchitekten.de/projects/baseplus.html

McCamant, K., \& Durrett, C. (2011). Creating cohousing building sustainable communities. Gabriola Island: New Society. 
Minuchin, L. (2017). Material Politics: Home. Retrieved October 15, 2017, from Material Politics website: https://www.materialpolitics.com

Minuchin, L. (2013), Material Politics: Concrete Imaginations and the Architectural Definition of Urban Life in Le Corbusier's Master Plan for Buenos Aires. Int J Urban Reg Res, 37: 238-258.

doi:10.1111/j.1468-2427.2012.01203.x

Rapoport, A. (1975). Toward a Redefinition of Density. Environment and Behaviour, 7 (2), 133 158. doi: 10.1177/001391657500700202

Rice, C. (2016). Interior urbanism: architecture, John Portman and downtown America. London: Bloomsbury.

Ryerson City Building Institute, Bedrooms in the Sky: Is Toronto Building the Right Condo Supply? (2017, Nov 7). Retrieved Nov 27, 2017, Ryerson University City Building Institute website:

https://www.citybuildinginstitute.ca/wp-content/uploads/2017/11/FINAL-

BedroomsInTheSky.pdf?mc_cid=6f60f274e8\&mc_eid=e42c28d767

Schittich, C., \& Ebner, P. (2007). Housing for people of all ages: flexible, unrestricted, seniorfriendly. Munchen: Detail

Schneider, T., \& Till, J. (2007). Flexible housing. Oxford: Architectural Press

Scotthansen, C., \& Scotthanson, K. (2005). The cohousing handbook: building a place for community. Gabriola Island: New Society.

Siupsinskas, M. (2013), Soviet Dreams: A New Organization of Life. MONU Communal Urbanism, Issue 18, p. 48

SmartHouse Amenities (2017). Retrieved Nov 15, 2017, from Smart House website: http://smarthousetoronto.com/smart-amenities.html\#

Upmeyer, B. (2013), Ecstasy and Privacy: Interview with Rainer Langhans. MONU Communal Urbanism, Issue 18, p. 15

Upmeyer, B. (2016), Domesticity: Interview with Herman Hertzberger. MONU Domestic Urbanism, Issue 24, p. 125

Upmeyer, B. (2016), The Home as Political Arena: Interview with Andres Jaque. MONU Domestic Urbanism, Issue 24, p. 5 
